ESTRATEGIA DE INTERVENCIÓN PSICOSOCIAL DESDE UN ENFOQUE SISTÉMICO PARA EL FORTALECIMIENTO DE LA EDUCACIÓN EN DERECHOS HUMANOS DE LAS DEFENSORÍAS DE FAMILIA DEL CENTRO ZONAL FONTIBON DEL INSTITUTO COLOMBIANO DE BIENESTAR FAMILIAR (ICBF)

ANA DE LA CRUZ MONTERO LÓPEZ

UNIVERSIDAD SANTO TOMÁS

FACULTAD DE DERECHO

BOGOTÁ, COLOMBIA 


\section{ESTRATEGIA DE INTERVENCIÓN PSICOSOCIAL DESDE UN ENFOQUE SISTÉMICO PARA EL FORTALECIMIENTO DE LA EDUCACIÓN EN DERECHOS HUMANOS DE LAS DEFENSORÍAS DE FAMILIA DEL CENTRO ZONAL FONTIBON DEL INSTITUTO COLOMBIANO DE BIENESTAR FAMILIAR (ICBF)}

\section{ANA DE LA CRUZ MONTERO LÓPEZ}

Tesis presentada como requisito parcial para optar al título de:
Magister en defensa de los Derechos Humanos y el Derecho Internacional Humanitario ante Organismos, Tribunales y Cortes Internacionales.

\section{Directora}

Elsa Bonilla Piratova

Línea de Investigación en Educación en Derechos Humanos

UNIVERSIDAD SANTO TOMÁS

FACULTAD DE DERECHO

BOGOTÁ, COLOMBIA 


\title{
Resumen
}

Este trabajo de grado responde a la necesidad de fortalecer las Defensorías de Familia del Centro Zonal Fontibón en la educación en derechos humanos desde un enfoque sistémico, debido a la dificultad que presentan sus funcionarios para vincularla en sus labores, por tanto tienden a prestar una atención desde posturas individuales y juzgamientos frente a la realidad del otro, siendo imperante el análisis del contexto global propio de cada persona y/o familia, para el reconocimiento de sus derechos. Se plantea una propuesta de intervención psicosocial que facilita la comprensión e interiorización de la educación en derechos humanos desde una mirada holística. Esta investigación sugiere la re-significación de los procesos de atención del Instituto Colombiano de Bienestar Familia (ICBF) como gestor de paz y armonía familiar; además representa el preludio para que funcionarios de otras entidades también se fortalezcan en el tema, contribuyendo así a la formación de una sociedad realmente democrática en donde se respeten y garanticen los derechos humanos.

\section{Palabras claves}

Propuesta Psicosocial, intervención, Educación en Derechos Humanos, Defensoría de Familia, enfoque sistémico, familias.

\begin{abstract}
This investigation answer to the need of strengthen the Family's Advocacy of Zonal Center Fontibon in human rights education from a systemic focus, due to officials's difficult for include it in their activities, because they give an Attention from an individual position and judgments in front of reality of the other, being important the analysis of each person's and family global context for the recognition of their rights.It arise a proposal psychosocial intervention that facilitates understanding and interiorization of human rights education from holistic look. This investigation suggests the re-significance of attention processes of Colombian Institute of Family Wellness as peace manager and family harmony; so it represents the prelude for that officials of other entities strengthen in the theme, thus contributing to the formation of a truly democratic society where human rights are respected and guaranteed.
\end{abstract}

\section{Keywords}

Proposal Psychosocial, Intervention, Human Rights Education, Family’s Advocacy, Systemic Focus, Families. 


\section{CONTENIDO}

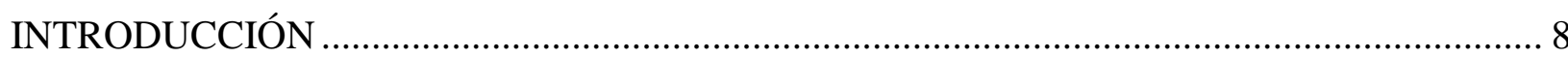

1. Problemática de atención psicosocial en las Defensorías de Familia................................. 11

1.1 Estado de la cuestión ................................................................................................. 11

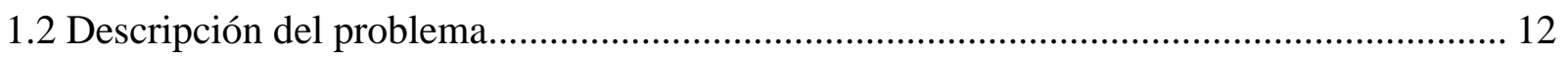

1.3 Pregunta de investigación ................................................................................. 14

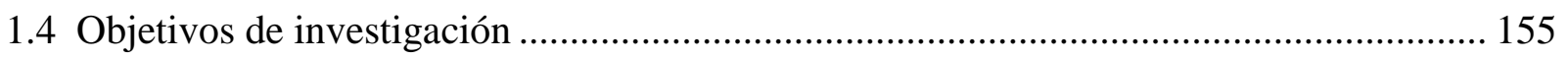

1.4.1 Objetivo General ............................................................................... 155

1.4.2 Objetivos Específicos.............................................................................. 15

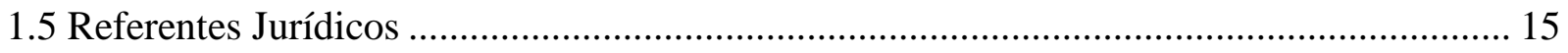

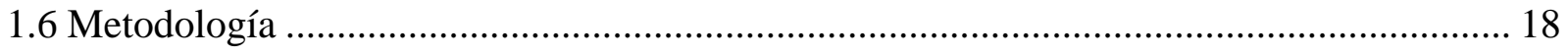

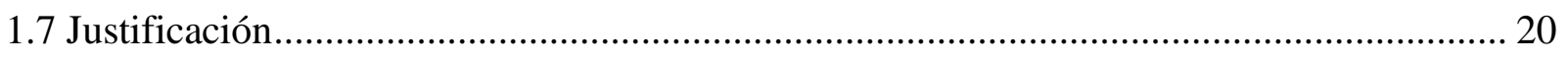

2. Intervención psicosocial desde un enfoque sistémico como dispositivo de apropiación y fortalecimiento de la Educación en Derechos Humanos: reflexiones y debates23

2.1 Derechos Humanos desde la exigibilidad y los juicios morales .................................. 23

2.2 Educación en Derechos Humanos .......................................................................... 25

2.3 Intervención psicosocial a partir de un enfoque sistémico........................................... 32

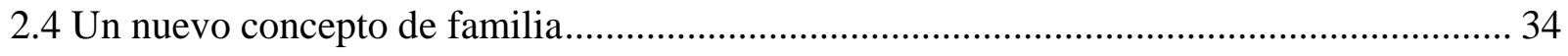

2.5 Las defensorías de familia y su rol fundamental en la práctica de la educación en derechos

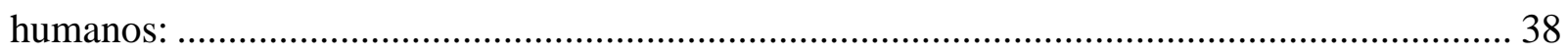

3. Propuesta psicosocial: transformando las dinámicas de las Defensorías de Familia del Centro Zonal Fontibón a partir de la perspectiva de la Educación en Derechos Humanos con un

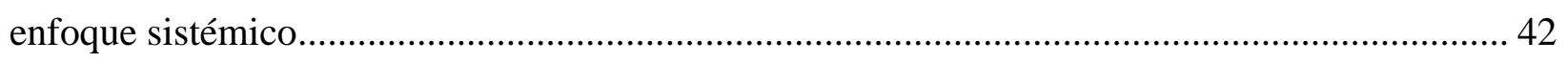

3.1 Contextualización de la propuesta..................................................................... 42

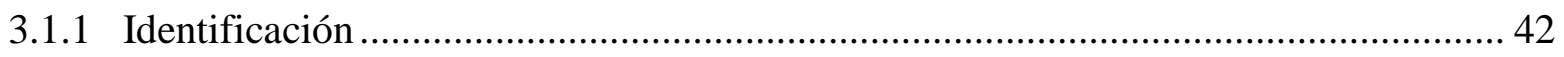

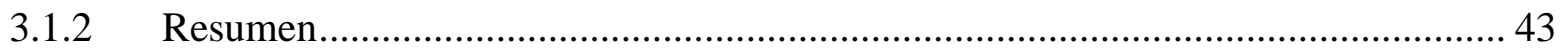




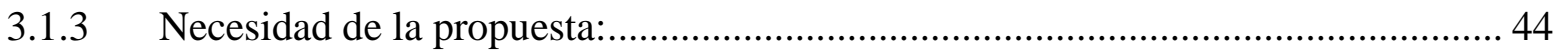

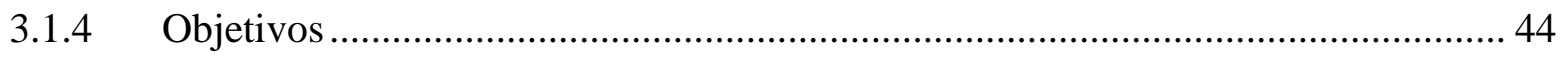

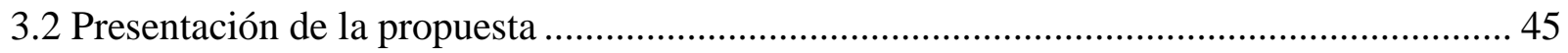

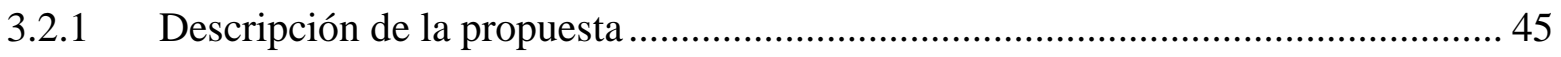

3.2.2 Características de la población a quien va dirigida la propuesta ............................. 46

3.2.3 Contexto de las Defensorías de Familia desde la perspectiva de la Educación en

Derechos Humanos a partir de un enfoque sistémico.................................................. 49

3.2.4 Plan estratégico para la mejora en los procesos de intervención a partir de una

Educación en Derechos Humanos .................................................................................... 51

3.2.5 Planificación de actividades y metodología para el desarrollo de la propuesta:..... 53

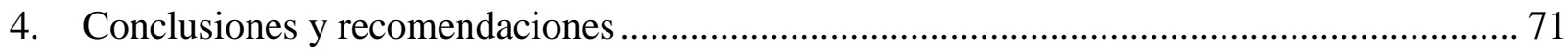

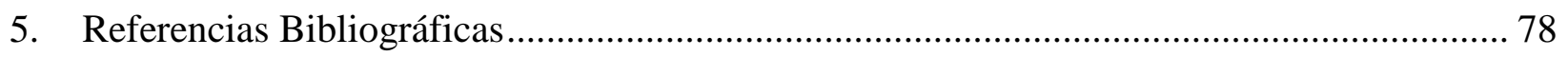

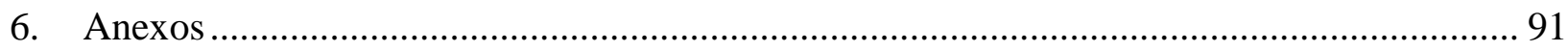

Anexo 1: Entrevista no estructurada aplicada a Defensorías de Familia del Centro Zonal Fontibón - Instituto Colombiano de Bienestar Familiar (ICBF) ........................................ 91

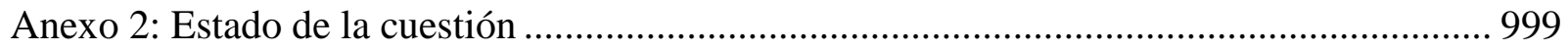

Anexo 3: Contexto de la Descripción del problema .................................................. 1077

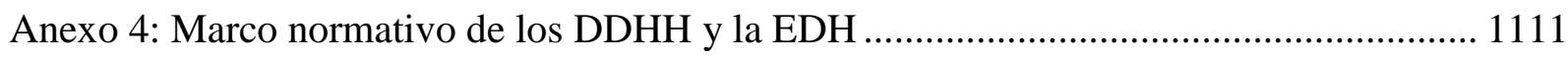




\section{Lista de Tablas}

Tabla $\mathbf{N}^{\circ}$ 1. Cargos en las Defensorías de Familia de los funcionarios que participaron de la entrevista.

Tabla $\mathbf{N}^{\circ}$ 2. Funciones desempeñadas por los funcionarios entrevistados de acuerdo a su Cargo.

Tabla $\mathbf{N}^{\circ}$ 3. Casos que atienden los funcionarios aproximadamente durante el mes.

Tabla $\mathbf{N}^{\circ} 4$ Problemáticas más comunes que presentan las familias que atienden las Defensorías de Familia.

Tabla $\mathbf{N}^{\circ}$ 5. Factores que consideran las Defensorías de Familia deben tenerse en cuenta durante la intervención con familia y que pueden contribuir a un verdadero cambio.

Tabla $\mathbf{N}^{\circ}$ 6. Definición de EDH por parte de las Defensoríasde Familia.

Tabla $\mathbf{N}^{\circ}$ 7. Importancia que le asignan las Defensorías de Familia a la EDH en la atención que brindan a las familias. 


\section{Lista de Gráficas}

Gráfico $\mathbf{N}^{\circ}$ 1. Funciones que desempeñan los funcionarios entrevistados de acuerdo con su Cargo.

Gráfico $\mathbf{N}^{\circ}$ 2. Casos que atienden los funcionarios aproximadamente durante el mes. 93

Gráfico $\mathbf{N}^{\circ}$ 3. Problemáticas más comunes que presentan las familias que atienden las Defensorías de Familia.

Gráfico $\mathbf{N}^{\circ}$ 4. Cargos en las Defensorías de Familia de los funcionarios que participaron de la entrevista.

Gráfico $\mathbf{N}^{\circ}$ 5. Factores que consideran las Defensorías de Familia que deben tenerse en cuenta durante la intervención con familia y que pueden contribuir a un verdadero cambio.

Gráfico $\mathbf{N}^{\circ}$ 6. Definición de educación en derechos humanos por parte de las Defensorías de Familia.

Gráfico N $^{\circ}$ 7. Importancia que le asignan las Defensorías de Familia a la educación en derechos humanos en la atención que brindan a las familias. 


\section{INTRODUCCIÓN}

Uno de los múltiples deberes que le atañen al Estado en su función Constitucional, garantista y protectora de derechos reconocidos tanto a nivel interno como internacional, es el de brindar a las familias herramientas suficientes que les permita fundamentar sus dinámicas y pautas de interacción con base en los principios de una educación en derechos humanos (EDH), particularmente en aquellos grupos familiares que se consideran vulnerables y por tanto, se convierten en población atendida por las Instituciones del Estado para reconocer, proteger y garantizar sus derechos, tal como ocurre con el Instituto Colombiano de Bienestar Familiar (en adelante ICBF).

El presente trabajo de investigación que se circunscribe a la Maestría en Defensa de los Derechos Humanos y el Derecho Internacional Humanitario ante Organismos, Tribunales y Cortes Internacionales, pretende intervenir aquellos escenarios de nuestra sociedad que requieren de una atención especial en educación en derechos humanos, como en el caso de las Defensorías de Familia del ICBF, siendo imperante que éstas brinden una atención soportada en un trato digno y respetuoso, reconociendo la influencia de los contextos en las problemáticas que se identifiquen, por lo que es imprescindible que en los procesos de atención los funcionarios que hacen parte de dichas defensorías de familia sean sensibles ante las necesidades de los demás, de manera que se reconozcan como sujetos de derechos, desde la realidad y el contexto propio de cada familia, niño, niña, adolescente, padre, madre o sujeto en particular.

Para la investigación se tuvo como muestra poblacional las cinco Defensorías de Familia del Centro Zonal Fontibón del ICBF conformadas por un equipo interdisciplinar: defensor de familia, psicólogo y trabajador social, además de dos nutricionistas que apoyan los procesos que requieren de su intervención, a quienes se les aplicó como métodos de recolección de 
información: la observación, durante el desarrollo de sus labores diarias, particularmente al momento de atender familias; llevadas a cabo durante los meses de agosto y septiembre de 2016, para posteriormente aplicar en septiembre de ese mismo año una entrevista no estructurada a los 17 funcionarios que hacen parte de éstas defensorías de familia, de los cuales no respondieron los cinco defensores de familia.

De acuerdo con los resultados obtenidos se diseña una propuesta psicosocial desde un enfoque sistémico, precisamente por el componente holístico que establece la educación en derechos humanos, ya que este enfoque aborda al ser humano desde su individualidad pero a la vez teniendo en cuenta los diferentes contextos que influyen en su conducta.

Las defensorías de familia del Centro Zonal Fontibón han de contar con la capacidad de brindar a dicha población una atención fundamentada en la educación en derechos humanos, de tal forma que se fortalezcan en habilidades y capacidades necesarias para orientar y contribuir al empoderamiento de las familias atendidas en su rol subsidiario, como garantes de derechos de los niños, niñas y adolescentes (en adelante NNA).

De esta manera, la presente investigación se estructuró en cuatro capítulos, cada uno de los cuales aborda un componente significativo para la constitución de la propuesta de intervención psicosocial. Así, en el primer capítulo denominado "Problemática de atención psicosocial en las defensorías de familia" se describen aspectos relacionados con los referentes del problema planteado, entre ellos: el estado de la cuestión, la descripción del problema, la metodología, fundamentación y los elementos jurídicos que sustentan la propuesta. En el segundo capítulo titulado "Intervención psicosocial desde un enfoque sistémico como dispositivo de apropiación y fortalecimiento de la educación en derechos humanos: reflexiones y debates" se fundamenta teórica y conceptualmente la propuesta de intervención. 
Por su parte, en el tercer capítulo se plantea la propuesta psicosocial: "transformando las dinámicas de las defensorías de familia del Centro Zonal Fontibón a partir de la perspectiva de la educación en derechos humanos con un enfoque sistémico", en ella se proponen diferentes estrategias tendientes a mejorar los procesos de atención dentro de las obligaciones que debe cumplir el Estado, representado en los funcionarios del ICBF. En el cuarto capítulo se desarrolla la Evaluación del Impacto e Innovación de la propuesta;finalmente se llega a las conclusiones con base en el análisis y resultados obtenidos en el desarrollo de dicha investigación. 


\section{Problemática de atención psicosocial en las Defensorías de Familia}

\subsection{Estado de la cuestión}

Teniendo en cuenta que la población objeto de la presente investigación son las defensorías de familia del Centro Zonal Fontibón del ICBF, quienes en el desarrollo de sus funciones deben garantizar los derechos de los NNA y velar por el bienestar de las familias colombianas, en la presente investigación fue necesario indagar el contexto socio histórico en el cual surgió el ICBF, así como las principales investigaciones adelantadas en el marco nacional e internacional con el tema de EDH y la atención brindada por agentes del Estado a las familias, algunas de ellas desde un enfoque psicosocial, cuyos principales aportes se pueden apreciar en el Anexo No.2 de esta Tesis.

Sin embargo, es importante resaltar algunas consideraciones al respecto: la mayoría de investigaciones se han desarrollado en un contexto escolar, no obstante hacen énfasis en el rol primordial que desempeña la familia en dicha temática, en la medida en que es el primer contexto con el cual se relaciona el ser humano, por ende lo que aprende allí tiende a replicarlo en otros ámbitos; así mismo algunas de éstas investigaciones reflejan la falta de coherencia respecto a lo establecido en las leyes y la realidad de la sociedad en cuanto al tema de educación en derechos humanos, en la medida en que existe dificultad para colocarse en el lugar del otro y respetar realmente sus derechos a la vez a que reconocer los propios; se identifica además que las investigaciones llevadas a cabo por el ICBF en su mayoría se tratan de estudios realizados a las familias, más no directamente sobre las dinámicas de las defensorías de familia y menos aún sobre el tema de educación en derechos humanos. 
Es por ello que en el presente trabajo de grado se consideró necesario plantear una propuesta psicosocial que permita fortalecer a las Defensorías de Familia del Centro Zonal Fontibón del ICBF en la Educación en Derechos Humanos.

\subsection{Descripción del problema}

Las dificultades evidenciadasen la atención que brindan las defensorías de familias del Centro Zonal Fontibón a la población,se identificaron a través de diferentes instrumentos de investigaciónaplicados(que serán explicados en el acápite Metodológico) y se encuentran profundizadas en el anexo No. 3 de esta Tesis. Sin embargo, a continuación se resalta el contexto problémico que da origen a la pregunta de investigación.

De acuerdo con la entrevista aplicada a los sujetos objeto de esta investigación (ver anexo No. 1), se evidencia un número considerable de casos atendidos por las defensorías de familia, situación que puede asociarse a los cambios que se han presentado desde el siglo XX a nivel de la estructura familiar, los cuales han generado aumento en el volumen de solicitudes para fijación de cuota alimentaria, visitas y custodia. Adicionalmente cabe mencionar la transformación en la situación coyuntural que el país atraviesa actualmente, debido al proceso de paz y demás políticas de gobierno que generan cambios significativos en la sociedad, como la vinculación de personas desmovilizadas a la vida civil.

El ICBF de acuerdo al Manual del Sistema Integrado de Gestión tiene como desafío fortalecerse en programas de atención de NNA desvinculados de grupos armados al margen de la ley, procesos dentro de los cuales desde una visión holística debe tenerse en cuenta la reestructuración familiar que implica éste suceso para las personas que eran parte de dichos grupos armados. 
Aunque no se desconoce que el ICBF ajusta sistemáticamente sus lineamientos y políticas públicas de acuerdo a las transformaciones sociales y culturales que van surgiendo con el tiempo, representando el modelo solidarioun logro significativo para los procesos de atención, el cual se sustenta en una visión holística; actualmente se observa que los sujetos de investigación pueden llegar a omitir elementos fundamentales dentro de los procesos de atención, como: brindar al otro un trato digno y respetuoso.

En suma, a través de la revisión documental y observación realizada en el presente trabajo investigativo, se encuentra que el ICBFaborda los derechos humanos desde una perspectiva jurídica fundamentada en tratados internacionales relacionados con los derechos de la niñez, la adolescencia y la familia, la Constitución Política de Colombia y la Ley 1098 de 2006, restando importancia a la interacción de éste componente legal con los demás contextos que influyen en la persona.

Por su parte,de los instrumentos de investigación aplicados, se logró inferir que las defensorías de familia escasamente reconocen algunosaspectos intrínsecos a la educación en derechos humanos, como lo es el respeto por el otro, construcción de estrategias de comunicación, toma de decisiones apropiadas, mejoramiento de las relaciones interpersonales, entre otras (ver anexo $\mathrm{N}^{\circ} 1$, tabla $\mathrm{N}^{\circ} 7$, Gráfica $\mathrm{N}^{\circ} 7$ ).

Reconocen los funcionarios identificados en el anexo 1,que en ocasiones no les atribuyen importancia alos elementos que implica una educación en derechos humanos desde un componente holístico,tales como: escuchar a las familias sin juzgar, ser cuidadoso en la actitud en general que se asume frente a ellas de acuerdo a su realidad e historia de vida, aspectos socioeconómicos y culturales, entre otros (ver anexo $\mathrm{N}^{\circ} 1$, tabla $\mathrm{N}^{\circ} 5$, Gráfica $\mathrm{N}^{\circ}$ ), existiendo el riesgo de llevar a cabo una atención desde la percepción del sujeto de investigación sin tener en 
cuenta la realidad y opinión del otro; aunque resaltan la importancia de sensibilizar a las familias respecto a los cambios que requieren,estos aspectos son poco cuidados por las defensorías de familia.

Se observa resistencia por parte de los defensores de familia frente a la necesidad de fortalecerse y llevar a la práctica la educación en derechos humanos, situación que se refleja en el hecho de no participar en la entrevista realizada a las defensorías de familia (ver anexo $\mathrm{N}^{\circ} 1$, tabla $\mathrm{N}^{\circ} 1$, Gráfica $\mathrm{N}^{\circ} 1$ ).

Por tanto, se percibe que las defensorías de familia, aunque logran identificar algunos aspectos de la educación en derechos humanos, presentan dificultad para emitir una respuesta clara y concisa respecto a su significado y aplicación en sus labores diarias. Por otro lado,desde una mirada holística, es importante identificar los factores externos que pueden estar influyendo en su desempeño como: la carga laboral teniendo en cuenta las cifras arrojadas por el SIM y lo observado en las rutinas del Centro Zonal, ya que dentro del discurso de éstos funcionarios una de las quejas principales es el exceso de trabajo debido a la cantidad de casos que atienden (ver anexo $\mathrm{N}^{\circ}$ 1, tabla $\mathrm{N}^{\circ} 3$, Gráfica $\mathrm{N}^{\circ} 3$ ).

En consonancia con lo anterior, la pregunta que le da sentido a éste trabajo de investigación es la siguiente.

\subsection{Pregunta de investigación}

¿Cuáles son los elementos que posibilitan plantear una propuesta psicosocial desde un enfoque sistémico para el fortalecimiento de las Defensorías de Familia del Centro Zonal Fontibón - ICBF en la Educación en Derechos Humanos dentro de la intervención que se lleva a cabo con familias? 


\subsection{Objetivos de investigación}

\subsubsection{Objetivo General}

- Diseñar una propuesta psicosocial que contribuya al fortalecimiento de la Educación en Derechos Humanos de las defensorías de familia del Centro Zonal Fontibón del ICBF, con el fin de brindar una atención eficaz a los ciudadanos que acuden a dicha entidad y así mismo garantizar la protección de los derechos de los niños, niñas, adolescentes y sus familias.

\subsubsection{Objetivos Específicos}

- Identificar los factores que se requieren fortalecer en los funcionarios que hacen parte de las Defensorías de Familia del Centro Zonal Fontibón, a fin de brindar a las familias una atención eficaz y que se ajuste a las necesidades de cada caso particular, a partir de la EDH.

- Fundamentar la propuesta psicosocial a partir de referentes teóricos existentes sobre DDHH, EDH y enfoque sistémico.

- Plantear estrategias pedagógicas que faciliten el fortalecimiento en la temática sobre EDH de acuerdo a la población objeto de ésta investigación.

\subsection{Referentes Jurídicos}

Los derechos humanos se conciben como una situación fundamental a la condición humana, sin embargo, su concepción jurídica y universal se remonta con posterioridad a la Segunda Guerra Mundial, luego de la expedición de convenios y tratados internacionales que buscaban su garantía y protección, principalmente a partir de la Declaración Universal de Derechos del Hombre el 10 de diciembre de 1948, aprobada por la Asamblea General de las Naciones Unidas 
en París y modificada en 1952 por la Declaración Universal de Derechos Humanos a fin de que su contenido hiciera referencia tanto a hombre como a mujer.

A pesar de la lucha por los derechos humanos y lograrse la democracia en varios países después de estar sometidos a gobiernos dictadores, de acuerdo con Magendzo (2008), no era suficiente para lograr la paz, el respeto y reconocimiento del otro como sujeto de derechos,surgiendo la necesidad de que a partir de los años 80’en Latinoamérica empezara a desarrollarse el concepto de educación en derechos humanos, momento a partir del cual ha tenido una evolución progresiva, implementándose a partir de políticas públicas que promueven su práctica tanto en el ámbito de la educación formal como no formal.

No obstante, el origen de la EDH se remonta a la Declaración Universal de Derechos Humanos, en la que se estableció la educación como un derecho que debía tener como objetivo el desarrollo pleno de la personalidad e incentivar el respeto por los derechos humanos; así mismo en la Declaración Americana de los Derechos y Deberes del Hombre en su artículo 12 se refiere al derecho a la educación con base en Principios como "libertad, moralidad y solidaridad humanas". Desde ese entonces y hasta la fecha, se ha promulgado el respeto por los derechos humanos a través de leyes y tratados internacionales.

De esta manera, se evidencia que existe una riqueza significativa en la normatividad Internacional que garantiza, enfatiza y promueve una cultura de la EDH. De igual manera Colombia posee referentes jurídicos que dan cuenta de la exigencia que se le realiza al Estado respecto a la implementación de la EDH en los diferentes contextos.

En el caso específico de Colombia, la educación en derechos humanos se ha desarrollado de manera progresiva desde los años $80^{\prime}$. Un avance significativo en este tema fue la expedición de la Constitución Política Colombiana de 1991, según el informe del Instituto Interamericano de 
Derechos Humanos (2009), a partir de dicha Constitución se implementó una educación cívica, democrática, moral, fundamentada en valores y en derechos humanos, por tanto Colombia empezó a considerarse como un estado social de derecho que debe brindar una EDH, como se estipula en su artículo 67 que la educación debe incentivar el respeto por los derechos humanos, la paz y la democracia; delega además a la Defensoría del Pueblo la responsabilidad de la defensa, protección, promoción y difusión de los derechos humanos.

Por otro lado, se implementó la EDH en diferentes leyes internas, como la Ley 115 de 1994 o Ley General de Educación, que la introduce como obligatoria en los artículos 5 y 14, éstos indican que la educación tiene por objetivo el respeto por los derechos humanos y que debe ser incorporado al currículo; además el decreto 1860 de 1994 que reglamentó dicha ley, estableció que la EDH debe desarrollarse desde un componente pedagógico.

Así mismo el Plan Decenal 2006-2016, propone que en Colombia debe fomentarse una educación en y para la Paz, la convivencia y la ciudadanía, por tanto considera a los estudiantes como sujetos de derechos en quienes debe promoverse la autonomía y el respeto por el otro, además debe tenerse en cuenta dentro de los planes educativos su diversidad cultural, étnica, de género, entre otros.

Así las cosas, en el sistema normativo colombiano, al igual que en el sistema internacional, existe una vasta riqueza legislativa que garantiza, exige y enfatiza en la necesidad de promover una cultura de la EDH en diferentes escenarios y desde diversas perspectivas individuales y colectivas, de manera que vincule a todos los ciudadanos y se cumpla con los fines constitucionales y legales de respeto por los derechos humanos.

Para mayor comprensión y conocimiento del desarrollo normativo de los derechos humanos y la educación en derechos humanos se encuentra explicitado en el anexo 4 de esta Tesis, en él se 
puede precisar cada uno de los instrumentos internacionales e internos, así como el fundamento de ésta investigación.

\subsection{Metodología}

La presente tesis se fundamenta en los preceptos de la investigación cualitativa de tipo etnográfico, de acuerdo con Rodríguez(citado por Martínez y Murillo, 2010) consiste en el estudio del estilo de vida de un grupo social específico. En relación a su complejidad según Spradley (citado por Martínez y Murillo, 2010) puede ser macro o micro etnográfica, centrándose ésta última en una sola institución o escenario social, la cual amerita poco tiempo y puede ser desarrollada por un solo investigador. Para efectos del presente trabajo de grado, se trata de una investigación micro etnográfica ya que se enfoca en las defensorías de familia del Centro Zonal Fontibón a quienes se estudiaron por un periodo de tiempo corto (segundo semestre de 2016), a través de técnicas propias de éste tipo de investigación, a fin de evaluar el conocimiento y comprensión que tienen acerca de la educación en derechos humanos y la necesidad de fortalecerse en dicho tema.

Dentro del presente estudio se emplearon como técnicas de recolección de datos: revisión documental con la cual se conoció información previa y pertinente al tema de Educación de Derechos Humanos y su puesta en práctica en las defensorías de familia del ICBF.

Otra técnica empleada es la observación participante, de acuerdo con Munarriz (1992) permite al investigador introducirse en el escenario objeto de estudio, como medio de obtención de la información y analizar las "propias reacciones, intenciones y motivos, y también de los demás" (Munarriz, 1992);o puede ocurrir que el investigador forma parte del escenario a observar pero no interviene en el mismo. Para efectos de la presente investigación se llevaron a cabo las dos modalidades descritas respecto a la observación participante, ya que la investigadora 
hace parte de una de las defensorías de familia en estudio, lo que le permitió de manera sistemática observar y analizar lo ocurrido en dicho grupo de trabajo, así como intervenir y aportar sugerencias para la mejora de la atención.

Se involucró además en las otras defensorías de familia en donde su participación radicó en observar lo ocurrido sin intervenir en dicho escenario, para lo cual se eligió al azar funcionarios de diferente profesión a quienes se les solicito su consentimiento para llevar a cabo la observación mientras ellos atendían algún caso, se les dio a conocer el objetivo de la misma con base en la naturaleza del presente trabajo de grado, se especificó que se llevaría a cabo durante toda la intervención y bajo el cumplimiento de la confidencialidad de la información. Se desarrolló durante el mes de septiembre de 2016, mediante el registro de notas de campo que posteriormente facilitaron el procesamiento de la información obtenida con base en las categorías de análisis establecidas para la presente investigación. Esta técnica permitió evaluar la existencia de elementos que evidenciaran o no la puesta en práctica de la Educación en Derechos Humanos por parte de las defensorías de familia.

Por otro lado, Vargas (2010) divide los métodos de entrevista en la investigación cualitativa en estructurada y no estructurada, para el desarrollo de la presente investigación se llevaron a cabo entrevistas no estructuradas, de acuerdo con Rincón (citado por Vargas, 2010), en éste tipo de entrevista se construyen una serie de preguntas, pero su secuencia no es estática, ya que pueden cambiar o agregarse otras durante su desarrollo, de manera que facilita la interacción con el entrevistado y permite profundizar acerca de su postura frente a un determinado tema. Esta clase de entrevista aplicada en el mes de octubre de 2016, a cinco trabajadoras sociales, cuatro psicólogas y dos nutricionistas que hacen parte de las defensorías de familia del Centro Zonal Fontibón, permitió examinar el conocimiento que poseen sobre EDH y 
las estrategias de intervención que emplean a diario en la atención con familias. Es de anotar que los defensores de familia no facilitaron el espacio para la entrevista, algunos argumentando no contar con tiempo, denotando con ello cierta apatía frente al tema, situación que se refleja en los resultados de la investigación.

\subsection{Justificación}

A nivel internacional y nacional en materia de derechos humanos se ha atribuido al Estado la responsabilidad de garantizar los derechos de sus ciudadanos y de establecer las medidas necesarias para su cumplimiento. En el transcurso de las últimas décadas de manera paulatina se ha introducido el tema de educación en derechos humanos tanto en la jurisdicción internacional como interna, la cual se ha considerado necesaria para formar sociedades autónomas y democráticas que contribuyan a la consecución de la paz, en donde se respete al otro desde su dignidad humana y como sujeto de derechos.

La EDH se ha pretendido desarrollar en los contextos de educación formal, educación para el trabajo y el desarrollo humano y educación informal. Sin embargo, va más allá del ámbito educativo, por tanto debe reflejarse en todas las áreas del ser humano, de modo que el ICBF no debe ser ajeno, dado que como representante del Estado se le ha delegado la obligación de velar porque a los NNA se les garanticen todos sus derechos. No obstante, la realidad parece ser otra, ya que en muchas ocasiones en las intervenciones que realizan algunos de sus funcionarios tienden a caer en el error de realizar juicios a priori desconociendo la realidad del otro y omitiendo la influencia de los contextos en el comportamiento humano.

Es así como se hace necesario que las defensorías de familia se fortalezcan en la EDH a partir de un componente holístico, de manera que desarrollen procesos de intervención desde ésta perspectiva, la cual les permita comprender la influencia de los contextos en el ser humano e 
intervenir sobre los mismos, primando siempre el trato adecuado y el respeto por la dignidad del otro sin importar su condición; así mismo permite establecer estrategias de solución fundamentadas en la realidad y el punto de vista de cada uno de los implicados en dicho proceso, logrando con ello un manejo adecuado de los contextos familiares, según sus condiciones socio económicas, culturales, educativas, entre otras.

Por otro lado, los cambios sociales que se han generado en Colombia desde la década de los años 50`a causa del conflicto armado interno, han ocasionado reestructuraciones a nivel familiar que en gran parte han incidido negativamente en el adecuado desarrollo emocional de los NNA. Ante esta realidad se requiere de un redimensionamiento por parte del ICBF, teniendo en cuenta que como entidad encargada de garantizar los derechos de la niñez y la adolescencia en Colombia, debe contar con profesionales idóneos para la atención de éste tipo de población, de modo que en lugar de juzgar, contribuyan al fortalecimiento de herramientas para el afrontamiento de nuevas situaciones dentro de la vida civil.

Así mismo en la atención a víctimas, es necesario tener la capacidad de entender su dolor, ansiedad, angustias y demás efectos negativos que pudieron causar las situaciones adversas afrontadas durante el conflicto, de manera que los profesionales a través de la intervención sean sensibles al identificar sus necesidades y la manera en que desean ser reparadas teniendo en cuenta las diferencias individuales. Contribuyendo así, a los procesos de reparación y por ende a la recuperación de la confianza en el Estado por parte de ésta población.

Por ello, teniendo en cuenta las dificultades que se perciben en los funcionarios del Centro Zonal Fontibón respecto a la comprensión del concepto e implementación de la EDH y retomando la misión del ICBF de garantizar los derechos de los NNA en Colombia, se considera necesario fortalecerlos en éste aspecto a partir de una visión holística que a su vez les facilite 
llevar a cabo procesos de atención bajo la primicia de que todos los seres humanos son sujetos de derechos que merecen un trato digno y de manera recíproca deben reconocer y respetar los derechos en el otro; para lo cual se requiere la formación de personas con un pensamiento crítico y emancipador que contribuyan a la transformación social que se requiere ante las injusticias e inadecuado manejo del poder que se evidencia en muchas ocasiones por parte de las entidades públicas no siendo ajenos los funcionarios de las defensorías de familia a ésta situación.

Este primer capítulo denota la importancia de fortalecer a las defensorías de familia del Centro Zonal Fontibón del ICBF en la EDH, teniendo en cuenta que en investigaciones previas no se ha abordado dicho tema de forma específica, pese a la exigibilidad jurídica que se le realiza al estado tanto a nivel interno como internacional de promover la EDH en los diferentes contextos que influyen en el ser humano. Identificándose por tanto que en el desempeño de sus labores diarias, dichas defensorías de familia presentan dificultad para comprenderla y colocar en práctica. Por tanto, se requiere de una re significación de los procesos de intervención en el cual las partes de manera recíproca se reconozcan como sujetos de derechos y con ello lograr cambios favorables en las dinámicas de las familias atendidas.

Para el cumplimiento de lo planteado es necesario promover la práctica de la EDH en las defensorías de familia a partir de un enfoque sistémico, teniendo en cuenta que ambos conceptos manejan un componente holístico, lo que implica conocer y comprender el significado de la EDH, las nuevas estructuras familiares y las dinámicas de éstas defensorías de familia, que se expone en el siguiente capítulo. 


\section{Intervención psicosocial desde un enfoque sistémico como dispositivo}

\section{de apropiación y fortalecimiento de la Educación en Derechos Humanos: reflexiones y debates}

El presente capítulo tiene como propósito exponer los referentes conceptuales en los que se fundamentó la propuesta de intervención psicosocial, para lo cual se tuvo en cuenta tres categorías de análisis: Derechos Humanos desde la exigibilidad y los juicios morales, Educación en Derechos Humanos e Intervención Psicosocial a partir de un enfoque sistémico.

\subsection{Derechos Humanos desde la exigibilidad y los juicios morales}

Como se expone en el marco jurídico de la presente investigación, de acuerdo con Menke y Pollmann (2010), sólo a partir de la expedición de la Declaración Universal de los Derechos Humanos, se empezaron a considerar los derechos humanos desde un componente jurídico, ya que anteriormente eran concebidos desde la moral, por tanto se sustentaban en el derecho natural y posturas filosóficas, exigiéndose desde lo individual. Sólo a partir de posturas positivistas del derecho se empezaron a exigir desde un nivel colectivo o del Estado, así mismo se reconoció el concepto de dignidad humana como una característica propia del ser humano y por ello todas las personas debían ser tratadas por igual.

Para Menke y Pollmann (2010), existen tres modelos a partir de los cuales se pueden concebir los Derechos Humanos. El primero de ellos es el contrato, el cual sustenta que los derechos humanos con los cuales cuenta una persona se debe a un acuerdo entre los miembros de la sociedad que se cumple por unos intereses comunes, en donde se reconocen los derechos de los demás, siempre y cuando el otro también lo haga. El siguiente modelo es el de la razón, el cual se basa en las teorías de Kant y reconoce las capacidades de una persona para decidir de manera autónoma y de reconocer los derechos de los demás. Un tercer modelo es el de 
reconocimiento, el cual fundamenta los derechos humanos en valores como la compasión y la simpatía, es decir, se basa en la capacidad de una persona de ver desde la perspectiva del otro.

Este tercer modelo es una aproximación a la visión holística desde la cual es importante concebir los derechos humanos, puesto que la misma permite reconocer los derechos propios como en los demás; así mismo tener la capacidad de entender la percepción del otro, evita la comisión de acciones que atenten contra sus derechos humanos, en la medida en que logra comprender su realidad y actúa en pro del beneficio del otro; de igual modo reconocer los propios derechos permite exigirlos y hacerlos respetar por parte de los demás. Dicho modelo de reconocimiento guarda relación con el concepto de universalización.

Los derechos humanos se han abordado desde el concepto de universalización y universalismo. Este último, de acuerdo con Michael Walzer (citado por Menke y Pollmann, 2010) tiende a estimar al ser humano de forma homogénea, en la medida en que no tiene en cuenta sus diferencias individuales; por el contrario la universalización enfatiza en la importancia de reconocer y respetar las características particulares de cada cultura y persona. Teniendo en cuenta estas concepciones teóricas, pareciera que en muchas sociedades prima el universalismo, debido a la tendencia a brindar un trato por igual a todos las personas, desconociendo sus diferencias particulares y que hacen parte de un sistema en donde confluyen aspectos individuales, familiares y sociales, los cuales deben ser tenidos en cuenta al momento de validar los derechos humanos para cada individuo y sociedad. No obstante, este panorama se torna complejo en la medida en que también se ha enfatizado en la importancia de tener en cuenta el concepto de igualdad, desde el punto de vista de que todos los seres humanos deben ser tratados por igual, pero de acuerdo a sus características e intereses particulares, esfuerzo que han realizado los organismos internacionales al tratar de que exista una homogeneidad en las leyes y 
normas expedidas a nivel mundial, a través de las cuales se pretende el respeto por los derechos humanos, sin desconocer las diferencias de cada país y cultura.

Pese a lo anterior, en pleno siglo XXI, aún se cuestiona en qué medida se cumple este principio de universalización, puesto que vivimos en un contexto en el que es más importante la obtención del poder, que una sociedad igualitaria en cuanto a derechos, en donde se respeten las diferencias individuales y el contexto en el cual se desenvuelve cada individuo.

En conclusión, el concepto de derechos humanos ha tenido una transformación que ha respondido a las características propias de cada momento histórico social. En la actualidad se propende por su exigibilidad y los Estados son responsables por su garantía y efectividad. Este análisis resulta pertinente para esta investigación, teniendo en cuenta que la propuesta de intervención psicosocial se encuentra fundamentada en el respeto y garantía de los derechos humanos.

\subsection{Educación en Derechos Humanos}

Diversos teóricos han centrado su atención en la educación en derechos humanos resaltando su importancia en la vida cotidiana de cualquier ser humano y su aplicación en los diferentes contextos en los cuales éste se desenvuelve. La EDH implica el "reconocimiento, la defensa, el respeto y la promoción de los Derechos Humanos y su objeto es desarrollar en los individuos y los pueblos sus máximas capacidades como sujetos de derechos y brindarles las herramientas y elementos para hacerlos efectivos" (Magendzo, 2008). Este autor reconoce el objetivo de constituir sujetos de derechos, en quienes se promueva la formación de valores teniendo como eje central la dignidad humana entendida desde la relación con el otro, así como la erradicación de la discriminación, ya que la formación de sujetos de derechos implica que el 
individuo reconozca sus derechos propios y en los demás, los exija y coloque en práctica en cada rol que desempeña dentro de la sociedad.

Por su parte, la Asamblea General de Naciones Unidas ha definido la Educación en Derechos Humanos como “el conjunto de actividades de capacitación, difusión e información encaminadas a crear una cultura universal en la esfera de los derechos humanos, actividades que se realizan transmitiendo conocimientos y moldeando actitudes" (ONU, citado por Espinel, 2013).

La educación en derechos humanos se considera fundamental para cualquier sociedad, de manera que hoy en día es concebida como un derecho humano. De acuerdo con Espinel (2013), esto se enfatizó en la Asamblea General de Naciones Unidas, cuyo propósito es que cada persona se reconozca como sujeto de derechos, de manera que pueda ejercer y exigir sus derechos, así mismo reconocerlos y respetar a los demás. Por tanto, las relaciones interpersonales deben caracterizarse por estar fundamentadas en valores y principios, considerándose la EDH como un camino hacia la paz y la transformación de sociedades en donde prime realmente la democracia, se respeten las diferencias y exista mayor sensibilidad por las necesidades del otro.

A partir de estos principios, los derechos humanos se conciben como aspiraciones morales, por tanto la EDH va más allá de la transmisión de derechos reconocidos internacionalmente, ya que debe convertirse en una práctica diaria del ser humano, que implica "una cultura de derechos humanos que inspire y abarque las relaciones humanas" (Espinel, 2010);se trata de formar sujetos de derechos capaces de transformar la sociedad, en lo cual concurran los diferentes contextos que influyen en el ser humano. Como lo señala Magendzo (2008) un aspecto determinante dentro de la educación en derechos humanos son los contextos, ya que los mismos orientan las propuestas para un cambio social, por tanto no se trata 
únicamente de una visión jurídico política como se concibieron en un primer momento los derechos humanos, sino que va más allá al tratarse de un conjunto de elementos jurídicos, pedagógicos, familiares, sociales, entre otros, que se interrelacionan entre sí.

Diversos autores han resaltado la influencia de los contextos en la EDH, entre ellos Stephen Kemmis (citado por Magendzo, 2008), desde la noción de comunidades críticas hace énfasis en la formación de valores y en la participación de diferentes actores como profesores, padres de familia, entre otras personas. Aunque Kemmis plantea que la educación en derechos humanos debe promoverse desde las aulas de clase, no es suficiente, ya que es necesario que se genere desde los diversos ámbitos que influyen en el ser humano, entre ellos las entidades de Estado representadas por sus servidores públicos, quienes en el desempeño de sus funciones es importante que promuevan el reconocimiento y el respeto por los derechos propios y de los demás.

Lo anterior implica la formación de sujetos de derechos con un pensamiento crítico y emancipador que conlleve a la transformación social. De acuerdo con Magendzo (2008), es fundamental que cada individuo:

a. Conozca las normas e instituciones a las cuales pueden recurrir frente a una situación en la que se le haya violado alguno de sus derechos.

b. Tenga la capacidad de defender sus derechos por medio de un lenguaje apropiado y que revele su empoderamiento frente al tema.

c. Haga valer sus derechos pero a la vez reconozca al otro y de manera recíproca espera a que ese otro también lo identifique y trate como sujeto de derechos.

d. Sea capaz de tener en cuenta al otro sin el ánimo de juzgarlo, mostrando una actitud comprensiva frente a su historia de vida. 
De modo que la EDH ha promovido la construcción de un conocimiento emancipador, el cual en términos de Habermas conlleva a la acción deliberada y colectiva, en pro de la justicia e igualdad social, por tanto facilita que las personas actúen bajo criterios propios respetando siempre al otro, así su práctica evitaría sociedades dominadas por aquellos que por poseer un cargo o posición dentro de un grupo social pretenden ejercer poder y lograr sumisión por parte de los más vulnerables por condiciones propias de personalidad, socio económicas, familiares, entre otras, ante las cuales es necesario que las personas muestren sensibilidad y actúen en favor del bienestar de los demás.

Por tanto, es necesario promover un pensamiento crítico y emancipador tal como lo propone Paulo Freire (citado por Espinel, 2010), quien considera que a través del mismo se logran aprendizajes significativos que conllevan a que se presenten cambios a nivel social, en lo cual juega un papel fundamental la subjetividad de la persona, a partir de la cual percibe y comprende el contexto en el que se encuentra y así mismo actúa, a la vez que influyen en ella las subjetividades de los demás, de manera que su propia identidad la construye a partir de lo individual y lo social.

Por otro lado, se han planteado diversas estrategias con el fin de fomentar en la sociedad una $\mathrm{EDH}$, dentro de las cuales se han propuesto los siguientes modelos:

Modelo de valores y percepción: su fin es transmitir un conocimiento elemental sobre derechos humanos y relacionarlos con los valores, a fin de que las personas respeten y se comprometan con los mismos. No obstante, éste modelo no impulsa a mejorar habilidades de comunicación, la solución adecuada de conflictos y el activismo.

Modelo de rendición de cuentas y responsabilidad: pretende que todos los seres humanos estén comprometidos con la protección de los derechos humanos, por tanto la violación de alguno de 
ellos se convierte en una labor propia, lo cual implica la capacidad para colocarse en el lugar del otro y entender su realidad.

Modelo de transformación: a través de programas se pretende que los individuos se empoderen y logren reconocer abusos a los derechos humanos y de ésta manera asuman el compromiso de prevenirlos.

Modelo problematizador: en relación a los anteriores modelos, es el más complejo pero a la vez el que guarda mayor relación con los objetivos de la educación en derechos humanos, ya que de acuerdo con Tibbits (citado por Magendzo, 2008), considera los derechos no solamente como un sistema normativo, sino como una práctica social, histórica y contextualmente construida.. De tal modo que la educación en derechos humanos implica una “educación integral holística" (Magendzo, 2008) la cual no se tuvo en cuenta en sus inicios, ya quelas naciones se enfocaron en defender sus derechos civiles y políticos, desde una visión jurídica y racional, desconociendo que la educación en derechos humanos debía estar implícita en la vida cotidiana del ser humano y de forma sistémica.

Ésta visión holística cobró importancia a partir del Decenio de las Naciones Unidas para la Educación en la Esfera de los Derechos Humanos (1995 - 2000), a partir de la cual se consideró que dicha educación en derechos humanos implica no solamente proporcionar información, sino que se trata de un proceso integral en el que las personas se concientizan de la importancia de respetar la dignidad de todas las personas sin importar sus condiciones, de modo que la misma incluye población que se ha considerado vulnerable como los niños y niñas, los ancianos, comunidades indígenas y demás minorías; quienes al conocer sus derechos se promueve en ellos mayor autonomía y una postura crítica al momento de acudir a mecanismos para su defensa. 
Por tanto, no se debe desconocerse su componente "ético - valórico" al que hace referencia Magendzo (2008), ya que la defensa y promoción de una educación en derechos humanos, debe implicar la puesta en práctica de valores como el respeto hacia el otro sin importar su situación física, social, económica, entre otras, de modo que en un grupo social la voz de cada integrante tenga valor y sea tenida en cuenta, logrando que cada persona se empodere de su condición como sujeto de derechos, logrando con ello sociedades más democráticas y respetuosas de las diferencias sociales.

Así, la EDH se considera hoy en día como un derecho humano que "implica la obligación del Estado de asegurar una práctica de la enseñanza y del aprendizaje que incorpore los conocimientos, valores, actitudes y competencias necesarios para formar ciudadanía consciente de ser sujetos de derechos y de responsabilidades" (IIED, citado por Espinel, 2003). La cual no solamente implica un componente jurídico, sino que incorpora una visión holística de los contextos basada en valores y principios éticos que facilitan un trato digno hacia el otro, de modo que requiere de la construcción de un tejido social frente a la formación de sujetos de derechos, comprometidos no solamente con sus intereses personales sino sensibles a las necesidades y derechos que tiene el otro.

Con todo lo anterior, es fundamental resaltar el objetivo del presente trabajo de investigación en relación al fortalecimiento de las defensorías de familia del Centro Zonal Fontibón del ICBF en la educación en derechos humanos, lo cual implica transcender de la visión jurídica en la cual se basan principalmente los defensores de familia y empezar a fundamentar su labor desde una visión pragmática, para lo cual se requiere de una re significación del pensamiento de dichos funcionarios en relación a la percepción que tienen de los ciudadanos atendidos, siendo importante retomar valores como la humildad al momento de 
tratar y considerar a los demás como sujetos de derechos, ya que en muchas oportunidades no sucede esto al considerar que por su cargo y poder para tomar decisiones sobre la vida y circunstancias del otro, pueden mostrar actitudes que desvalorizan a la persona, en muchas ocasiones sin ser conscientes de ello.

De esta manera, en el contexto de esta investigación, se entiende la Educación en Derechos Humanos como una posibilidad de buen trato entre diferentes personas, de tal suerte que las relaciones que se establezcan, se encuentren permeadas por el respeto y garantía de la universalidad de derechos, reconocidos por los Estados y protegidos por la Comunidad Internacional. Si se trata de relaciones entre los funcionarios del Estado (representados en este caso por los sujetos de la investigación: defensorías de familia del Centro Zonal Fontibón) y cualquier ciudadano, ha de tener especial consideración en las características propias de éste, y no homogenizar el trato y las relaciones, dado que cada uno tiene necesidades particulares.

Por lo que se requiere que la educación en derechos humanos se aborde desde un componente holístico en donde al interior de las relaciones interpersonales prime el respeto por la dignidad humana, ya sea en el trato entre funcionarios o de éstos con las familias atendidas. Desde la visión y misión del ICBF, el reconocimiento del otro como sujeto de derechos, facilita el cumplimiento de los objetivos de dicha entidad en relación a la protección de los niños, niñas y adolescentes y sus familias.

En conclusión, la EDH resulta de suma importancia para establecer relaciones de respeto y dignidad hacia el otro, de modo que contribuya a una re significación de los procesos de atención del ICBF que beneficien a todas las partes. El aporte para esta investigación, va direccionado a la fundamentación y estructuración de la propuesta psicosocial. 


\subsection{Intervención psicosocial a partir de un enfoque sistémico}

La propuesta psicosocial planteada en el presente trabajo de grado, se fundamentó en teorías sistémicas, que han explicado el comportamiento humano y las dinámicas relacionales a partir de la influencia de los contextos en el ser humano. Según Ludewig (2001) debe ser comprendido desde un componente biológico, psicológico y social, dicho autor considera que toda persona tiene un origen social desde el cual sólo puede ser comprendido, denominado Principio Sistémico. Además se aborda desde una mirada psicosocial, planteada a partir de diversos principios, como lo son: "dignidad, apoyo mutuo, solidaridad, vida con calidad, enfoque de derechos, enfoque de género y desarrollo humano integral en salud mental”, González y Villa (citados en Villa, 2012).

Teniendo en cuenta que la educación en derechos humanos se ha desarrollado desde una visión holística, para el cumplimiento de los objetivos de la presente investigación, es necesario que la misma se aborde desde una perspectiva psicosocial acompañada de una postura sistémica, la cual se fundamenta en un enfoque integral que desde la psicología no desconoce las demás teorías, pero que a la vez las integra retomando de cada una lo que considera importante según la problemática presentada y de ésta manera contribuir a un cambio en el ser humano; ejemplo de ello son las teorías conductistas, ya que desde lo sistémico se ha considerado que la conducta del ser humano va más allá de la causa - efecto que ha planteado el conductismo, el cual atribuye el cambio directamente al ser humano desconociendo la influencia que puede generar en éste la interacción de los diferentes contextos en los cuales se desenvuelve y sobre los cuales es necesario intervenir, por ejemplo en problemas de comportamiento no es suficiente abordar sólo al individuo y atribuirle a éste la responsabilidad de un cambio, sino que es necesario analizar 
cómo la familia, la escuela, la sociedad, entre otros ámbitos influyen en la persona y de ésta manera trabajar sobre los mismos.

Por otro lado, la intervención desde un enfoque sistémico, implica una retroalimentación constante entre los participantes, como se ha indicado desde la cibernética planteada por Bateson (citado por García, González y Talavera, 1999), la misma puede ser: positiva, cuando se logran cambios debido a la apertura de los sistemas al tener en cuenta el aporte de los demás; o negativa cuando el sistema es estático y no permite que la percepción del otro permee en su punto de vista, por tanto lograr un cambio se torna más difícil.

Los cambios también dependen del ambiente que genere el terapeuta y la capacidad de éste para lograr interactuar de forma dinámica con su interviniente, como lo señala Ludewig (2001), aunque en la terapia se orienta al cliente para que sea él mismo el que genere el cambio, es el terapeuta quien tiene la responsabilidad de establecer un contexto apropiado y beneficioso para el otro, que conlleve a diálogos dentro de los cuales se reconozca y transforme su realidad; es fundamental tener en cuenta aspectos del pasado que influyen en su presente, los cuales tienden a desconocerse en muchas ocasiones por el terapeuta, pero que son necesarios, ya que "a través del lenguaje se construyen mundos humanos, no simplemente se transmiten mensajes de un lugar a otro" (Galán \& Pinzón, 2002).

Por tanto, en la terapia es importante promover la participación de cada integrante del sistema familiar, en donde a través del análisis del contexto se integren las narrativas de cada uno, que permita comprender su percepción de la situación y plantear soluciones a partir de las herramientas o recursos con los cuales cuentan, sin centrarse en el síntoma o conductas a mejorar, ya que es una postura equivocada pretender lograr transformaciones a través de 
señalamientos y juzgamientos, lo cual puede generar un resultado contrario a lo que se espera de la intervención.

Para Ochoa (1995) resulta importante no considerar a la familia como la causante del síntoma presentado por alguno de sus miembros, por el contrario se debe orientar al descubrimiento de sus potencialidades y capacidades que les permita superar las dificultades presentadas, para lo cual es importante que se perciba como "un grupo humano con capacidades y recursos para ayudar a sus componentes a superar los problemas e incluso salir renovados de la crisis".

En conclusión, existe una interrelación entre el enfoque sistémico y la educación en derechos humanos, que permite una atención más efectiva, una percepción más amplia sobre las verdaderas necesidades y recursos con los cuales cuenta el otro y de acuerdo a elloproporcionar las herramientas adecuadas, para lograr soluciones eficaces. El enfoque sistémico es fundamental para la estructuración de la propuesta psicosocial.

\subsection{Un nuevo concepto de familia}

En cualquier proceso de intervención con familia es importante tener en cuenta los cambios que se han generado durante las últimas décadas respecto a su concepto y dinámicas, así como los factores que han influido en los mismos, lo que permite una mayor comprensión de su realidad y evita que se generen juzgamientos. Por lo cual, a continuación se expone brevemente dichas transformaciones presentadas en las familias.

De acuerdo con Arriagada (2002), a partir de 1950 la sociología realizó estudios acerca de la familia, a través de los cuales trataban de establecer la relación entre las dinámicas sociales y la estructura familiar, predominando en ese entonces la teoría de que en la familia existían roles definidos y diferentes en cuanto al hombre y la mujer, considerándose al primero como el 
proveedor, mientras que el género femenino era sinónimo de reproducción, de cumplir con los deberes del hogar y cuidar de los niños y ancianos. Pero con la aparición de la industria y la vinculación de la mujer a la misma, dicha teoría fue perdiendo validez en la medida en que fue ajustada a los nuevos sistemas sociales, principalmente por movimientos feministas.

De tal modo que los cambios de roles que se han presentado en la sociedad, han generado el “desplazamiento del hombre como proveedor único” (Salles y Tuirán, 1996), lo que a la vez ha conllevado a que la mujer se perciba menos dependiente de su pareja, con mayor autonomía y capacidad de proyectarse respecto a sus propias metas. De acuerdo con Vitelma (2003), los nuevos estereotipos en cuanto a lo femenino y lo masculino afectan las relaciones familiares, de manera que hoy en día han aumentado las tasas de divorcio, convirtiéndose a la vez el matrimonio y el deseo de tener hijos como una opción.

Las transformaciones que se han presentado de manera progresiva en las familias se deben a la influencia de factores como: "el contexto urbano o rural, la clase social y las diversas experiencias de las sociedades latinoamericanas", Salles y Tuirán (citados por Arriagada, 2002). En América Latina se han presentado cambios en el ciclo de vida familiar generados a la vez por transformaciones a nivel demográfico como: descenso en las tasas de natalidad, incremento de adultos mayores solos, viudez especialmente por parte de la mujer, disminución del número de hijos y aumento respecto a la edad para casarse.

Para el caso particular de Colombia los principales cambios que han surgido a nivel de la familia se empezaron a generar a mitad del siglo XX, como causa del desplazamiento forzoso que ha ocasionado la violencia, lo que ha implicado otras dinámicas familiares como el hecho de que la mujer se vinculara en el mundo laboral al tener que suplir los gastos del hogar, ya fuera por viudez o porque los ingresos de su pareja no eran suficientes para cubrir las necesidades 
económicas del sistema. Dichos aspectos deben ser tenidos en cuenta en la intervención con familias, como se ha indicado anteriormente, permiten comprender su realidad y encontrar soluciones factibles que generen cambios reales.

Como consecuencia de los cambios ocurridos en la sociedad, diversos autores han clasificado a la familia en diferentes tipologías que casi siempre coinciden, lo que las diferencia es la denominación que le asignan, en éste caso se menciona la aportada por González (2007) quien cataloga a las familias en:

$>$ Familia extensa: la conforman individuos de todas las generaciones: cónyuges, hijos, padres, etc.

$>$ Familia troncal: queda un hijo que se casa y continúa viviendo con sus padres.

$>$ Nuclear: la constituye una pareja casada con o sin hijos.

$>$ Mixta: similar a la nuclear, pero se incluyen miembros de relaciones anteriores.

$>$ De unión de hecho: familia nuclear, sin nexo legal.

$>$ Monoparental: un solo padre.

$>$ Comuna familiar: hay más de dos generaciones.

$>$ Familia serie: formada por un varón y una mujer que han pasado por una sucesión de matrimonios, han tenido varios esposos y diferentes familias a lo largo de sus vidas.

$>$ Familia compuesta: cuando dos o más familias nucleares comparten un mismo marido o una misma mujer.

Cohabitación: dos personas solteras conviven sin vínculos legales.

Familias gay: parejas del mismo sexo, con hijos biológicos de uno de los miembros o no. Dichos cambios a nivel de la estructura familiar ha implicado a su vez modificaciones en las dinámicas de estos sistemas, ya que anteriormente la familia tradicional conllevaba a que la progenitora permaneciera en el hogar cuidando de los hijos, por tanto le era más fácil tener el control frente a cualquier situación que pudiera ocurrir con ellos. Dicha independencia laboral y 
económica de acuerdo con Herrera (2000) ha implicado para la mujer una sobre carga de responsabilidades. Lo cual no significa que sea la mujer la que deba llevar la carga y responsabilidad de la familia, tanto el hombre como la mujer tienen responsabilidades compartidas y los dos se encuentran en las mismas posibilidades de poder ser profesionales, trabajadores o cuidadores del hogar.

Por tanto, es importante tener en cuenta el aporte de Ríos (citado por González, 2007), en cuanto a las características que debe poseer una familia para que exista una adecuada interacción entre las personas que componen el sistema familiar:

- Los miembros sean algo más que la suma de sus partes.

- Tengan bien definido los límites o fronteras entre sí.

- Cada uno de los miembros tenga identidad y autonomía.

- La autonomía no debe ser una amenaza a la autoridad y jerarquía del sistema global.

- La familia facilite a cada miembro el planteamiento y la resolución de la autonomía, la competencia, la intimidad y la sana independencia.

Pero como ya se ha mencionado, la armonía de las dinámicas familiares no dependen exclusivamente de la familia, también de los demás contextos en los cuales se encuentra inmersa como lo son los sistemas educativos, sociales, políticos, entre otros; considerándose el estado como el principal responsable de proporcionarle a dichos sistemas los recursos suficientes para poder manejar adecuadamente las problemáticas que pueden presentarse, por lo cual es importante crear políticas públicas que respondan a los intereses de las familias, de manera que en realidad brinden un apoyo significativo a la misma.

En conclusión, la familia ha ido transformándose poco a poco, generando con ello nuevos conflictos y nuevos retos para instituciones estatales como el ICBF quienes deben además adecuar sus intervenciones según las necesidades propias de cada persona o familia. 


\subsection{Las defensorías de familia y su rol fundamental en la práctica de la educación en derechos humanos:}

De acuerdo al objetivo de la presente investigación es importante dar a conocer las funciones que cumplen las defensorías de familia del ICBF en su labor fundamental de garantizar derechos a los NNA y sus familias; y cómo desde su labor diaria pueden colocar en práctica la educación en derechos humanos para una atención más efectiva, en la cual de manera recíproca sus participantes se reconozcan como sujetos de derechos. Por lo cuala continuación se exponen brevemente diversas concepciones de los NNA como sujetos de derechos y el rol que han desempeñado las Defensorías de Familia como garantes de estos, así como las fortalezas y debilidades que las mismas han presentado en el desempeño de sus funciones.

En Colombia a partir de la política de primera infancia del ICBF (2006), se enfatizó en la importancia de considerar a los niños y niñas como sujetos de derechos, por tanto es primordial garantizar a dicha población sus derechos humanos para el mejoramiento de su calidad de vida. Esto teniendo en cuenta que la primera infancia se trata de una etapa decisiva del ser humano en donde se establecen las bases de su desarrollo futuro, ya que desde el momento en que nace la relación que establece con los demás y el ambiente que le rodea van a determinar su forma de actuar, su desarrollo integral, su estabilidad emocional, entre otros aspectos relevantes en la vida del ser humano. Por ende se ha considerado importante que desde el momento del nacimiento el ser humano sea reconocido como sujeto de derechos teniendo en cuenta que los niños y niñas son seres únicos con características propias de personalidad, biológicas, psíquicas, sociales y culturales.

Los adolescentes al igual que la primera infancia son sujetos de derechos, a quienes debe respetarse y tener en cuenta su opinión, como lo han señalado Guiñazú y otros (2012), desde un 
enfoque de derechos. Sin embargo, en la realidad a veces ocurre lo contrario, ya que ésta población tiende a ser rechazada y juzgada por su personalidad y comportamiento cuando va en contra de la norma, ya que en dicha etapa del desarrollo se presentan cambios hormonales que traen consecuencias en su estado de ánimo y formas de actuar, además se encuentran en una transición de la etapa de la niñez a la adulta, la cual trae consigo conflictos internos respecto a su manera de actuar, lo que a la vez conlleva a que los adolescentes presenten dificultad para acatar las normas y reglas que le establecen en el contexto en el cual se desenvuelve. Además en casos en los que no han recibido desde la niñez atención, afecto y apoyo, pueden llegar a presentar dificultades a nivel académico y comportamentales como involucramiento con pares negativos, permanencia en calle, consumo de SPA, actividades delictivas, entre otras; puesto que tienden a ser bastante influenciables y a suplir vacíos afectivos a través de éstas conductas.

Por lo anterior, es fundamental que de manera mancomunada la familia, la sociedad y el Estado asuman la responsabilidad de promover y garantizar los derechos de NNA, evitando exponerlos a situaciones que puedan colocar en riesgo su integridad física o psicológica.

De igual manera se tengan en cuenta las voces de los NNA en la creación de políticas públicas y demás programas de prevención del Estado, como lo ha indicado Rosemberg (s.f.) respecto a la primera infancia y Krauskopf (1999) en cuanto a los adolescentes.

Como parte de las estrategias para la garantía de los derechos de los NNA, al interior del ICBF se crearon las Defensorías de Familia las cuales son "una instancia que busca atender oportuna y eficazmente a los niños, niñas y adolescentes, a quienes se les han vulnerado sus derechos para evitar secuelas traumáticas en su desarrollo" (Jiménez, 2012), dicho concepto es limitado en relación al total de funciones que realizan, ya que además de atender casos de vulneración de derechos, se desempeñan en el campo extra procesal como se ha denominado a 
los asuntos conciliables, entre ellos: definición de custodias, fijación de visitas y regulación de alimentos, campo desde el cual el ICBF puede potencializarse a nivel preventivo.

Las defensorías de familia, están compuestas por; un defensor de familia el cual debe ser abogado, cumplir con los requisitos y funciones contemplados en los Art. 80 y 82 de la Ley de Infancia y Adolescencia y regirse por el código único disciplinario de conformidad con el Estatuto del Defensor de Familia. Aunque ésta figura es quien coordina y define los procesos, se apoya en los saberes de un equipo interdisciplinario conformado por un psicólogo, trabajador social, nutricionista y en algunos casos por un antropólogo o sociólogo, principalmente cuando la intervención requiere de un enfoque diferencial.

El Código de Infancia y Adolescencia resalta el trabajo interdisciplinario de las defensorías de familia, por lo cual se implementó un modelo de atención fundamentado desde una perspectiva sistémica el cual se denomina modelo solidario, con el fin de que los funcionarios fundamenten su intervención a partir del reconocimiento de la influencia de los contextos en el ser humano y con base en ello tomar decisiones de manera integrada.

Así mismo, de acuerdo con la experiencia en este escenario, a nivel general del ICBF existe carga laboral debido a la falta de personal para la atención oportuna de la demanda existente, dicha saturación afecta los procesos de atención a las familias que acuden a los Centros Zonales; además la ciudadanía en muchas ocasiones presenta denuncias falsas lo que implica un desgaste para los equipos de las defensorías de familia, ya que de acuerdo a los procesos y procedimientos del ICBF todas deben ser verificadas y dar respuesta dentro de los términos de ley establecido (ICBF, 2016).

Es de aclarar que la recepción de los casos está asignada al área de relación con el ciudadano, cargo que es desempeñado por un psicólogo o trabajador social que tiene como 
función "atender, informar, orientar, clasificar, registrar y direccionar las peticiones recibidas..." (ICBF, 2016), las cuales son recepcionadas desde diferentes canales de atención, ya sea presencial, escrita o verbal, por parte de diferentes entidades y ciudadanos; posteriormente son direccionadas a la defensoría de familia que le corresponda según un orden establecido para dicho reparto.

Una vez la defensoría de familia recibe el caso, realiza una verificación de derechos (Art. 51 de la Ley 1098 de 2006) y de manera individual cada profesional actúa y emite un concepto desde su área, el cual tiene carácter pericial (Art. 79 de la Ley 1098 de 2006), para que de manera articulada se tome una decisión o medida. De acuerdo con el Art. 53 de la Ley 1098 de 2006, éstas medidas pueden ser: amonestar a los padres con remisión a curso pedagógico en la defensoría del pueblo (Art. 54 de la Ley 1098 de 2006); retiro o ubicación inmediata del NNA de su medio familiar; ubicación en Centro de Emergencia cuando se define que el NNA debe ingresar bajo medida de protección; o la adopción cuando el NNA se encuentra bajo medida de protección y se hayan agotado todos los recursos para la ubicación en medio familiar de acuerdo a la Sentencia T-844 de 2011.

Teniendo en cuenta las funciones principales de las defensorías de familia, es importante que los procesos de atención se soporten en los principios de la educación en derechos humanos, como lo es el trato adecuado, confrontaciones bajo principios del respeto y la tolerancia, tener la capacidad de colocarse en el lugar del otro y así mismo entender su realidad a partir de los diferentes contextos en los cuales se desenvuelve la persona.

En conclusión, las Defensorías de Familia son de gran importancia para la garantía de derechos de los NNA, cuya intervención debe hacerse en concordancia con el respeto por los DDHH, lo cual exige de sus funcionarios una EDH garante y respetuosa del otro. 


\section{Propuesta psicosocial: transformando las dinámicas de las Defensorías de Familia} del Centro Zonal Fontibón a partir de la perspectiva de la Educación en Derechos

\section{Humanos con un enfoque sistémico}

\subsection{Contextualización de la propuesta}

\subsubsection{Identificación}

Propuesta de intervención psicosocial de Educación en Derechos Humanos desde un enfoque sistémico, dirigido a las cinco Defensorías de Familia del Centro Zonal Fontibón del ICBF, tres de ellas encargadas del área de protección y dos de extra procesal.

\section{Glosario de palabras claves}

- Derechos humanos: según las naciones unidas los derechos humanos son innatos a todo ser humano, por tanto deben ser respetados sin importar la nacionalidad, raza, religión, etnia, o demás características individuales de una persona. Estos derechos se interrelacionan, son por tanto indivisibles e interdependientes.

- Educación en derechos humanos: Magendzo (2008) la define como el "reconocimiento, la defensa, el respeto y la promoción de los Derechos Humanos y que tiene por objeto desarrollar en los individuos y los pueblos sus máximas capacidades como sujetos de derechos y brindarles las herramientas y elementos para hacerlos efectivos".

- Intervención psicosocial: de acuerdo con Villa (2012) implica "una acción centrada en la promoción de prácticas relacionales basadas en el reconocimiento y la valoración del ser humano en ejercicio de construcción”, lo cual no solamente implica la acción del psicólogo sino que se trata de un trabajo interdisciplinario en el que diversos profesionales deben contar con la capacidad de intervenir a partir de la realidad del otro y 
teniendo en cuenta la influencia de los diferentes contextos en la misma, para poder tomar decisiones que se ajusten a las necesidades de cada caso.

- Enfoque sistémico: Se basa en la teoría de sistemas el cual explica el comportamiento humano a partir de la interrelación de los diferentes contextos, de manera que estos son vistos como un todo pero a la vez con características particulares que se articulan dentro de un proceso dinámico.

- Defensorías de Familia: de acuerdo al estatuto integral del defensor de familia, las defensorías de familia son dependencias multidisciplinarias del ICBF, que tienen como función prevenir, garantizar y restablecer los derechos de los niños, niñas y adolescentes; integrados por un equipo interdisciplinario conformado por defensor de familia, psicólogo, trabajador social y nutricionista.

Duración de la propuesta: Teniendo en cuenta que cada taller planteado para la ejecución de la propuesta se llevaría a cabo en el desarrollo de los Grupos de Estudio Técnicos (GET) los cuales se desarrollan una vez al mes en el Centro Zonal, la misma tendría una duración de cinco meses dentro de los cuales se les asignará tareas a las Defensorías de Familia que les permita colocar en práctica las temáticas desarrolladas.

Categorías: Derechos humanos, Educación en derechos humanos, intervención psicosocial y enfoque sistémico.

\subsubsection{Resumen}

La propuesta de intervención psicosocial se fundamenta en la necesidad de fortalecer a las Defensorías de Familia del Centro Zonal Fontibón en la Educación en Derechos Humanos, la cual es importante que se refleje en las labores diarias que cada integrante realiza desde su rol profesional, de manera que se garantice el trato hacia el otro como sujeto de derechos y así 
mismo se puedan generar cambios en los sistemas familiares, a través de un análisis y

comprensión holística de la realidad que conlleven a tomar decisiones en conjunto. Se busca una transformación que contribuya al cumplimiento del objetivo del ICBF de promover y garantizar los derechos de los NNA y velar por el bienestar de las familias colombianas.

\subsubsection{Necesidad de la propuesta:}

Teniendo en cuenta las dificultades identificadas en las Defensorías de Familia del Centro Zonal Fontibón respecto a la comprensión y aplicación del concepto de EDH, se consideró necesario elaborar la presente propuesta psicosocial, la cual se fundamenta en las teorías del enfoque sistémico, teniendo en cuenta que la educación en derechos humanos exige una mirada holística que permita comprender al otro desde los diferentes contextos en los cuales se desenvuelve y que influyen en el ser humano, de manera que éste se aborde desde su realidad y se tengan en cuenta sus verdaderas necesidades.

Se considera el enfoque sistémico como el más apropiado al momento de intervenir a las familias, en la medida en que a través del mismo se logra abordar al otro como parte de un todo que a la vez conserva su individualidad, lo que facilita a la vez que sea reconocido como sujeto de derechos y éste a su vez reconozca los derechos del otro, por lo cual dicha interacción que se genera durante la intervención debe caracterizarse por la reciprocidad en el trato que se brinde el uno al otro.

\subsubsection{Objetivos}

\subsubsection{Objetivo General}

Fortalecer las Defensorías de Familia del Centro Zonal Fontibón en la temática sobre educación en derechos humanos, como estrategia para mejorar en la atención que brindan a las familias, siendo imperante que dentro de sus labores reconozcan y respeten realmente los 
propios derechos y los del otro, de manera que se lleven a cabo procesos de atención en el que se tenga en cuenta la realidad de cada participante.

\subsubsection{Objetivos Específicos}

- Implementar la presente propuesta psicosocial en las Defensorías de Familia del Centro Zonal Fontibón del ICBF.

- Desarrollar mediante talleres actividades didácticas y de reflexión, que promuevan un pensamiento crítico, el cual facilite el análisis y comprensión del significado real de la educación en derechos humanos y cómo la puesta en práctica de la misma puede contribuir a una atención más eficiente.

- Evaluar mediante un pre-test - post-test la puesta en práctica de la propuesta psicosocial, a fin de medir el impacto causado en las Defensorías de Familia.

\subsection{Presentación de la propuesta}

\subsubsection{Descripción de la propuesta}

La presente propuesta se desarrolla a partir de una mirada psicosocial y se fundamenta en las bases conceptuales del enfoque sistémico, a través de la cual se proponen acciones encaminadas a fortalecer la educación en derechos humanos en las Defensorías de Familia del Centro Zonal Fontibón del ICBF, de modo que los funcionarios que componen dichas defensorías realicen una labor más eficiente en la atención a familias, en la medida en que logren interiorizar el significado de dicha educación en derechos humanos aplicándolo a su quehacer profesional y a las funciones asignadas.

Así las cosas, se plantea una serie de cinco talleres didácticos y procesos de autoevaluación, mediante los cuales las defensorías de familia logren interiorizar en su práctica profesional los principios de la educación en derechos humanos. 


\subsubsection{Características de la población a quien va dirigida la propuesta}

El Centro Zonal Fontibón se encuentra ubicado al noroccidente de la ciudad de Bogotá, cuenta con cinco Defensorías de Familia cada una de ellas compuesta por: defensor de familia, psicólogo y trabajador social, además de dos nutricionistas que apoyan las mismas en los casos que se requiere de su atención. Tres de ellas se encargan de los casos de protección, es decir de aquellos en los que se presume una amenaza, vulneración o inobservancia de derechos de un niño, niña o adolescente; las otras dos son del área extra procesal, es decir abordan los casos que se consideran conciliables como: custodias, fijación de cuota de alimentos y revisión de visitas; además de trámite para salidas del país, investigación de paternidad, impugnación de paternidad, entre otros.

Algunos de los profesionales cuentan con estudios en Especialización o Maestría de acuerdo a su área; además el ICBF mediante el programa de Escuela Virtual y otros procesos de educación para el trabajo y el desarrollo humano (antes llamada educación no formal), han abordado con los funcionarios temas relacionados con derechos humanos. Sin embargo, no se percibe como tal una formación específica en el tema de Educación en Derechos Humanos, por tanto presentan dificultad al momento de definir, comprender y colocar en práctica la misma.

A continuación se presenta una breve descripción de la percepción que tienen las Defensorías de Familia sobre el tema de EDH, resultado de una entrevista no estructurada aplicada a los funcionarios del Centro Zonal Fontibón que las integran. El objetivo fue establecer un diagnóstico de la población respecto al saber y comprensión que poseen sobre el tema y evaluar si el mismo se refleja en la práctica de sus funciones diarias. Dichos resultados se comparan a la vez con la realidad de lo que significa realmente la educación en derechos 
humanos y se describen los resultados que se pretenden alcanzar a partir de la ejecución de la presente propuesta psicosocial.

\begin{tabular}{|c|c|c|}
\hline $\begin{array}{c}\text { Realidad de las Defensorías de } \\
\text { Familia }\end{array}$ & $\begin{array}{c}\text { Perspectiva a partir de la } \\
\text { Educación en Derechos } \\
\text { Humanos }\end{array}$ & $\begin{array}{l}\text { Expectativa de los } \\
\text { logros a alcanzar }\end{array}$ \\
\hline $\begin{array}{l}\text { Se tiende a creer que la } \\
\text { Educación en Derechos } \\
\text { Humanos consiste únicamente } \\
\text { en la transmisión de deberes y } \\
\text { derechos. }\end{array}$ & $\begin{array}{l}\text { La educación en derechos } \\
\text { humanos va más allá de la } \\
\text { transmisión de deberes y } \\
\text { derechos, ya que debe ser un } \\
\text { aspecto inherente al ser } \\
\text { humano el cual le facilita } \\
\text { reconocerse y reconocer al otro } \\
\text { como sujeto de derechos. }\end{array}$ & $\begin{array}{l}\text { Aprendizaje de las } \\
\text { Defensorías de Familia } \\
\text { respecto al verdadero } \\
\text { significado de } \\
\text { educación en derechos } \\
\text { humanos. }\end{array}$ \\
\hline $\begin{array}{l}\text { Aunque se tiene claridad } \\
\text { respecto a algunos elementos a } \\
\text { tener en cuenta durante la } \\
\text { intervención con familias, falta } \\
\text { mayor conciencia por parte del } \\
\text { funcionario sobre el rol } \\
\text { fundamental que éste desempeña } \\
\text { para la generación de un cambio. }\end{array}$ & $\begin{array}{l}\text { El cambio, aunque depende del } \\
\text { sistema familiar que se } \\
\text { interviene, influye en el mismo } \\
\text { la intervención que lleve a cabo } \\
\text { el profesional. }\end{array}$ & $\begin{array}{l}\text { Reforzar en las } \\
\text { defensorías de familia } \\
\text { habilidades de } \\
\text { intervención enfocadas } \\
\text { en reconocer al otro } \\
\text { como sujeto de } \\
\text { derechos, que requiere } \\
\text { una orientación } \\
\text { respetuosa a través de la } \\
\text { cual se le faciliten las } \\
\text { herramientas necesarias } \\
\text { para un cambio. }\end{array}$ \\
\hline $\begin{array}{l}\text { Existe la tendencia en el } \\
\text { funcionario de llevar a cabo } \\
\text { intervenciones sin tener en } \\
\text { cuenta la influencia de los } \\
\text { contextos en la realidad de cada } \\
\text { individuo. Por tanto se dificulta }\end{array}$ & $\begin{array}{l}\text { Las defensorías de familia } \\
\text { deben contar con la capacidad } \\
\text { de analizar cada caso a partir } \\
\text { de los factores que pueden } \\
\text { estar influyendo en la } \\
\text { problemática, ya sean de tipo }\end{array}$ & $\begin{array}{l}\text { Capacidad de análisis } \\
\text { por parte de las } \\
\text { defensorías de familia } \\
\text { de las problemáticas } \\
\text { identificadas a partir de } \\
\text { los diferentes contextos }\end{array}$ \\
\hline
\end{tabular}




\begin{tabular}{|c|c|c|}
\hline $\begin{array}{l}\text { comprender la causa del } \\
\text { problema. }\end{array}$ & $\begin{array}{l}\text { personal, familiar, } \\
\text { socioeconómico, entre otros, } \\
\text { los cuales inciden de forma } \\
\text { mutua en el comportamiento de } \\
\text { la persona. Esto teniendo en } \\
\text { cuenta que la educación en } \\
\text { derechos humanos se } \\
\text { fundamenta en una visión } \\
\text { holística. }\end{array}$ & $\begin{array}{l}\text { en los que se } \\
\text { desenvuelve la persona, } \\
\text { de manera que se } \\
\text { cuente con una visión } \\
\text { más amplia de la } \\
\text { situación y así mismo } \\
\text { encontrar una solución } \\
\text { a partir de la percepción } \\
\text { de cada participante, es } \\
\text { decir, tanto del } \\
\text { ciudadano como del } \\
\text { funcionario, a fin de } \\
\text { tomar decisiones en } \\
\text { conjunto. }\end{array}$ \\
\hline $\begin{array}{l}\text { Las estrategias de formación en } \\
\text { realidad no contribuyen a un } \\
\text { cambio }\end{array}$ & $\begin{array}{l}\text { Las defensorías de familia } \\
\text { mediante procesos de } \\
\text { introspección pueden } \\
\text { comprender la relevancia de la } \\
\text { educación en derechos } \\
\text { humanos con el fin de lograr } \\
\text { una transformación en las } \\
\text { dinámicas de intervención a } \\
\text { partir de la Educación en } \\
\text { Derechos Humanos. }\end{array}$ & $\begin{array}{l}\text { Reconocimiento por } \\
\text { parte de las defensorías } \\
\text { de familia de la } \\
\text { relevancia de colocar en } \\
\text { práctica la educación en } \\
\text { derechos humanos para } \\
\text { una transformación } \\
\text { personal, familiar y } \\
\text { social, de modo que se } \\
\text { logre un } \\
\text { reconocimiento propio } \\
\text { y del otro como sujeto } \\
\text { de derechos. }\end{array}$ \\
\hline
\end{tabular}

Fuente: Elaboración propia (Noviembre, 2016)

La tabla anterior permite entrever la diferencia abismal existente entre lo que realmente se percibe en las defensorías de familia respecto al tema de educación en derechos humanos y la 
expectativa de lo que se pretende lograr con la presente propuesta psicosocial. De manera que es imperante que se comprenda el impacto que causaría y de ésta manera se refleje en las labores diarias de sus funcionarios, logrando que no se trate únicamente de expectativas e ideales sino que su aplicación se refleje en el desarrollo de sus labores como un aspecto inherente a ellos.

\subsubsection{Contexto de las Defensorías de Familia desde la perspectiva de la Educación en}

\section{Derechos Humanos a partir de un enfoque sistémico}

Las defensorías de familia a diario se enfrentan a diferentes situaciones al abordar problemáticas presentadas por las familias que recurren al Centro Zonal Fontibón, lo cual implica asumir desafíos y tomar decisiones que consideren pertinentes de acuerdo a cada caso. En dicha labor, la mayoría de ocasiones se pierde de vista el modelo solidario que se ha promovido desde el ICBF como estrategia de intervención, el cual se sustenta en un enfoque sistémico en el que se supone que las decisiones deben ser tomadas en conjunto y teniendo en cuenta la voz de todos los participantes. Por el contrario se tiende a decidir de manera individual y no se dedica el tiempo para analizar la situación desde una mirada holística, en lo cual pueden tener incidencia factores como: el exceso de carga laborar, falta de recurso humano para cubrir toda la demanda o poco fortalecimiento en herramientas y habilidades personales que faciliten mejorar la calidad de la intervención.

Es importante que las defensorías de familia interioricen y así mismo puedan poner en práctica los principios de una educación en derechos humanos, de manera que comprendan que ésta no se limita a un simple concepto, sino que conlleva a que en la práctica se considere al otro como sujeto de derechos, por tanto es digno de que se le respeten sus derechos y su dignidad humana, pero a la vez que éste los reconozca en los demás. Así mismo permite comprender la 
realidad de los sistemas familiares, lo cual evita que se lleven a cabo juicios de valor, como en ocasiones ocurre en la atención a familias por parte de estos funcionarios.

Por tanto para tratar el tema de educación en derechos humanos con los funcionarios que hacen parte de las defensorías de familia del Centro Zonal Fontibón se propone llevar a cabo talleres en los cuales se plantean actividades lúdicas que conlleven a la adquisición de saberes, la comprensión de la educación en derechos humanos y la reflexión sobre la aplicación de la misma en el cumplimiento de las funciones asignadas de acuerdo a la profesión y área en la cual se desempeñan, de manera que se promueva un pensamiento crítico que les permita cuestionar asuntos que interfieren negativamente en la eficacia de su labor y por sí mismos sean agentes de cambio que faciliten la transformación de los sistemas familiares.

En el cumplimiento de lo anterior, se cuenta con la aprobación de la Sede Nacional del ICBF para el desarrollo de la propuesta, para lo cual se plantea que los talleres se desarrollen durante los grupos de estudios técnicos (GET) que se llevan a cabo una vez al mes en el Centro Zonal. Por tanto, sería viable que dentro de dichos GET la coordinadora del Centro Zonal permita designar en la agenda una hora para el desarrollo de los talleres y con base en los resultados obtenidos se podría extender la propuesta a los otros Centros Zonales a nivel de la regional Bogotá y quizá tener la posibilidad de un abordaje del tema a nivel nacional. Para lo cual es importante enfatizar en que los mismos se desarrollen dentro de la unidad de servicio, ya que se ha observado que el ICBF al implementar una nueva temática, suele delegar a unos cuantos funcionarios para que asistan a dicho proceso de educación para el trabajo y el desarrollo humano, quienes se supone deben replicar la información a los demás servidores públicos, pero que en realidad en muchas ocasiones esto no ocurre, lo que impide su aplicación, además se corre el riesgo de que se pierda la esencia de las actividades planteadas en la propuesta, ya que 
las mismas facilitan la interiorización del concepto de educación en derechos humanos y su relación con el enfoque sistémico.

El desarrollo de la propuesta implica un Plan Estratégico que se fundamenta en cuatro ejes temáticos, los cuales consisten en: comprensión del concepto educación en derechos humanos, puesta en práctica de la EDH, influencia de los contextos en la realidad de cada individuo y evaluar el impacto que puede llegar a generar la EDH en las Defensorías de Familia.

Seguidamente se describen una serie de talleres a través de los cuales se pretende abordar cada uno de éstos ejes temáticos, para lo cual se plantean actividades pedagógicas que faciliten el proceso de formación en el tema.

\subsubsection{Plan estratégico para la mejora en los procesos de intervención a partir de} una Educación en Derechos Humanos

\begin{tabular}{|l|l|l|l|l|}
\hline \multicolumn{1}{|c|}{$\begin{array}{c}\text { Eje } \\
\text { Temático }\end{array}$} & \multicolumn{1}{c|}{ Objetivo } & \multicolumn{1}{c|}{ Tácticas } & \multicolumn{1}{c|}{ Indicadores } & \multicolumn{1}{c|}{ Resultados } \\
\hline $\begin{array}{l}\text { Comprensió } \\
\text { n del } \\
\text { concepto } \\
\text { educación en } \\
\text { derechos } \\
\text { humanos. }\end{array}$ & $\begin{array}{l}\text { Facilitar de } \\
\text { forma } \\
\text { dinámica la } \\
\text { comprensión } \\
\text { de aspectos } \\
\text { conceptuales } \\
\text { de la } \\
\text { educación en } \\
\text { derechos } \\
\text { humanos. }\end{array}$ & $\begin{array}{l}\text { Desarrollo de } \\
\text { actividades } \\
\text { lúdicas que } \\
\text { conlleven a } \\
\text { comprender el } \\
\text { significado de } \\
\text { la EDH. }\end{array}$ & $\begin{array}{l}\text { Comprensión } \\
\text { del concepto de } \\
\text { educación en } \\
\text { derechos } \\
\text { humanos en } \\
\text { toda su } \\
\text { dimensión. }\end{array}$ & $\begin{array}{l}\text { Las Defensorías de } \\
\text { Familia comprenden la } \\
\text { EDH como un proceso } \\
\text { inherente al individuo y } \\
\text { no solamente como una } \\
\text { transmisión de valores, } \\
\text { deberes y derechos. }\end{array}$ \\
\hline $\begin{array}{l}\text { Puesta en } \\
\text { práctica de la } \\
\text { educación en } \\
\text { derechos }\end{array}$ & $\begin{array}{l}\text { Generar } \\
\text { espacios de } \\
\text { reflexión } \\
\text { sobre la } \\
\text { importancia de } \\
\text { que la EDH } \\
\text { sea inherente a }\end{array}$ & $\begin{array}{l}\text { Juegos de roles } \\
\text { y otras } \\
\text { actividades que } \\
\text { permitan } \\
\text { identificar } \\
\text { aspectos a tener } \\
\text { en cuenta al }\end{array}$ & $\begin{array}{l}\text { La educación } \\
\text { en derechos } \\
\text { humanos se } \\
\text { refleja en las } \\
\text { labores diarias }\end{array}$ & $\begin{array}{l}\text { Las defensorías de } \\
\text { familia logran llevar a } \\
\text { cabo procesos de } \\
\text { intervención a la luz de } \\
\text { la EDH. }\end{array}$ \\
\hline
\end{tabular}




\begin{tabular}{|c|c|c|c|c|}
\hline humanos. & $\begin{array}{l}\text { la labor que } \\
\text { realizan las } \\
\text { defensorías de } \\
\text { familia. }\end{array}$ & $\begin{array}{l}\text { momento de } \\
\text { colocar en } \\
\text { práctica la } \\
\text { EDH. }\end{array}$ & $\begin{array}{l}\text { que realiza } \\
\text { cada } \\
\text { funcionario. }\end{array}$ & \\
\hline $\begin{array}{l}\text { Influencia de } \\
\text { los contextos } \\
\text { en la } \\
\text { realidad de } \\
\text { cada } \\
\text { individuo. }\end{array}$ & $\begin{array}{l}\text { Analizar la } \\
\text { relación que } \\
\text { existe entre } \\
\text { educación en } \\
\text { derechos } \\
\text { humanos y el } \\
\text { enfoque } \\
\text { sistémico. }\end{array}$ & $\begin{array}{l}\text { Juegos de roles } \\
\text { y otras } \\
\text { actividades que } \\
\text { conlleven a la } \\
\text { reflexión sobre } \\
\text { la importancia } \\
\text { de percibir y } \\
\text { comprender al } \\
\text { ser humano } \\
\text { desde una } \\
\text { perspectiva } \\
\text { holística. }\end{array}$ & $\begin{array}{l}\text { Se logra } \\
\text { comprender al } \\
\text { otro durante los } \\
\text { procesos de } \\
\text { intervención de } \\
\text { acuerdo a los } \\
\text { diferentes } \\
\text { contextos que } \\
\text { influyen en el } \\
\text { mismo. }\end{array}$ & $\begin{array}{l}\text { Las defensorías de } \\
\text { familia comprenden } \\
\text { que para generar } \\
\text { cambios se debe } \\
\text { intervenir a partir de la } \\
\text { realidad de cada } \\
\text { participante y no } \\
\text { únicamente desde la } \\
\text { subjetividad o de un } \\
\text { conocimiento teórico. }\end{array}$ \\
\hline $\begin{array}{l}\text { Impacto de } \\
\text { la educación } \\
\text { en derechos } \\
\text { humanos en } \\
\text { las } \\
\text { defensorías } \\
\text { de familia. }\end{array}$ & $\begin{array}{l}\text { Evaluar el } \\
\text { impacto } \\
\text { generado en } \\
\text { las defensorías } \\
\text { de familia a } \\
\text { partir de la } \\
\text { ejecución de } \\
\text { la propuesta. }\end{array}$ & $\begin{array}{l}\text { A partir de las } \\
\text { labores diarias } \\
\text { y de la } \\
\text { aplicación de } \\
\text { un pretest - } \\
\text { postest se } \\
\text { evalúa el } \\
\text { conocimiento } \\
\text { adquirido y se } \\
\text { determina si en } \\
\text { realidad se } \\
\text { refleja en la } \\
\text { práctica. }\end{array}$ & $\begin{array}{l}\text { La educación } \\
\text { en derechos } \\
\text { humanos se } \\
\text { refleja en las } \\
\text { dinámicas de } \\
\text { las defensorías } \\
\text { de familia } \\
\text { durante la } \\
\text { atención al } \\
\text { ciudadano } \\
\text { como en la } \\
\text { interacción } \\
\text { entre los } \\
\text { funcionarios. }\end{array}$ & $\begin{array}{l}\text { Mediante la } \\
\text { intervención realizada } \\
\text { por las defensorías de } \\
\text { familia desde la } \\
\text { perspectiva de la EDH } \\
\text { se ha logrado la } \\
\text { transformación de las } \\
\text { dinámicas familiares y } \\
\text { sociales de los } \\
\text { ciudadanos atendidos, } \\
\text { en las cuales se trata a } \\
\text { cada persona como } \\
\text { sujeto de derechos } \\
\text { incluyendo } \\
\text { funcionarios y familias. }\end{array}$ \\
\hline
\end{tabular}

Fuente: Elaboración propia (Noviembre, 2016)

El Plan Estratégico planteado en la anterior tabla para la ejecución de la presente propuesta psicosocial, refleja una síntesis de las temáticas a desarrollar dentro de la misma y los 
objetivos que se pretenden alcanzar con cada una de ellas. Seguidamente se plantean de manera detallada las actividades y metodologías que faciliten el cumplimiento de dichos logros.

\subsubsection{Planificación de actividades y metodología para el desarrollo de la propuesta:}

A continuación se describen los talleres planteados para la ejecución de la propuesta, cada uno se desarrolla a partir de los cuatro ejes temáticos mencionados anteriormente: comprensión del concepto educación en derechos humanos, puesta en práctica de la educación en derechos humanos, influencia de los contextos en la realidad de cada sujeto y el impacto de la educación en derechos humanos en las defensorías de familia del Centro Zonal Fontibón.

\section{TALLER $\mathbf{N}^{\circ} \mathbf{1}$}

\section{Aspectos conceptuales de la Educación en Derechos Humanos}

Dirigido a: Defensorías de Familia Centro Zonal Fontibón

\section{Objetivo}

Lograr de forma dinámica que los funcionarios de las defensorías de familia del Centro Zonal Fontibón comprendan el concepto de EDH y su importancia en las funciones que cada uno cumple desde su rol profesional.

\section{Material}

Hojas, esferos, material audiovisual.

\section{Metodología}

$1^{\circ}$ Momento (5 minutos)

Introducción y contextualización del tema a tratar.

$2^{\circ}$ Momento (20 minutos)

a. Se le solicita a cada participante escribir en una hoja lo que entiende por el concepto de Educación en Derechos Humanos. 
b. Posteriormente se socializan las respuestas.

c. Por último se hace una retroalimentación de las respuestas dadas por cada funcionario.

$3^{\circ}$ Momento (15 minutos)

- Transmisión de un video en el cual se expone el tema de educación en derechos humanos.

Disponible en la página web https://www.youtube.com/watch?v=wY91k76Ro7A

- Se le solicita a los profesionales dar a conocer la reflexión que dicho video les generó teniendo en cuenta las respuestas emitidas durante la actividad del segundo momento.

$4^{\circ}$ Momento (15 minutos)

- Breve exposición sobre el concepto de Educación en Derechos Humanos.

- Aclaración de inquietudes o socialización de ideas respecto al tema expuesto.

$5^{\circ}$ Momento (5 minutos)

Cierre de la actividad que conlleve a la reflexión acerca de la puesta en práctica de la educación en derechos humanos en las labores diarias que realizan las defensorías de familia, enfatizando en que ella debe ir más allá de la transmisión de valores y el reconocimiento de los derechos humanos, ya que implica el compromiso de respetar la dignidad humana en sí mismo y en el otro, en cada relación interpersonal que se establece.

\section{Impacto esperado}

A través del desarrollo de éste taller se espera que los participantes logren comprender el significado real del concepto educación en derechos humanos de manera que eliminen paradigmas acerca del mismo, como lo es considerar que se trata únicamente de transmitir valores, derechos y deberes de forma pedagógica, por el contrario dicho concepto transciende a la práctica diaria dentro de la cual se reconoce al otro y así mismo como sujeto de derechos. Con ello se aspira a que reconozcan la importancia de dicha educación en derechos humanos en el 
desempeño de las funciones que a cada uno le compete en la defensoría de familia, lo que facilita que se lleven a cabo procesos de intervención en los que se respeta la dignidad del otro.

\section{TALLER $\mathbf{N}^{\circ} \mathbf{2}$}

\section{Reflexiones sobre la práctica de la Educación en Derechos Humanos en las Defensorías de Familia}

Dirigido a: Defensorías de familia Centro Zonal Fontibón

\section{Objetivo}

Generar espacios de reflexión que le permitan a las defensorías de familia del Centro Zonal Fontibón comprender la importancia de colocar en práctica la educación en derechos humanos dentro de las labores que realizan a diario.

\section{Material}

Hojas, esferos, lápices, material audiovisual.

\section{Metodología}

$1^{\circ}$ Momento (5 minutos)

Introducción y contextualización del tema.

$2^{\circ}$ Momento (15 minutos)

a. Se solicita a los participantes dividirse en grupos de 5 personas, indicándoles que seleccionen un representante.

b. Se dan instrucciones al representante para que dibuje en una hoja una figura geométrica, la cual debe ser oculta para los demás integrantes del grupo.

c. Posteriormente se le indica al representante que mediante instrucciones verbales describa a los demás integrantes del grupo el dibujo, a fin de que éstos lo reproduzcan en hojas individuales, pero sin permitir que observen el dibujo original. 
d. Al terminar el dibujo, se compara cada reproducción con el original y de acuerdo a los resultados arrojados se motiva a los participantes a opinar respecto a las dificultades que existieron al momento de dibujar la figura.

e. Finalmente se lleva a cabo una pequeña reflexión sobre la importancia de contar con habilidades para expresarnos verbalmente, escuchar y analizar en el momento de intervenir a las familias y encontrar soluciones.

$3^{\circ}$ Momento (20 minutos)

Se conservan los grupos conformados en la anterior actividad, a cada uno se le facilita una situación en la que un ciudadano expresa inconformidad respecto a la atención recibida por parte de algún funcionario de las defensorías de familia. Se solicita leerla y analizarla desde el punto de vista del denunciante y del funcionario implicado. Dichas situaciones corresponden a las siguientes:

\section{$\operatorname{Caso} \mathrm{N}^{\circ} 1$ :}

El día jueves 07 de noviembre de 2016, siendo las 8:00 am, se acerca Pedra Mendieta al Centro Zonal Fontibón a cumplir con la cita asignada por la Defensoría de Familia $N^{\circ}$ X de Protección, para llevar a cabo valoración por el área de psicología a fin de evaluar su idoneidad para asumir el cuidado de su nieto Juanito Cárdenas, el cual se encuentra en hogar sustituto desde el mes de abril. Sin embargo, al anunciarse en portería le informan que la funcionaria que llevará a cabo la valoración aún no ha arribado al Centro Zonal, por tanto se le solicita esperar en la sala unos minutos mientras ella llega, la señora tranquilamente se acomoda en una de las sillas y espera para ser atendida. Sobre las 9:00 am la señora un poco enojada pregunta nuevamente a vigilancia si llegó la funcionaria teniendo en cuenta que había transcurrido una hora después de la programada, por tanto pone en conocimiento de la situación a un integrante de la Defensoría de familia quien inmediatamente se acerca a la señora Pedra y le informa que la psicóloga no puede 
atenderla ese día ya que se encuentra en una capacitación, por tanto debe esperar a que se le reprograme la cita, ya que el día anterior se había tratado de obtener comunicación con ella para cancelar la misma, pero no fue posible.

Ante ésta situación la señora Pedra se enoja y manifiesta su inconformidad por no habérsele informado a tiempo, la profesional por su parte en un tono de voz alto le manifiesta que ella no tiene la culpa de que no haya contestado el celular, además de que hasta ese momento era que se le había informado que se encontraba en el Centro Zonal, en medio de la discusión la usuaria amenaza con colocar una queja ante la Sede Nacional del ICBF por la ineficiencia en el servicio y en la resolución de casos, teniendo en cuenta el tiempo que lleva su nieto bajo medida de protección, frente a lo cual la funcionaria en tono despectivo le refiere que puede hacerlo que ella no le tiene miedo a sus comentarios.

\section{$\operatorname{Caso} \mathrm{N}^{\circ}$ 2:}

Después de finalizada la audiencia de conciliación de fijación de custodia y alimentos del día 09 de febrero de 2016,el señor Pablo Ariza, padre del niño Sebastián Ariza, radica un derecho de petición en donde expresa no estar de acuerdo en la decisión tomada por el defensor de familia al considerar que la cuota establecida es muy alta para él, teniendo en cuenta sus ingresos y egresos mensuales, además no está de acuerdo en que se le haya otorgado la custodia a la progenitora al considerar que es negligente en el desempeño de su rol, pero que en el proceso ha percibido que el defensor de familia tiende a defenderla por ser mujer, considerando que sus derechos como padre se le están vulnerando y que en estos casos se le otorga un lugar privilegiado a la progenitora, con lo cual él no se encuentra de acuerdo.

\section{Caso $\mathbf{N}^{\circ} 3$}

Policía de Infancia y Adolescencia el 23 de marzo de 2016 arriba al Centro Zonal con la adolescente Mariana Torres de 13 años de edad quien fue sorprendida en flagrancia hurtando unas golosinas de un supermercado en compañía de otra adolescente de 15 años de edad. El defensor 
de familia tan pronto recibe el caso baja a la sala de espera en busca de la adolescente y al identificarla le refiere "ah es usted la ladrona, acá si va a aprender a comportarse" y la hace seguir para ser valorada por el área de trabajo social y psicología, quienes identifican que era la primera vez que Mariana presentaba conducta de hurto, la misma había ocurrido por influencia de la adolescente que la acompañaba al momento de los hechos y que había accedido debido a que sabía que en su casa posiblemente no iba a encontrar almuerzo, ya que su progenitora se había quedado sin empleo desde hace tres meses y ayer había gastado el último capital que le quedaba de los ahorros y liquidación del trabajo anterior.

Se les solicita a cada grupo dramatizar la situación que les correspondió, para lo cual pueden delegar el número de participantes que ellos consideren para llevar a cabo dicha actividad.

Posteriormente se solicita a cada participante que dramatizó la situación, socializar las emociones y sentimientos experimentados a partir del rol desempeñado.

De acuerdo a la socialización del punto anterior, se conlleva a reflexionar sobre cada caso expuesto, enfatizando en la posición de cada parte y plantear la alternativa de solución más eficaz y satisfactoria para los involucrados en cada situación.

Al finalizar se realiza una retroalimentación de la actividad, enfatizando en la importancia de colocarse en el lugar del otro al momento de enfrentar alguna dificultad o conflicto, lo cual permite mayor sensibilidad a la realidad y necesidades de los demás; a la vez que optar por una actitud asertiva que conlleve a encontrar soluciones frente a la problemática presentada, de manera que a través de dichas prácticas la EDH haga parte del quehacer de cada profesional. $4^{\circ}$ Momento (15 minutos)

Transmisión de un video que conlleve a la reflexión sobre la práctica de la educación en derechos humanos para lograr un verdadero cambio, el cual se encuentra disponible en la página Web https://www.youtube.com/watch?v=zX68gSdRym8. 
Se motiva a los profesionales a socializar el impacto que generó en ellos el video expuesto y qué enseñanza les transmite respecto a las funciones desempeñadas al interior de la defensoría de familia.

$5^{\circ}$ Momento (5 minutos)

Cierre de la actividad para lo cual se motiva a los participantes a reflexionar sobre aspectos que deben tener en cuenta durante las intervenciones que realizan con familias y que reflejen realmente una práctica de la EDH.

\section{Impacto esperado}

Con el desarrollo de ésta actividad se espera que las defensorías de familia lleven a cabo procesos de reflexión que les permita concientizarse de la importancia de poner en práctica los principios de la educación en derechos humanos, lo que implica colocarse en el lugar del otro, comprender su realidad y abordar las problemáticas presentadasa partir del análisis de los diversos contextos que influyen en las mismas, entendiendo que en el ser humano actúan factores que son necesarios tener en cuenta durante los procesos de intervención, independientemente del rol que desempeñe cada profesional en la defensoría de familia. Por tanto, se busca que al finalizar el taller las defensorías de familia logren interiorizar que la puesta en práctica de la educación en derechos humanos facilita un trato digno hacia todos los participantes y permite una intervención más eficaz, lo que contribuye a la garantía de derechos de los niños, niñas y adolescentes y al bienestar de las familias. 
TALLER $\mathbf{N}^{\circ} \mathbf{3}$

Intervención psicosocial desde un enfoque sistémico y su relación con la Educación en Derechos Humanos

Dirigido a: Defensorías de familia Centro Zonal Fontibón

\section{Objetivo}

Entender la interrelación que existe entre educación en derechos humanos y el enfoque sistémico, enfatizando en la importancia de llevar a cabo procesos de intervención a partir de éstos elementos.

\section{Material}

Hojas, esferos, material audiovisual.

\section{Metodología}

$1^{\circ}$ Momento (5 minutos)

Introducción y contextualización del tema.

$2^{\circ}$ Momento (15 minutos)

a. Transmisión del cuento "El pueblo del Arco Iris", el cual se encuentra disponible en la página web https://www.youtube.com/watch?v=t92hTaD15_c

b. Al finalizar el video se solicita que en grupos de seis personas analicen el desarrollo del cuento y reflexionen frente a los aportes que les deja para la intervención con familias y para el trabajo en equipo que deben desarrollar como defensorías de familia.

c. Se solicita a cada grupo socializar las reflexiones a las que llegaron.

d. Retroalimentación de acuerdo a los aportes emitidos por cada grupo, enfatizando en la importancia de tener en cuenta las diferencias individuales al momento de atender familias y la manera en que la interacción entre sus miembros puede afectar o no la 
dinámica de las mismas. Así como también resaltar la importancia de tener en cuenta las potencialidades y aspectos a mejorar en cada integrante, sin realizar juzgamientos, sino por el contrario reconocer en qué medida diversos factores han incidido en la realidad de cada individuo y cómo entre todos pueden aportar a que se origine un cambio, e incluso la forma como los miembros de las defensorías de familia pueden contribuir a dicho cambio, de manera que comprendan que éste depende de la confluencia de los contextos.

$3^{\circ}$ Momento (20 minutos)

a) Se solicita a cada participante organizarse en grupos de seis personas, cada uno debe plantear una problemática que usualmente abordan durante la intervención con familias.

b) De acuerdo al tema seleccionado se les solicita que mediante juego de roles representen dicha problemática y planteen la manera más efectiva en que la defensoría de familia abordaría la misma.

c) Al finalizar se le solicita a los demás participantes realizar una retroalimentación de los elementos observados durante el juego de roles, enfatizando en las fortalezas y debilidades que presentó cada uno al abordar la problemática, teniendo en cuenta los principios de la educación en derechos humanos desde un enfoque sistémico.

$4^{\circ}$ Momento (15 minutos)

Breve exposición sobre los principios y bases conceptuales del enfoque sistémico. Aclaración de inquietudes y socialización de ideas respecto al tema expuesto y como éste se relaciona con la EDH.

$5^{\circ}$ Momento (5 minutos)

Cierre de la actividad que conlleve a la reflexión acerca de lo imprescindible que resulta la aplicación de la educación en derechos humanos, que interrelacionada con el enfoque sistémico 
puede causar impactos positivos en la atención a familias y en general en las dinámicas relacionales de las Defensorías de Familia, en la medida en que se actúa y se plantea soluciones a partir de una visión holística.

Se motiva a los participantes a colocar en práctica los temas abordados durante los talleres, indicándoles la realización de una evaluación del impacto generado a través de sus labores diarias. Para lo cual se le solicita a cada profesional grabar dos intervenciones que lleven a cabo con familia a fin de evaluar las estrategias de intervención empleadas y en qué medida se desarrolló desde el enfoque sistémico, se hace la aclaración que para la ejecución de la actividad deben solicitar el consentimiento del entrevistado.

\section{Impacto esperado}

Al finalizar el taller se espera que las defensorías de familia comprendan la relación existente entre Educación en Derechos Humanos y el enfoque sistémico, en la medida en que ambos términos proponen entender al otro desde su individualidad y como un ser único, pero que a la vez influyen en el mismo factores externos que conllevan a que presente conductas y comportamientos particulares. De modo que en la atención a familias es importante tener en cuenta la interrelación que existe entre éstos dos conceptos para la generación de cambios, en la medida en que durante los procesos de intervención se planteen soluciones teniendo en cuenta los contextos en los que se desenvuelve la persona y que inciden en ella, lo que permite comprender su realidad a la vez que garantiza que el ciudadano perciba que se le están respetando sus derechos. 


\title{
TALLER $\mathbf{N}^{\circ} 4$
}

\section{Puesta en práctica de la Educación en Derechos Humanos desde un enfoque sistémico}

\author{
Dirigido a: Defensorías de familia Centro Zonal Fontibón
}

\section{Objetivo}

Evaluar el impacto generado en las Defensorías de Familia del Centro Zonal Fontibón durante el desarrollo de las actividades llevadas a cabo sobre educación en derechos humanos desde un enfoque sistémico.

\section{Material}

Hojas, esferos, material audiovisual y audios presentados por cada profesional.

\section{Metodología}

$1^{\circ}$ Momento (5 minutos)

Introducción y contextualización del tema.

$2^{\circ}$ Momento (15 minutos)

a. Inicialmente se lleva a cabo un ejercicio de sensibilización respecto a las temáticas abordadas durante los talleres anteriores, para lo cual se expone el cuento "El árbol que no tenía hojas”, que se encuentra disponible en la página Web https://www.youtube.com/watch?v=FzxwodUB6sU

b. Posterior al video se solicita a los participantes que conformen tres grupos a fin de que determinen qué reflexión les generó el video respecto al desempeño de las labores que cada uno realiza desde su profesión.

c. Cada grupo da a conocer el análisis realizado del video y se lleva a cabo una retroalimentación que conlleve a la reflexión respecto a la capacidad de ser agentes de cambio de acuerdo al uso de los recursos con los cuales cada uno cuenta. 
$3^{\circ}$ Momento (15 minutos)

Se conservan los grupos conformados a fin de que al interior de los mismos escojan y observen dos de las intervenciones grabadas por parte de ellos de acuerdo a las instrucciones dadas al finalizar el taller $\mathrm{N}^{\circ} 4$.

Se les solicita a los participantes que mientras observan el video lo analicen a la luz de los siguientes elementos: aspectos a mejorar y fortalezas del profesional durante la intervención, momentos en los que se refleja la aplicación de la educación en derechos humanos, identificar situaciones en las que no se haya tenido en cuenta la aplicación de los principios de una EDH, determinar si en el desarrollo de la intervención se logró entender al sujeto desde los diferentes contextos en los que se desenvuelve, evaluación de la eficacia de las soluciones encontradas a la problemática y determinar si realmente se actuó desde una postura sistémica interrelacionada con los principios de la educación en derechos humanos.

Cada grupo debe exponer el análisis realizado de los videos, para posteriormente llevar a cabo una reflexión sobre los aspectos a mejorar y enfatizar en las fortalezas presentadas por cada profesional, resaltando en que como seres humanos estamos en constante aprendizaje, por lo que es importante ser conscientes de los aspectos por mejorar para que realmente se lleve a cabo una adherencia de la EDH en el desempeño de las labores que realiza cada defensoría de familia. $4^{\mathrm{o}}$ Momento (15 minutos)

- Cierre de la actividad: para lo cual se les solicita a los participantes realizar una evaluación verbal acerca de la pertinencia y eficacia de los talleres dentro de sus labores diarias, expresen en qué aspectos se fortalecieron y cuáles aún son necesarios reforzar, y con base en ello propongan sugerencias para próximas actividades, teniendo en cuenta el impacto (positivo o negativo) que les generó el desarrollo de los mismos. 


\section{Impacto esperado}

Al culminar los talleres se espera que las defensorías de familia hayan interiorizado el concepto de Educación en Derechos Humanos y su interrelación con el enfoque sistémico de manera que logren llevar a cabo intervenciones en donde los funcionarios generen el ambiente propicio para atender a las familias que recurren al Centro Zonal, para lo cual es necesario tener en cuenta que en el ser humano influye un componente biológico, psicológico y social, de manera que al tratarse de un ser social durante la intervención debe generarse una influencia recíproca entre los participantes, de la cual surja una retroalimentación constante, sin que se realicen juzgamientos a priori, por el contrario se les oriente para el fortalecimiento de herramientas y perciban las dificultades como una oportunidad de cambio. Así mismo se reconozca al otro como sujeto de derechos de manera que se respeten los derechos propios y los de los demás, teniendo en cuenta la individualidad de cada persona pero a la vez los contextos en los que se desenvuelve y las realidades que han afrontado y que influyen en su situación actual, para que de ésta manera se logren establecer soluciones factibles que conlleven a cambios reales en las dinámicas de las familias atendidas en el Centro Zonal y primen en cada una de ellas valores, principios, se respeten deberes y derechos, por ende representen un factor protector para los NNA.

\subsection{Evaluación del Impacto e Innovación}

A fin de evaluar el impacto que generó la propuesta de intervención en las Defensorías de Familia del Centro Zonal Fontibón, se aplicará un pre-test - pos-test que permita determinar el aprendizaje adquirido durante el desarrollo de las diversas actividades llevadas a cabo y si las mismas generaron procesos de interiorización respecto a la importancia de la aplicación de la 
educación en derechos humanos a partir de un enfoque sistémico durante la intervención que éstas realizan con familias.

Para la presente propuesta se plantea la aplicación del siguiente pre test y pos test:

\section{Evaluación del efecto causado en los participantes: Pre test - Pos test}

Pre - test:

A continuación encontrará una serie de afirmaciones que deben evaluarse de acuerdo con su postura frente a ella. Siendo 1. En desacuerdo, 2. Algo de acuerdo, 3. De acuerdo y 4. Muy de acuerdo.

\begin{tabular}{|c|c|c|c|c|c|}
\hline 1 & $\begin{array}{l}\text { La Educación en Derechos Humanos consiste en estrategias } \\
\text { pedagógicas a través de las cuáles se transmiten valores y se } \\
\text { dan a conocer los derechos humanos que tiene toda persona. }\end{array}$ & 1 & 2 & 3 & 4 \\
\hline 2 & $\begin{array}{l}\text { El cambio de un sistema familiar depende de la persona que } \\
\text { presenta el síntoma. }\end{array}$ & 1 & 2 & 3 & 4 \\
\hline 3 & $\begin{array}{l}\text { En un caso de abuso sexual en donde el agresor es el } \\
\text { padrastro, la culpable es la progenitora por su negligencia. }\end{array}$ & 1 & 2 & 3 & 4 \\
\hline 4 & $\begin{array}{l}\text { Todos los niños que presentan desnutrición deben ingresar } \\
\text { bajo medida de protección, ya que los padres no han logrado } \\
\text { suplir sus necesidades básicas. }\end{array}$ & 1 & 2 & 3 & 4 \\
\hline 5 & $\begin{array}{l}\text { La violencia intrafamiliar se mantiene por la falta de } \\
\text { capacidad de la víctima de tomar decisiones. }\end{array}$ & 1 & 2 & 3 & 4 \\
\hline 6 & $\begin{array}{l}\text { La Defensoría de Familia orienta el proceso, el cambio } \\
\text { depende únicamente del sistema familiar. }\end{array}$ & 1 & 2 & 3 & 4 \\
\hline 7 & $\begin{array}{l}\text { El defensor de familia es el responsable de las decisiones } \\
\text { que se tomen frente a un caso. }\end{array}$ & 1 & 2 & 3 & 4 \\
\hline
\end{tabular}




\begin{tabular}{|c|c|c|c|c|c|}
\hline 8 & $\begin{array}{l}\text { El defensor de familia tiene la autonomía de tomar medidas } \\
\text { frente a cualquier caso, por tanto no necesariamente debe } \\
\text { tener en cuenta el concepto emitido por los demás } \\
\text { profesionales si lo considera pertinente. }\end{array}$ & 1 & 2 & 3 & 4 \\
\hline 9 & Un padre consumidor de SPA nunca va a cambiar. & 1 & 2 & 3 & 4 \\
\hline 10 & $\begin{array}{l}\text { Cuando el NNA presenta problemas de comportamiento no } \\
\text { debe tenerse en cuenta su opinión en la toma de decisiones } \\
\text { frente al caso, ya que puede estar manipulando la situación. }\end{array}$ & 1 & 2 & 3 & 4 \\
\hline 11 & $\begin{array}{l}\text { Un padre que llega tarde a la cita debe esperar a que el } \\
\text { funcionario tenga tiempo para atenderlo, } \\
\text { independientemente de las razones de su tardanza. }\end{array}$ & 1 & 2 & 3 & 4 \\
\hline 12 & $\begin{array}{l}\text { Las soluciones que se planteen frente a un caso, dependen } \\
\text { del equipo profesional. }\end{array}$ & 1 & 2 & 3 & 4 \\
\hline
\end{tabular}

Fuente: Elaboración propia (Noviembre, 2016)

El anterior pre test puede aplicarse momentos previos a iniciarse el primer taller planteado dentro de la propuesta, a fin de evaluar el nivel de conocimiento y capacidad de las defensorías de familia para aplicar los principios de la Educación en Derechos Humanos en sus labores diarias. El cual está compuesto por 12 ítems correspondientes a creencias y mitos que se presentan respecto a las familias que suelen atenderse en el Centro Zonal Fontibón y que conllevan a que las intervenciones se desarrollen con base en ellas. Por tanto, entre mayor sea el puntaje que obtenga el funcionario, más se aleja del significado y puesta en práctica de la educación en derechos humanos. 


\section{Post- test:}

A continuación encontrará una serie de afirmaciones que deben evaluarse de acuerdo con su postura frente a ella. Siendo 1. En desacuerdo, 2. Algo de acuerdo, 3. De acuerdo y 4. Muy de acuerdo.

\begin{tabular}{|c|c|c|c|c|c|}
\hline 1 & $\begin{array}{l}\text { La Educación en Derechos Humanos implica reconocer al } \\
\text { otro como sujeto de derechos y fortalecer las herramientas } \\
\text { necesarias para ser precursores de sus propios derechos y de } \\
\text { los demás. }\end{array}$ & 1 & 2 & 3 & 4 \\
\hline 2 & $\begin{array}{l}\text { La familia es un sistema en el cual existe una interacción } \\
\text { recíproca entre sus miembros, por tanto ante alguna } \\
\text { problemática se debe indagar sobre la dinámica del sistema } \\
\text { en su totalidad y no solamente abordar a la persona que } \\
\text { presenta el síntoma. }\end{array}$ & 1 & 2 & 3 & 4 \\
\hline 3 & $\begin{array}{l}\text { En un caso de abuso sexual en donde el agresor es el } \\
\text { padrastro, debe evaluarse los diferentes factores que } \\
\text { pudieron generar el mismo, de manera que la intervención } \\
\text { debe orientarse hacia la disminución de aquellos elementos } \\
\text { que representan un riesgo y el aporte de herramientas que } \\
\text { les permita disminuir dichos factores de riesgo. }\end{array}$ & 1 & 2 & 3 & 4 \\
\hline 4 & $\begin{array}{l}\text { La desnutrición de un niño en un grupo familiar no } \\
\text { necesariamente implica negligencia por parte de los padres, } \\
\text { es por ello que debe tenerse en cuenta todas las posibles } \\
\text { causas e intervenir sobre las mismas. }\end{array}$ & 1 & 2 & 3 & 4 \\
\hline 5 & $\begin{array}{l}\text { La violencia intrafamiliar debe estar orientada hacia el } \\
\text { fortalecimiento de recursos tanto internos como externos en } \\
\text { la víctima que conlleven a que reconozca sus derechos y de } \\
\text { esta manera facilitar la toma decisiones que lepermita salir }\end{array}$ & 1 & 2 & 3 & 4 \\
\hline
\end{tabular}




\begin{tabular}{|c|c|c|c|c|c|}
\hline & del ciclo de maltrato. & & & & \\
\hline 6 & $\begin{array}{l}\text { La atención a familias debe ser un proceso de interacción } \\
\text { reciproca en el cual se tenga en cuenta la voz de todos los } \\
\text { participantes al momento de plantear soluciones. }\end{array}$ & 1 & 2 & 3 & 4 \\
\hline 7 & $\begin{array}{l}\text { Aunque el defensor de familia es la figura legal del proceso } \\
\text { y quien toma una última decisión frente al mismo, ésta no } \\
\text { debe ser considerada de manera arbitraria desconociendo los } \\
\text { derechos de los demás. }\end{array}$ & 1 & 2 & 3 & 4 \\
\hline 8 & $\begin{array}{l}\text { Las leyes le otorgan al defensor de familia la potestad de } \\
\text { tomar medidas frente a cualquier caso, la misma debe } \\
\text { sustentarse a partir del conjunto de situaciones observadas } \\
\text { durante la intervención, es decir, tanto el concepto emitido } \\
\text { por cada profesional como la realidad del grupo familiar, lo } \\
\text { que implica que dicha decisión debe ser tomada entre todos } \\
\text { y a partir de reconocer los derechos del otro. }\end{array}$ & 1 & 2 & 3 & 4 \\
\hline 9 & $\begin{array}{l}\text { Un padre consumidor de SPA debe ser escuchado dentro del } \\
\text { proceso y brindársele la oportunidad de presentar cambios a } \\
\text { través de un proceso de intervención efectivo que facilite la } \\
\text { modificación de factores que mantienen la conducta. }\end{array}$ & 1 & 2 & 3 & 4 \\
\hline 10 & $\begin{array}{l}\text { Cuando el NNA presenta problemas de comportamiento } \\
\text { debe escucharse dentro del proceso sin ser juzgado, por el } \\
\text { contrario su discurso debe representar una herramienta que } \\
\text { permita conocer su realidad y así mismo trabajar sobre los } \\
\text { factores que influyen de manera negativa en su actuar. }\end{array}$ & 1 & 2 & 3 & 4 \\
\hline 11 & $\begin{array}{l}\text { Un padre que llega tarde a la cita tiene derecho a ser } \\
\text { escuchado con respeto y a entender las razones de su } \\
\text { tardanza. }\end{array}$ & 1 & 2 & 3 & 4 \\
\hline
\end{tabular}




\begin{tabular}{|l|l|ll|}
\hline 12 & $\begin{array}{l}\text { Las soluciones que se planteen frente a un caso, dependen } \\
\text { del análisis sistémico que se realice de los diversos } \\
\text { elementos que están influyendo en la problemática } \\
\text { presentada y con base en ello entre todos los participantes se } \\
\text { propongan soluciones que faciliten el cambio. }\end{array}$ & & \\
& & & \\
\end{tabular}

Fuente: Elaboración propia (Noviembre, 2016)

Este pos test debe aplicarse al finalizar los talleres planteados, su fin es evaluar el nivel de comprensión adquirido respecto al concepto de educación en derechos humanos y su relación con el enfoque sistémico, a la vez mide la capacidad del funcionario de llevar a la práctica dichos conceptos de manera que cuente con la habilidad de analizar y plantear soluciones frente a cada caso a partir de una visión holística y de reconocer al otro como sujeto de derechos. Dicho pos test contiene ítems relacionados con el pre test pero con un grado de complejidad mayor a partir de lo que se espera en los procesos de intervención por parte de las defensorías de familia, por ello contrario al pre test, en éste caso una puntuación mayor indica un nivel de comprensión superior respecto a las temáticas abordadas en la propuesta psicosocial.

La propuesta psicosocial planteada desde el enfoque sistémico facilita que se lleve a cabo una re significación de los procesos de atención, ya que las actividades planteadas permiten la reflexión del quehacer diario de cada profesional, como el mismo afecta positiva o negativamente cada proceso y como la educación en derechos humanos permite mejorar los resultados de la intervención al facilitar la comprensión del otro como sujeto de derechos sin desconocer ni relegar los derechos propios. Esta propuesta conlleva a un proceso circular en donde el interviniente como el ciudadano atendido son merecedores de un trato digno. 


\section{Conclusiones y recomendaciones}

Teniendo en cuenta lo desarrollado en este trabajo de grado se concluye que la concepción jurídica y universal de los derechos humanos que empezó a reconocerse después de la Segunda Guerra Mundial con la expedición de Convenios y Tratados Internacionales, además de la promoción de sociedades democráticas, no eran suficientes para la garantía de éstos derechos fundamentales en una sociedad. Es por ello que en los años 80’surge la necesidad en Latinoamerica de implementar una educación en derechos humanos, de manera que los estados realizan esfuerzos porque en sus políticas públicas se incluyan programas transversalizados por la inclusión y respeto de los derechos humanos. En el contexto colombiano, existe toda una estructura sólida y normativa que garantiza la protección de los DDHH dentro de la cual se encuentra el Instituto Colombiano de Bienestar Familiar con especial énfasis en población vulnerable (NNA y la familia en general). Sin embargo, a la educación en derechos humanos no se le presta la suficiente atención en los procesos de atención que brinda dicha entidad, pese a que la misma se ha considerado como un derecho humano y una obligación del Estado su implementación.

Los diferentes estudios e investigaciones en el escenario de las ciencias humanas y sociales, reconocen que para que haya progreso social en los países como el nuestro, donde el índice de violencia e injusticia social es elevado, se requiere de procesos, programas y políticas estatales que promuevan la participación ciudadana, empoderen a la población y fortalezcan la educación a través de un pensamiento crítico y emancipador, liberándola de la sumisión frente a las posturas dictatoriales que impiden el progreso nacional, de modo que se genere una verdadera democracia, en la cual se evidencie los valores y derechos reconocidos en la Constitución. Esta 
educación no debe limitarse exclusivamente al contexto académico, ha de trascender en diferentes escenarios en los cuales se desenvuelve el ser humano, de manera que el reconocimiento, la exigencia y respeto por los derechos humanos sea una práctica común en la sociedad, lograble mediante la educación en derechos humanos.

Bajo esta perspectiva y como aporte a la transformación que requiere la sociedad para ser más justa, equitativa y donde prime el respeto por el otro, se resalta la importancia de fortalecer a las defensorías de familia del Centro Zonal Fontibón en la educación en derechos humanos como estrategia para mejorar los procesos de intervención. Si se tiene en cuenta que, precisamente el objetivo central del ICBF es garantizar los derechos de los niños, niñas y adolescentes, además del bienestar de las familias (función que le es asignada principalmente a las defensorías de familia), se observa dificultad en los sujetos de esta investigación para comprender el concepto de educación en derechos humanos, el cual conciben como la transmisión de conocimiento acerca de valores y derechos, más no como la interiorización y puesta en práctica de dicho concepto; por tanto, no se le da la relevancia que requiere dentro de los procesos de intervención, por el contrario, se tiende a plantear soluciones desde la perspectiva del funcionario, minimizando la participación del ciudadano y desconociendo los diversos contextos que pueden estar influyendo en la problemática. Por tanto, se corre el riesgo de pasar por alto principios propios de la $\mathrm{EDH}$ sin que el sujeto de la investigación se percate de las consecuencias de su actuar, siendo imprescindible que la educación en derechos humanos se refleje en la práctica diaria de las defensorías de familia ya que la población atendida en su mayoría se caracteriza por su condición de vulnerabilidad, requiriéndose mayor sensibilidad frente a sus necesidades, dentro de los procesos de atención que se llevan a cabo en el ICBF. 
El ICBF ha planteado estrategias para mejorar la atención al ciudadano mediante programas de escuela virtual y otros procesos de educación para el trabajo y el desarrollo humano, aun así, el tema de educación en derechos humanos no se ha abordado de manera específica, presentándose dificultades para llevar a cabo una atención desde una perspectiva holística a partir de los diversos contextos que influyen en el comportamiento humano. Igualmente, se identificó que los sistemas de evaluación de desempeño de los sujetos de investigación se enfocan en indicadores respecto al número de casos atendidos y resueltos, restando relevancia a la necesidad de verificar el impacto de la atención para un cambio favorable.

De acuerdo a lo anterior se consideró necesario llevar a cabo el presente trabajo de investigación desde una metodología etnográfica, lo cual implicó involucrarse en el contexto de las defensorías de familia del Centro Zonal Fontibón a fin de conocer sus dinámicas, identificar las dificultades presentadas para llevar a cabo una atención a partir de los principios de la educación en derechos humanos y así mismo poder plantear estrategias de solución que permitan llevar a cabo procesos de reflexión que creen conciencia frente a la necesidad de una resignificación de los procesos de intervención, los cuales requieren ir más allá de un conocimiento o experiencia profesional. Así, es necesario que asimilen e interioricen el concepto de educación en derechos humanos, reconociendo que a través de su puesta en práctica aportan a la transformación de los sistemas familiares atendidos, generando a su vez satisfacción en la medida en que todos los participantes son reconocidos como sujetos de derechos y se evitan procesos de intervención desgastantes que no conllevan al cambio que se requiere.

En suma, ante la situación coyuntural que afronta el país actualmente con el pos conflicto, se hace necesario que las defensorías de familia lleven a cabo procesos de intervención con 
población desmovilizada, como medio para el fortalecimiento de recursos dejando a un lado actitudes que puedan parecer discriminatorias hacia dicha población, en la medida en que sus funcionarios logren comprender la realidad de cada persona y orienten en herramientas que les facilite adaptarse adecuadamente a su nuevo estilo de vida, garantizando con ello el respeto por la dignidad del otro como sujeto de derechos.

Por otro lado, se consideró necesario recurrir a posturas conceptuales que fundamentaran jurídica y teóricamente la propuesta elaborada, la cual se planteó desde una perspectiva psicosocial teniendo en cuenta que ésta conlleva a una intervención desde una postura más humana, que facilita llevar a cabo procesos de intervención en los cuales se respete la dignidad del otro, de manera que se reconozca como sujeto de derechos. De igual manera se consideró relevante abordarla desde un enfoque sistémico, teniendo en cuenta la visión holística de la educación en derechos humanos, posturas que proponen abordar al ser humano no sólo desde su individualidad, sino a partir de todo el conjunto de factores que inciden en su conducta y condiciones de vida.

En este sentido, es relevante fortalecer a las defensorías de familia en la educación en derechos humanos desde una perspectiva psicosocial con un enfoque sistémico en pro de mejorar los procesos de intervención, dado que en la medida en que el ser humano es comprendido desde todas sus dimensiones se aumentan las probabilidades de un cambio favorable. Por otro lado, lo sistémico implica una retroalimentación constante de los sistemas y en la medida en que se tiene en cuenta la postura de los demás, se logra una mayor comprensión de su realidad y se pueden plantear soluciones factibles que beneficie a todos sus miembros; así, en los procesos de intervención se requiere generar un ambiente propicio en el que se promueva la participación de todos, se oriente hacia el descubrimiento de potencialidades y recursos con los cuales cuentacada 
persona para superar las dificultades, en lugar de juzgar y atribuir culpables, se buscan alternativas de solución viables y eficaces. De modo que la puesta en práctica de la educación en derechos humanos por parte de las defensorías de familia conjugada con un enfoque sistémico facilita llevar a cabo procesos de intervención efectivos que generen cambios reales que satisfagan a todos los implicados.

De acuerdo a lo precedente, en este trabajo de grado fue imperante desarrollar una propuesta que contribuyera a la solución de los aspectos a mejorar identificados, que no se limitara a una mera descripción de la necesidad hallada, sino que aporta en la práctica a la transformación de los procesos de intervención llevados a cabo por las defensorías de familia del Centro Zonal Fontibón.

De esta manera, la propuesta psicosocial se sustenta en el enfoque sistémico, cuya ejecución facilita que las defensorías de familia junto con los ciudadanos atendidos, en el desarrollo de la intervención generen estrategias de solución, las cuales impliquen el análisis de los diferentes contextos que influyen en el ser humano y se comprenda la complejidad de los mismos, a fin de encontrar soluciones que contribuyan a la transformación social y a la formación de sujetos con un pensamiento crítico y emancipador, permitiéndoles romper con esquemas y principios aparentemente democráticos pero que no permiten el crecimiento personal, familiar y social; lo que sólo se logra mediante la comprensión, interiorización y aplicación de la educación en derechos humanos.

Es de resaltar que dentro del presente proceso de investigación surgieron algunas dificultades que es importante tener en cuenta dentro de la aplicación de la propuesta psicosocial planteada, así como en futuras investigaciones asociadas a éste tema, como lo es la poca disposición e interés por parte de algunos profesionales, principalmente defensores de familia; y 
la falta de tiempo debido al exceso de carga laboral. De modo que se debe ser práctico, innovador y flexible en el momento de la ejecución de la propuesta con dichas defensorías de familia.

Esta propuesta psicosocial además de ser una estrategia que permite mejorar los procesos de atención que brindan las defensorías de familia a los NNA y sus familias, aporta a la transformación social que se requiere ante las atrocidades y violaciones a los derechos humanos afrontadas durante las últimas décadas en el país; ya que partiendo del principio de que la familia es la base de toda sociedad, en la medida en que se logran cambios favorables en sus dinámicas, dentro de las cuales prime el respeto por la dignidad del otro, se reconozcan derechos propios como de los demás y se promueva la defensa de los mismos, cada uno de éstos sistemas familiares aporta a dicho cambio social.

Igualmente, a través de dicha propuesta se promueve la formación de funcionarios más humanos y sensibles a las necesidades del otro, de manera que esto facilita recuperar la confianza de la sociedad en el Estado, la cual se ha perdido como consecuencia de posibles atropellos que se cometen en contra de la ciudadanía por parte de las entidades públicas y que colocan en riesgo la dignidad humana. Por ello, es importante que el tema de educación en derechos humanos sea abordado no solo con las defensorías de familia, sino con todos los funcionarios vinculados al ICBF; con agentes educativos de los diversos programas de atención con los cuales cuenta dicha entidad en sus diferentes modalidades, dirigidos a la primera infancia, adolescencia, madres gestantes y lactantes, entre otros. Siendo necesario adaptar la propuesta de acuerdo a las necesidades de fortalecimiento en el tema y las labores que desarrolla cada funcionario y agente educativo, generando así una re-significación global de los procesos de atención que brinda ésta 
entidad y contribuyendo a su objetivo de garantizar los derechos de NNA y a la armonía familiar, que por consiguiente aporta a su función como rector de paz y convivencia ciudadana.

Como conclusión final, los resultados de la presente investigación dan cuenta de la necesidad de que la educación en derechos humanos se trate de un aspecto intrínseco en las defensorías de familia del Centro Zonal Fontibón, la cual se refleje en su modo de actuar y pensar; para ello es necesario que comprendan e interioricen su significado y como se integra con el enfoque sistémico a partir de su visión holística. Logrando con ello una re significación de los procesos de atención que contribuyan a la transformación social a partir de los cambios positivos que se generen en las pautas de interacción entre las defensorías de familia y los ciudadanos atendidos basadas en un trato digno y en el reconocimiento mutuo de deberes y derechos; lo cual implica una reestructuración del pensamiento respecto al rol de servicio que cada integrante de la defensoría de familia debe ejercer, dejando a un lado cualquier intención de superioridad o dominancia sobre el otro. 


\section{Referencias Bibliográficas}

Alcaldía Mayor de Bogotá (2012). Historia del poblamiento de Fontibón. Recuperado de http://www.bogota.gov.co/localidades/fontibon/poblamiento

Arriagada, I (2002). Cambios y desigualdad en las familias latinoamericanas. Revista de la Cepal 77, pp. 143 - 161. Recuperado de http://biblioteca2012.hegoa.efaber.net/system/ebooks/12139/original/cambios_y_desigual dad_en_las_familias_latinoamericanas.pdf

Arteaga, B (2012). Caracterización de las familias en Colombia. Instituto Colombiano de Bienestar Familiar (ICBF). Bogotá.

Arteaga, B \& Rojas. E (2012). La familia en el ICBF (1968 - 2012). Reseña Histórica. Bogotá. Recuperado de http://www.icbf.gov.co/portal/page/portal/IntranetICBF/macroprocesos/misionales/famili as/i/LA\%20FAMILIA\%20EN\%20EL\%20ICBF\%20rese $\%$ C3\%B1a\%20hist\%C3\%B3rica\%20(1968-2012).pdf

Carías, C (2010). Las prácticas de la violencia escolar entre iguales en el contexto del aula de clase: Una perspectiva desde la educación en derechos humanos (Tesis de maestría). Universidad Pedagógica Nacional Francisco Mozarán. Tegucigalpa, Honduras. Recuperado de file://C:/Users/USER/Downloads/las-practicas-de-la-violencia-escolarentre-iguales-en-el-contexto-del-aula-de-clase-una-perspectiva-desde-la-educacion-enderechos-humanos.pdf

Carrillo, L (2009). La familia, la autoestima y el fracaso escolar del adolescente (Tesis doctoral). Universidad de Granada. España. Recuperado de http://digibug.ugr.es/bitstream/10481/2150/1/17811089.pdf 
Céspedes, D (2010). El significado psicosocial de las capacitaciones en derechos humanos de la niñez. Un estudio de casos: Costa Rica, Chile y República Dominicana. Ediciones Universitarias. Universidad Autónoma de Centro América. Costa Rica. Recuperado de http://www.corteidh.or.cr/tablas/27111.pdf

Cillero, M (2007). El interés superior del niño en el marco de la convención internacional sobre los derechos del niño. Justicia y Derechos del Niño 9, pp. 125 - 142. Santiago, Chile. Recuperado de http://www.unicef.cl/archivos_documento/236/justcia\%20_y_derechos_9.pdf\#page=125

CINEP (2015). Derechos humanos y paz. Manual de ciudadanía y convivencia desde la construcción colectiva de sentidos y redes. Bogotá, D.C. Recuperado de http://www.redacademica.edu.co/archivos/redacademica/proyectos/pecc/centro_documen tacion/caja_de_herramientas/serie_2_metodologias/derechos_humanos_y_paz.pdf

CINEP (2015). Experiencias de comunidades escolares que transforman realidades. Bogotá, D.C. Recuperado de http://www.cinep.org.co/publicaciones/es/producto/experiencias-decomunidades-escolares-que-transforman-realidades/

Comisión Presidencial Coordinadora de la Política del Ejecutivo en Materia de Derechos Humanos -COPREDEHPACTO- (2011). Pacto internacional de derechos civiles y políticos, versión comentada. Guatemala. Recuperado de http://www.corteidh.or.cr/tablas/28145.pdf

Comisión Presidencial Coordinadora de la Política del Ejecutivo en Materia de Derechos Humanos -COPREDEHPACTO- (2011). Pacto internacional de derechos económicos, sociales y culturales, versión comentada. Recuperado de http://www.corteidh.or.cr/tablas/28142.pdf 
Congreso de la República de Colombia (1991). Ley 12 de 1991. Por la medio de la cual se aprueba la Convención sobre los derechos del niño adoptada por la Asamblea General de las Naciones Unidas el 20 de noviembre de 1989. Diario Oficial No. 39640 de 22 de enero de 1991. Recuperado de http://www.oas.org/dil/esp/Convencion_Internacional_de_los_Derechos_del_Nino_Colo mbia.pdf

Congreso de la República de Colombia (1968). Ley 74 de 1968. Por la cual se aprueban los Pactos internacionales de derechos económicos, sociales y culturales, de derechos civiles y políticos, así como el protocolo facultativo de éste último, aprobado por la asamblea general de las Naciones Unidas en votación unánime en Nueva York, el 16 de diciembre de 1966. Recuperado de file:///C:/Users/Karin/Downloads/6468\%20(2).pdf

Congreso de la República de Colombia (1994). Ley 115 de febrero 8 de 1994. Por la cual se expide la ley general de educación. Recuperado de http://www.mineducacion.gov.co/1621/articles-85906_archivo_pdf.pdf

Congreso de la República de Colombia (2006). Ley 1098 de 2006. Por la cual se expide el Código de la Infancia y la Adolescencia. Diario Oficial № 46.446 del 8 de Noviembre de 2006. Recuperado de http://www.ins.gov.co:81/normatividad/Leyes/LEY\%201098\%20DE\%202006.pdf

Consejo Superior de la Judicatura, Sala Administrativa Centro de Documentación Judicial CENDOJ- (2010). Constitución Política de Colombia de 1991. Actualizada con los actos legislativos hasta 2010. Recuperado de: https://www.ramajudicial.gov.co/documents/10228/1547471/CONSTITUCIONinteriores.pdf/8b580886-d987-4668-a7a8-53f026f0f3a2 
Corte Constitucional de Colombia (2011). Sentencia T 844 de 2011. Recuperado de http://www.corteconstitucional.gov.co/relatoria/2011/t-844-11.htm

Corte Interamericana de Derechos Humanos (2013). El ABC de la Corte Interamericana de Derechos Humanos. El qué, cómo, cuándo, dónde y por qué de la Corte Interamericana. Recuperado de http://www1.umn.edu/humanrts/research/colombia/ABC\%20Corte\%20IDH.pdf

Convención Interamericana para la eliminación de todas las formas de discriminación contra las personas con discapacidad (1999). Guatemala. Recuperado de http://apw.cancilleria.gov.co/tratados/AdjuntosTratados/064dd_OEA1999\%20DISCAPACIDAD.PDF

Convención Interamericana para prevenir, sancionar y erradicar la violencia contra la mujer Convención Belém do pará - (1995). San Salvador, El Salvador. Recuperado de https://www.oas.org/dil/esp/Convencion_Belem_do_Para.pdf

Convención interamericana para prevenir y sancionar la tortura (1985). Cartagena, Colombia. Recuperado de http://relapt.usta.edu.co/images/1985-Convencion-Interamerican-aparaprevenir-y-sancionar-la-Tortura.pdf

Convenio 169 de la Organización Internacional del Trabajo - OIT, sobre los pueblos indígenas y tribales en países independientes (1989). Ginebra. Recuperado de http://www.ilo.org/wcmsp5/groups/public/@ed_norm/@normes/documents/publication/ wcms_100910.pdf

Declaración Americana de los Derechos y Deberes del Hombre (1948). Aprobada en la novena conferencia internacional americana. Bogotá, D.C. Recuperado de 
https://www.oas.org/dil/esp/Declaraci\%C3\%B3n_Americana_de_los_Derechos_y_Deber es_del_Hombre_1948.pdf

Declaración de los principios de la Cooperación Cultural Internacional (1966). Recuperado de http://portal.unesco.org/es/ev.php-

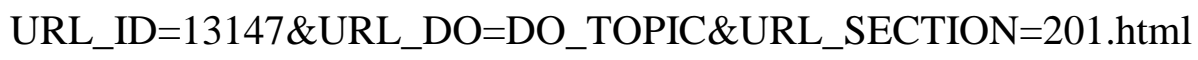

Declaración Universal de Derechos del Niño (1959). Recuperado de www.oas.org/dil/esp/Declaración\%20de\%20los\%20Derechos\%20del\%20Niño\%20Repu blica\%20Dominicana.pdf

Declaración Universal Derechos Humanos (1948). Recuperado dehttp://www.hchr.org.co/documentoseinformes/documentos/carceles/1_Universales/B\% E1sicos/1_Generales_DH/1_Declaracion_Universal_DH.pdf

Departamento Administrativo para la Prosperidad Social (2015). Decreto 1084 de 2015. Por medio del cual se expide el Decreto Único Reglamentario del Sector de Inclusión Social y Reconciliación. Diario Oficial $\mathrm{N}^{\circ} 49.523$ de 26 de mayo de 2015.Recuperado de http://www.icbf.gov.co/cargues/avance/docs/decreto_1084_2015_pr009.htm\#2.4.1.3

Dueñas, C (2012). Educación, derechos humanos y familia. Análisis de una experiencia de gestión comunitaria Colegio Ciudadela Educativa la Presentación Cali. Recuperado de file://C:/Users/Karin/Downloads/716-1851-1-PB.pdf

Espinel, O (2010). Pedagogías críticas y educación en derechos humanos. Una mirada desde escenarios escolares y no escolares. Bogotá.

Espinel, O (2013). Educación en Derechos Humanos. Esbozo de una lectura bio política. Revista colombiana de educación, n. 65. 
Galán, E \& Pinzón, M (2002). Observatorio Nacional de Infancia, familia y discapacidad. Revista psicología desde el Caribe, n 9, pp. 125 - 150. Universidad del Norte. Barranquilla, Colombia. Recuperado de http://www.redalyc.org/pdf/213/21300907.pdf

García, M, González, A \& Talavera, J (1999). Equismogenesis. Un concepto Sistémico Transdiciplinar Aplicado en Psiquiatría. Revista Electrónica de Psiquiatría, n4, vol 3. Recuperado de http://www.psiquiatria.com/revistas/index.php/psiquiatriacom/article/viewFile/521/500

González, F (2007). Salud mental a nivel familiar desde la perspectiva de alteridad. Psicología desde el Caribe. (20),1-27. Universidad del Norte. Recuperado de http://ciruelo.uninorte.edu.co/pdf/psicologia_caribe/20/1_Salud\%20mental.pdf

Guiñazú y otros (2012). Adolescentes como sujeto de derecho: implicancias y experiencias de trabajo en los Centros de APS. Buenos Aires Argentina. Recuperado de http://www.codajic.org/sites/www.codajic.org/files/Adolescentes \%20como\%20sujeto\%2 0de\%20derecho.pdf

Gutiérrez, M; Salazar, M; Castellanos, S; Giraldo, G; Gallego, L \& Cardona, Y (2010). Análisis de los procesos de atención de los niños, niñas en situación de adoptabilidad o vulneración, en seis instituciones de restablecimiento de derechos - Modalidad Internado- ICBF - Regional Caldas. Recuperado de https://icbfgob.sharepoint.com/sites/Dir_Planeacion_y_control_gestion/sub_direccion_m onitoreo_evaluacion/Biblioteca_Virtual/bv_centro_documentacion/Documentos/Protecci $\% \mathrm{C} 3 \% \mathrm{~B} 3 \mathrm{n} /$ investigacion_caldas.pdf

Herrera (2000). Rol de Género y Funcionamiento Familiar. Revista Cubana Medicina General Integral, n 6, vol. 16. Ciudad de la Habana, Cuba. Recuperado de http://scielo.sld.cu/pdf/mgi/v16n6/mgi08600.pdf 
Hurtado (2011). Informe de Investigación. El conocimiento de la dinámica intrafamiliar: Una posibilidad para transformar, Centro Zonal Florencia Uno. Florencia, Caquetá.

Instituto Colombiano de Bienestar Familiar - ICBF - (2016). Cifras Proceso Administrativo de Restablecimiento de Derechos - PARD - por poblaciones. Recuperado de http://www.icbf.gov.co/portal/page/portal/IntranetICBF/organigrama/Proteccion/PARD/P $\operatorname{ard} 2016$

Instituto Colombiano de Bienestar Familiar - ICBF - (sf). Estatuto integral del defensor de familia. Recuperado de http://www.icbf.gov.co/portal/page/portal/Descargas1/EstatutoIntegral_Defensor-de-Familia.pdf

Instituto Colombiano de Bienestar Familiar - ICBF - (2016). Lineamientos Técnicos de Modalidades para la Atención de Niños, Niñas y Adolescentes con Derechos Inobservados, Amenazados o Vulnerados. Recuperado de http://www.icbf.gov.co/portal/page/portal/PortalICBF/macroprocesos/misionales/restable cimiento/2/LM30\%20MPM5\%20P1\%20\%20Lineamiento\%20T\%C3\%A9cnico\%20Mod alidades\%20Atenci\%C3\%B3n\%20NNA\%20V2.pdf

Instituto Colombiano de Bienestar Familiar - ICBF - (2016). Lineamientos Técnico del Modelo para la Atención de los Niños, las Niñas y los Adolescentes con derechos inobservados, amenazados o vulnerados. Recuperado de http://www.icbf.gov.co/portal/page/portal/PortalICBF/macroprocesos/misionales/restable cimiento/2/LM19\%20MPM5\%20P1\%20Lineamiento\%20T\%C3\%A9cnico\%20Modelo\% 20Atenci\%C3\%B3n\%20NNA.pdf

Instituto Colombiano de Bienestar Familiar - ICBF - (2007). Lineamientos Técnicos para la Inclusión y Atención de Familias. Recuperado de 
http://www.icbf.gov.co/portal/page/portal/PortalICBF/macroprocesos/misionales/familias /2/LM1.MPM3\%20lineamientosT\%C3\%A9cnico\%20Inclusi\%C3\%B3n\%20y\%20Atenci \%C3\%B3n\%20de\%20Familias\%20v2.pdf

Instituto Colombiano de Bienestar Familiar - ICBF - (2017). Manual del Sistema Integrado de Gestión. Recuperado de http://www.icbf.gov.co/portal/page/portal/PortalICBF/procesos/estrategico/direccionamie $\underline{\text { nto }}$

Instituto Colombiano de Bienestar Familiar - ICBF - (2013). Observatorio del bienestar de la niñez $N^{\circ}$ 15. La familia: El entorno protector de nuestros niños, niñas y adolescentes colombianos. Bogotá: Procesos digitales S.A.S. Recuperado de http://www.icbf.gov.co/portal/page/portal/Observatorio1/Archivo/2013/publicacion47.pdf

Instituto Colombiano de Bienestar Familiar - ICBF - (2006). Política de primera infancia. Recuperado de http://www.cinde.org.co/PDF/Politica\%20publica\%20primera\%20infancia\%20Colombia \%20(v.\%2011\%20nov\%2006).pdf

Instituto Colombiano de Bienestar Familiar - ICBF - (2016). Proceso Relación con el Ciudadano. Recuperado de http://www.icbf.gov.co/portal/page/portal/PortalICBF/procesos/misionales/relacionciudadano/P1.RC\%20Procedimiento\%20Atenci\%C3\%B3n\%20de\%20Peticiones\%20v1.p df 
Instituto Colombiano de Bienestar Familiar (ICBF) Centro Zonal Suroriental (2014).

Reconstrucción de los modelos de manejo de conflictos en familias adscritas al Centro Zonal Suroriental del ICBF en Barranquilla. Barraquilla, Atlántico.

Instituto Colombiano de Bienestar familiar (2016). Sistema de información misional SIM. Recuperado de https://sim.icbf.gov.co/sim/dwacceso.aspx

Instituto Interamericano de Derechos Humanos (2009). Informe Interamericano de la Educación en Derechos Humanos: un estudio en 19 países, compendio de los primeros cinco informes 2002 - 2006. San José, Costa Rica: Edisa, S.A. Recuperado de http://www.iidh.ed.cr/multic/UserFiles/Biblioteca/IIDH/9_2010/fe22f95d-bb81-4859a029-d383a54f576e.pdf

Jiménez, R (2012). Naturaleza del defensor de familia como institución garante de la eficacia de los derechos de la niñez y la adolescencia ¿Conciliador o juez? Universitas n. 24, pp.169 - 199. Recuperado de http://www.scielo.org.co/pdf/vniv/n124/n124a08.pdf

Krauskopf, D (1999). Dimensiones críticas en la participación social de las juventudes. San José, Costa Rica. Recuperado de http://ww.centroamericajoven.org/sites/default/files/dimensiones_criticas_participacion_j uveni_0.pdf

López, M (2005). Derechos humanos, familia y educación. Revista estudios sobre educación, v. 8, pp. 145-163. Universidad de Navarra, ISSN: 1578-7001. España. Recuperado de http://dadun.unav.edu/bitstream/10171/8882/1/Nc.pdf

Ludewig, K (2001). Realidad y construcción en psicoterapia: sentido y sinsentido de ésta distinción. Muenster, Alemania. Recuperado de http://www.kurtludewig.de/Downloads/39\%20Realidad\%202007.pdf 
Magendzo, A (2008). La escuela y los derechos humanos. México, DF.

Magendzo, A (2008). Pensamiento e ideas - fuerza de la educación en derechos humanos en Iberoamérica. Unesco. Fundación IDEAS. Chile.

Martínez, C y Murillo, J (2010). Investigación etnográfica. Métodos de investigación educativa en Ed. Especial. Recuperado de https://www.uam.es/personal_pdi/stmaria/jmurillo/InvestigacionEE/Presentaciones/Curso _10/I_Etnografica_Trabajo.pdf

Menke, C. y Pollmann, A (2010). Filosofía de los Derechos Humanos. Barcelona, España. Herder Editorial.

Ministerio de Educación Nacional (1994). Decreto reglamentario 1860 de 1994. Por el cual se reglamenta parcialmente la Ley 115 de 1994 en los aspectos pedagógicos y organizativos generales. Diario Oficial N 41.473 del 5 de Agosto de 1994. Recuperado de http://www.educacionbogota.edu.co/archivos/SERVICIOS/Auditoia\%20Matriculas/norm atividad/Decreto_1860_1994.pdf

Ministerio de Educación Nacional (2006). Plan Decenal de Educación 2006 - 2016. Recuperado https://www.minsalud.gov.co/sites/rid/Lists/BibliotecaDigital/RIDE/INEC/IGUB/Plan\%2 Odecenal\%20de\%20educacion\%202006\%20-\%202016.pdf

Munarriz, B (1992). Técnicas y métodos de investigación cualitativa. Universidad del país Vasco. España. Recuperado de http://ruc.udc.es/dspace/bitstream/handle/2183/8533/CC02art8ocr.pdf? sequence $=1 \&$ isAllowed $=\mathrm{y}$

Naciones Unidas (1999). Declaración sobre el derecho y el deber de los individuos, los grupos y las instituciones de promover y proteger los derechos humanos y las libertades 
fundamentales universalmente reconocidos. Recuperado de http://www.ohchr.org/Documents/Issues/Defenders/Declaration/declaration_sp.pdf

Naciones Unidas (1990). Directrices de las Naciones Unidas para la prevención de la delincuencia juvenil (Directrices del Riad). Resolución 45/112. Universidad de Gante. Centro de derecho de los niños. La Habana, Cuba. Recuperado de http://iin.oea.org/cd_resp_penal/documentos/0043889.pdf

Naciones Unidas (1990). Directrices sobre la función de los fiscales. La Habana, Cuba. Recuperado de http://www.ohchr.org/SP/ProfessionalInterest/Pages/RoleOfProsecutors.aspx

Naciones Unidas (1990). Principios básicos sobre el empleo de la fuerza y de las armas de fuego por los funcionarios encargados de cumplir con la ley. La Habana, Cuba. Recuperado de http://www.ohchr.org/SP/ProfessionalInterest/Pages/UseOfForceAndFirearms.aspx

Naciones Unidas (s.f.). Que son los derechos humanos. Recuperado de http://www.ohchr.org/SP/Issues/Pages/WhatareHumanRights.aspx

Ochoa, I (1995). Enfoque en terapia familiar sistémica. Barcelona, España: Herder

Palomares, J (2008). Metodología de la investigación jurídica y socio jurídica. Modulo № 56. Universidad Santo Tomas. Bogotá: Consejo Editorial

Plan Nacional de Educación en Derechos Humanos - Planedh (2014). Buenos y Creativos S.A.S. Recuperado de http://www.ohchr.org/Documents/Issues/Education/Training/actionsplans/Colombia.pdf

Pérez, E \& Fernández, M (2002). Observatorio de Infancia y familia Suba: Creencias, prácticas y conversaciones en el Centro Zonal Suba-ICBF. Recuperado de https://icbfgob.sharepoint.com/sites/Dir_Planeacion_y_control_gestion/sub_direccion_m 
onitoreo_evaluacion/Biblioteca_Virtual/bv_centro_documentacion/Documentos/Protecci \%C3\%B3n/Creencias_CZsuba.pdf

Pradolini, (2010). Promoción de Derechos Humanos “en” y “con” las familias. Revista Terapia Ocupacional. Universidad de Sao Paulo, V. 21, n.3, pp. 255-262. Recuperado de http://www.revistas.usp.br/rto/article/view/14112/15930

Rosemberg, F (s. f.). Niños pequeños en la agenda de políticas para la infancia: representaciones sociales y tensiones. La primera infancia $(0-6$ años) y su futuro. Madrid, España: Santillana. Recuperado de file://C:/Users/Karin/Downloads/LAPRIMERAINFANCIA\%20(5).pdf

Salles, V \&Tuirán, R (1996). El giro cultural en la investigación socio demográfica: Estrategias de sobrevivencia, cursos de vida, hogares, familias y redes. Revista del departamento de sociología-Sociológica, V. 11, n 32. Universidad Autónoma Metropolitana. Recuperado de http://www.revistasociologica.com.mx/pdf/3211.pdf

San Romualdo, R (2013). Educación en derechos humanos como propuesta transversal en un aula de educación (tesis de grado). Universidad de Valladolid, España. Recuperado de http://cerro.cpd.uva.es/handle/10324/3235

Secretaría Distrital de Planeación (2009). Conociendo la localidad de Fontibón: Diagnóstico de los aspectos físicos, demográficos y socioeconómicos. Bogotá, Colombia. Recuperado de http://www.sdp.gov.co/portal/page/portal/PortalSDP/InformacionEnLinea/InformacionDe scargableUPZs/Localidad\%209\%20Fontib\%F3n/monografia/09\%20Localidad\%20de\%2 0Fontib\%F3n.pdf 
UNESCO (1978). Declaración sobre la raza y los prejuicios Raciales. Paris, Francia.

Recuperado de

http://participaz.com/images/pdf/Capitulo11/declaracion_UNESCO_sobre_la_raza.pdf

UNESCO \& Centro de Derechos Humanos de las Naciones Unidas (1993). Informe del director general sobre los trabajos del congreso internacional sobre educación para los derechos humanos y la democracia y seguimiento a los estados miembros del Plan de Acción Mundial sobre Educación para los Derechos Humanos y la Democracia. Montreal, Canadá. Recuperado de http://unesdoc.unesco.org/images/0009/000954/095433so.pdf

UNESCO (1995). Conferencia general de la UNESCO en su $28^{a}$ reunión. Declaración de la $44^{\mathrm{a}}$ reunión de la Conferencia Internacional de Educación. Paris, Francia. Recuperado de http://www.unesco.org/cpp/sp/declaraciones/educacion.htm

UNESCO (2012). Programa Mundial Para La Educación En Derechos Humanos. Plan de Acción, Segunda Etapa. Nueva York y Ginebra. Recuperado de http://www.ohchr.org/Documents/Publications/WPHRE_Phase_2_sp.pdf

Unicef (2006). Convención Internacional sobre los derechos del niño (1989). Recuperado de http://www.un.org/es/events/childrenday/pdf/derechos.pdf

Vargas, I (2010). La entrevista en la Investigación Cualitativa: nuevas tendencias y retos. Revista CAES V. 31, n. 1. Costa Rica. Recuperado de https://dialnet.unirioja.es/servlet/articulo?codigo=3945773

Villa, J (2012). La acción y el enfoque psicosocial de la intervención en contextos sociales: ¿Podemos pasar de la moda a la precisión teórica, epistemológica y metodológica? Revista de ciencias sociales el Ágora USB V. 12, n.2, pp. 349 - 365. Medellín, Colombia: 
Bonaventuriana. Recuperado de

http://www.revistas.usb.edu.co/index.php/Agora/article/view/208/91

\section{Anexos}

\section{Anexo 1: Entrevista no estructurada aplicada a Defensorías de Familia del Centro Zonal Fontibón -Instituto Colombiano de Bienestar Familiar (ICBF)}

Para efectos de la presente entrevista participaron 11 funcionarios que componen las Defensorías de Familia del Centro Zonal Fontibón.

Tabla $\mathrm{N}^{\circ}$ 1. Cargos en las Defensorías de Familia de los funcionarios que participaron de la entrevista:

\begin{tabular}{|l|l|l|}
\hline \multicolumn{1}{|c|}{ CARGO } & $\begin{array}{c}\text { N }{ }^{\circ} \text { DE } \\
\text { FUNCIONARIOS }\end{array}$ & $\begin{array}{c}\text { PORCENTAJE EN } \\
\text { RELACIÓN A LA } \\
\text { MUESTRA }\end{array}$ \\
\hline Trabajador social & 5 & $45.4 \%$ \\
\hline Psicólogo & 4 & $36.3 \%$ \\
\hline Nutricionista & 2 & $18.1 \%$ \\
& & \\
\hline
\end{tabular}




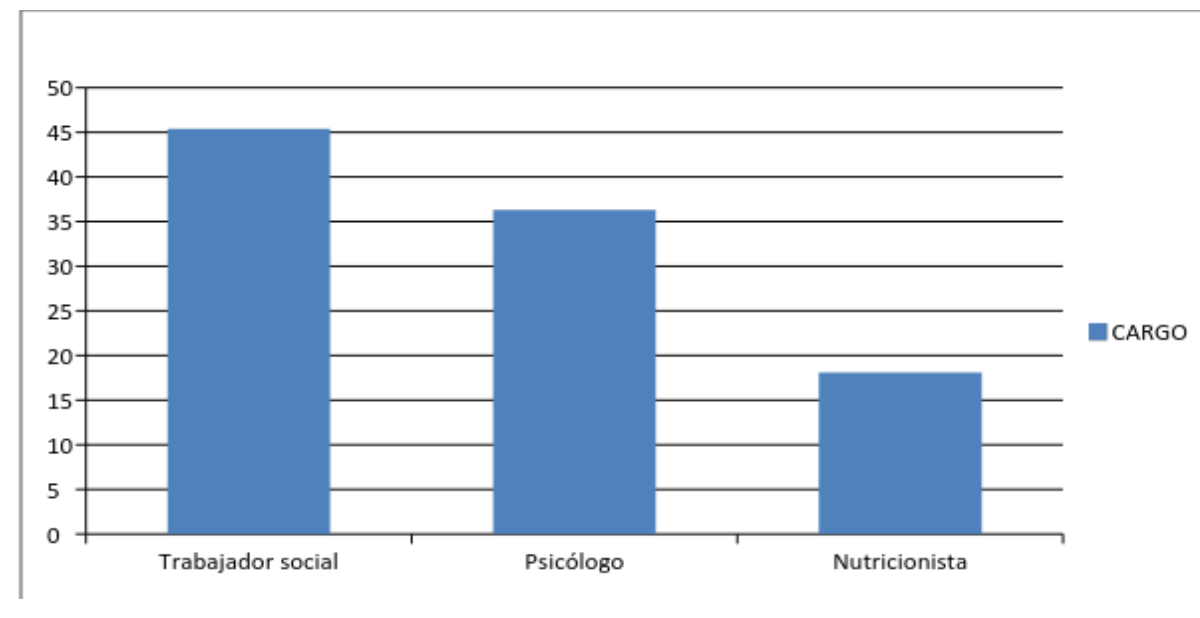

Grafico $N^{\circ}$ 1.- Cargos de los funcionarios

Tabla $N^{\circ}$ 2. Funciones que desempeñan los funcionarios de acuerdo con su cargo:

\begin{tabular}{|l|l|l|}
\hline \multicolumn{1}{|c|}{ FUNCIONES } & \multicolumn{1}{|c|}{$\begin{array}{c}\text { N }{ }^{\circ} \text { DE } \\
\text { FUNCIONARIOS }\end{array}$} & $\begin{array}{c}\text { PORCENTAJE EN } \\
\text { RELACIÓN A LA } \\
\text { MUESTRA }\end{array}$ \\
\hline Valoraciones iniciales & 11 & $100 \%$ \\
\hline Seguimiento & 8 & $72.7 \%$ \\
\hline Atención a familias & 7 & $63.6 \%$ \\
\hline Verificación de derechos & 4 & $36.3 \%$ \\
\hline Verificación de denuncias & 3 & $27.2 \%$ \\
\hline Visitas domiciliarias & 3 & $27.2 \%$ \\
\hline Visita hogares sustitutos & 2 & $18.1 \%$ \\
\hline Visita a instituciones & 2 & $18.1 \%$ \\
\hline Referente hogar gestor & 1 & $9.0 \%$ \\
\hline Apoyo modalidad externado & 1 & $9.0 \%$ \\
\hline Asistencia a audiencias de fallo & 1 & $9.0 \%$ \\
\hline Selección madres comunitarias & 1 & \\
\hline
\end{tabular}




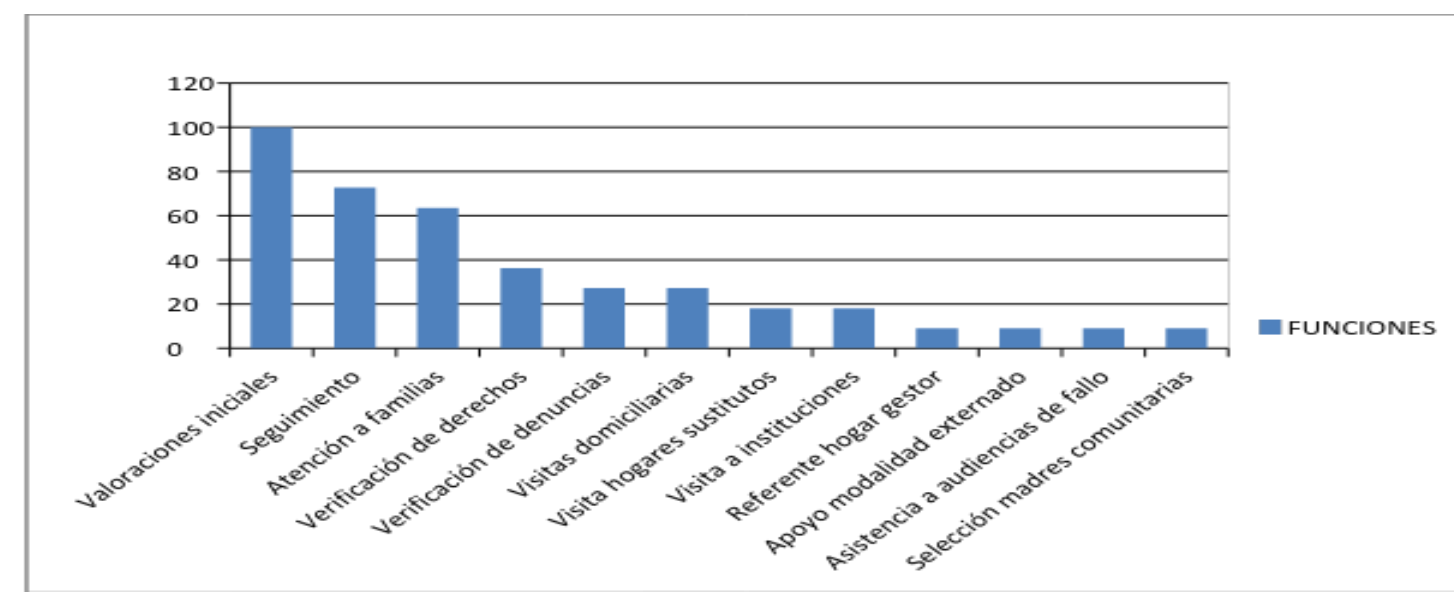

Grafico $N^{\circ}$ 2.- Funciones

Tabla $\mathrm{N}^{\circ}$ 3. Casos que atienden los funcionarios aproximadamente durante el mes:

\begin{tabular}{|l|l|l|}
\hline \multicolumn{1}{|c|}{$\mathbf{N}^{\circ}$ DE CASOS } & \multicolumn{1}{|c|}{$\begin{array}{c}\mathbf{N}^{\circ} \text { DE } \\
\text { FUNCIONARIOS }\end{array}$} & $\begin{array}{c}\text { PORCENTAJE EN } \\
\text { RELACIÓN A LA } \\
\text { MUESTRA }\end{array}$ \\
\hline $20-30$ & 1 & $9.0 \%$ \\
\hline $31-40$ & 3 & $27.2 \%$ \\
\hline $41-50$ & 0 & $0 \%$ \\
\hline $51-60$ & 3 & $27.2 \%$ \\
\hline $61-70$ & 1 & $9.0 \%$ \\
\hline $71-80$ & 3 & $27.2 \%$ \\
\hline
\end{tabular}




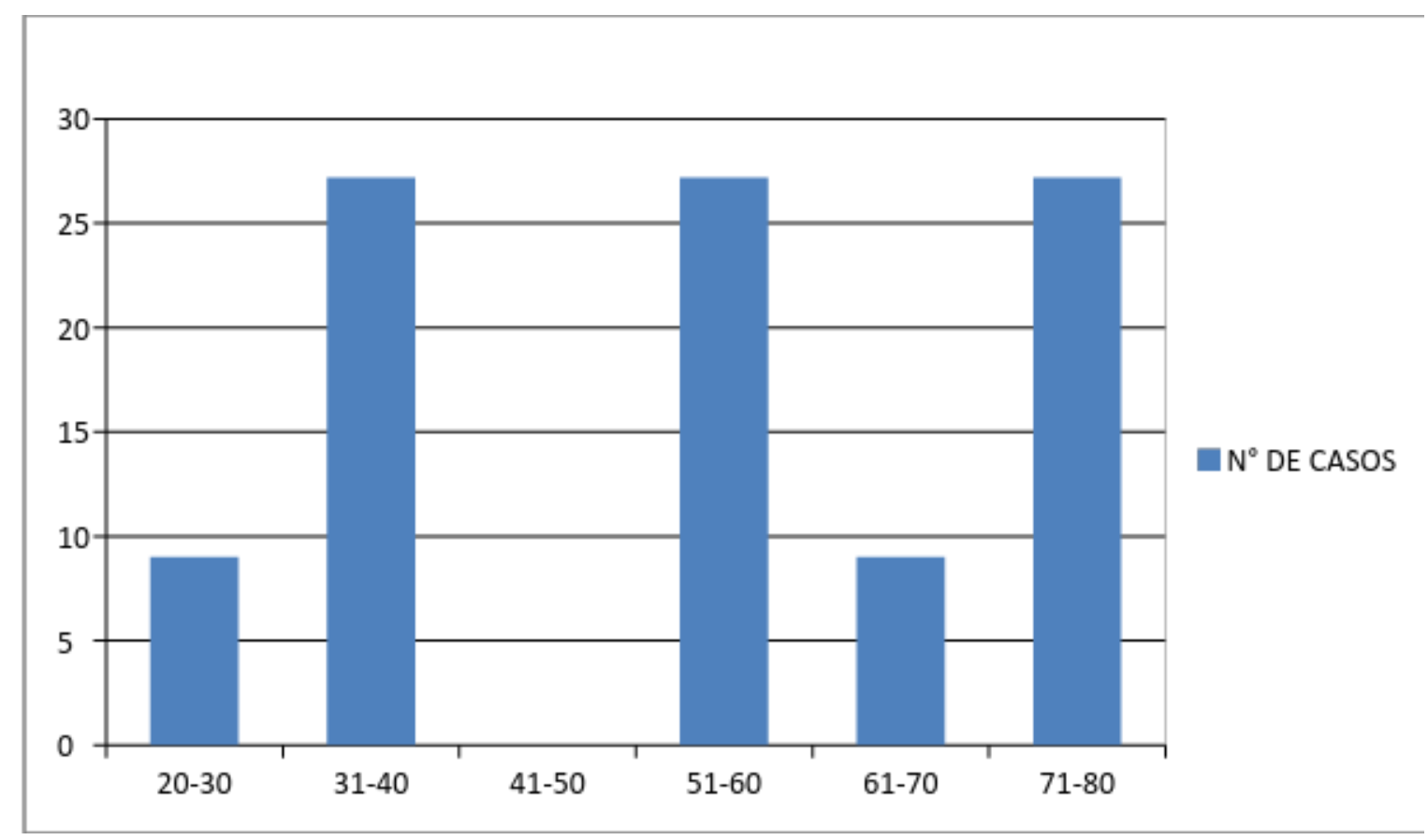

Gráfico $\mathrm{N}^{\circ}$ 3. Número de Casos

Tabla $N^{\circ} 4$ Problemáticas más comunes que presentan las familias que atienden las Defensorías de Familia

\begin{tabular}{|l|l|l|}
\hline \multicolumn{1}{|c|}{ PROBLEMÁTICA } & \multicolumn{1}{|c|}{$\begin{array}{c}\mathbf{N}^{\circ} \text { DE } \\
\text { FUNCIONARIOS }\end{array}$} & $\begin{array}{c}\text { PORCENTAJE EN } \\
\text { RELACIÓN A LA } \\
\text { MUESTRA }\end{array}$ \\
\hline Maltrato físico y/o psicológico & 7 & $63.6 \%$ \\
\hline Abuso sexual & 7 & $63.6 \%$ \\
\hline Consumo SPA & 7 & $63.6 \%$ \\
\hline Problemas de comportamiento & 5 & $45.4 \%$ \\
\hline Negligencia & 3 & $27.2 \%$ \\
\hline Inmigrantes & 2 & $18.1 \%$ \\
\hline Violencia intrafamiliar & 1 & $9.0 \%$ \\
\hline Trabajo infantil & 1 & $9.0 \%$ \\
\hline Custodia & 1 & $9.0 \%$ \\
\hline
\end{tabular}




\begin{tabular}{|l|l|l|}
\hline Demanda por alimentos & 1 & $9.0 \%$ \\
\hline Investigación de paternidad & 1 & $9.0 \%$ \\
\hline Impugnación de paternidad & 1 & $9.0 \%$ \\
\hline Trámite para salida del país & 1 & $9.0 \%$ \\
\hline
\end{tabular}

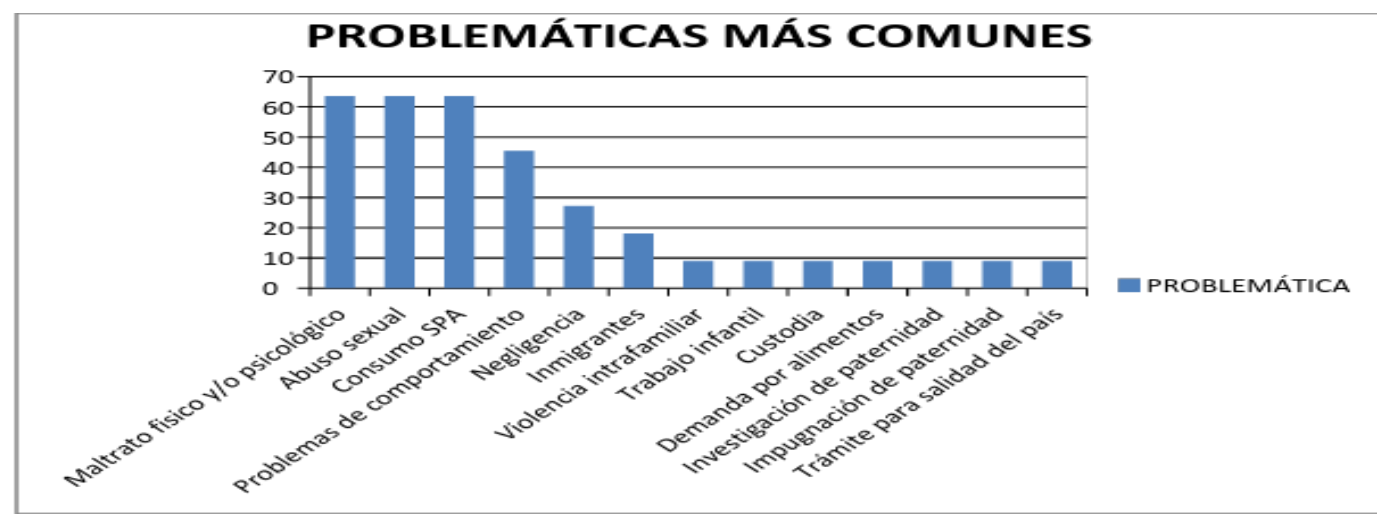

Gráfico $\mathrm{N}^{\circ}$ 4: Problemas más comunes en las familias

Tabla $\mathrm{N}^{\circ} 5$. Factores que consideran las Defensorías de Familia que deben tenerse en cuenta durante la intervención con familia y que pueden contribuir a un verdadero cambio

\begin{tabular}{|l|l|l|}
\hline \multicolumn{1}{|c|}{ FACTOR } & \multicolumn{1}{c|}{$\begin{array}{c}\mathbf{N}^{\circ} \text { DE } \\
\text { FUNCIONARIOS }\end{array}$} & $\begin{array}{c}\text { PORCENTAJE EN } \\
\text { RELACIÓN A LA } \\
\text { MUESTRA }\end{array}$ \\
\hline $\begin{array}{l}\text { Sensibilización respecto a conductas por } \\
\text { mejorar }\end{array}$ & 5 & $45.4 \%$ \\
\hline Aspectos socio-económicos y culturales & 3 & $27.2 \%$ \\
\hline Establecer compromisos & 2 & $18.1 \%$ \\
\hline Seguimiento a los casos & 2 & $18.1 \%$ \\
\hline Observación & 2 & $18.1 \%$ \\
\hline $\begin{array}{l}\text { Movilizar el Sistema Nacional de Bienestar } \\
\text { Familiar (SNBF) }\end{array}$ & 2 & $18.1 \%$ \\
\hline
\end{tabular}




\begin{tabular}{|l|l|l|}
\hline Actitud de los funcionarios & 2 & $18.1 \%$ \\
\hline Empatía & 1 & $9.0 \%$ \\
\hline Remitir a proceso terapéutico & 1 & $9.0 \%$ \\
\hline No juzgar & 1 & $9.0 \%$ \\
\hline Comunicación asertiva & 1 & $9.0 \%$ \\
\hline Objetividad & 1 & $9.0 \%$ \\
\hline Escuchar a las familias & 1 & $9.0 \%$ \\
\hline Historia de vida & 1 & $9.0 \%$ \\
\hline
\end{tabular}

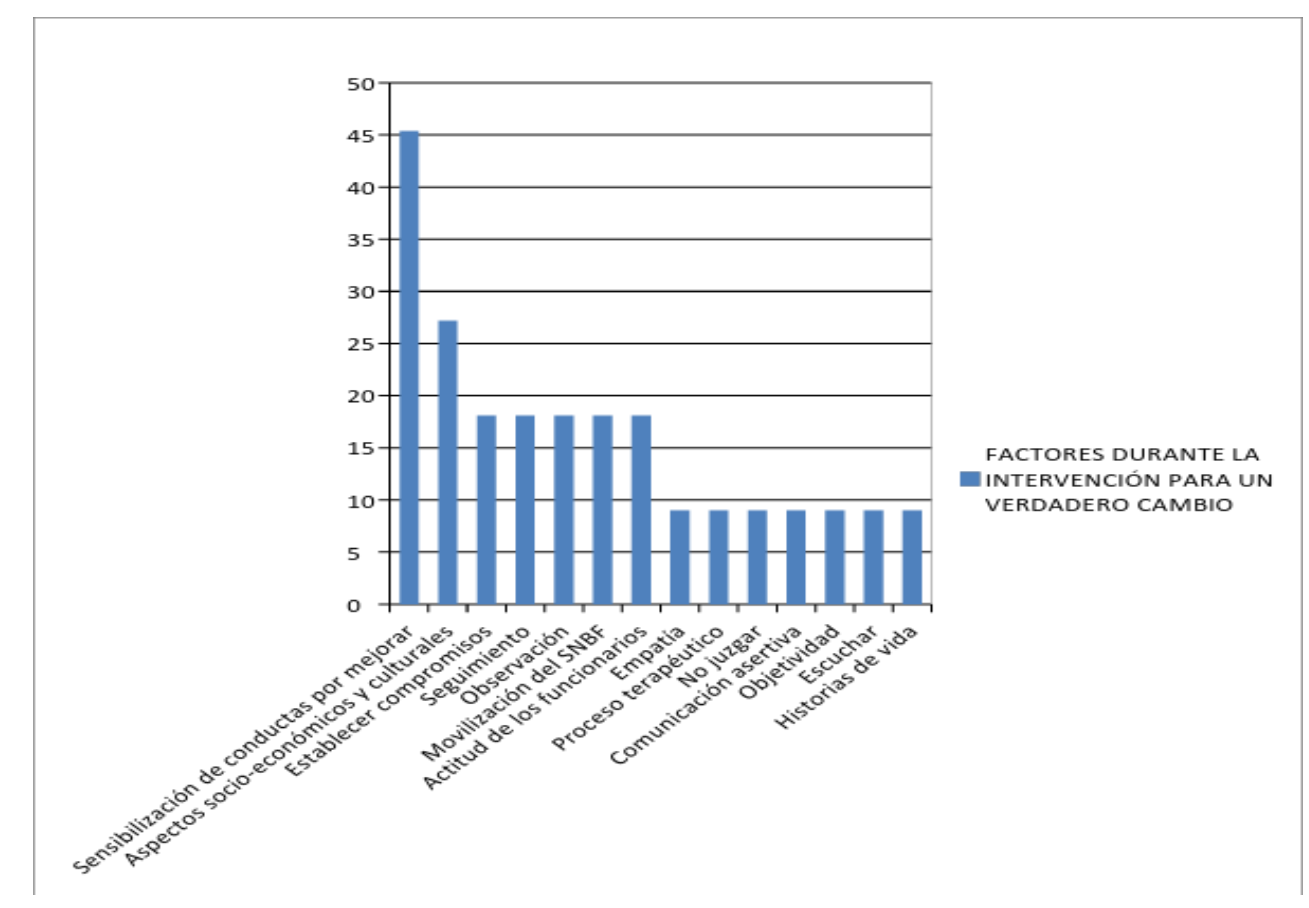

Gráfico $\mathrm{N}^{\circ}$ 5.- Factores durante la intervención para un verdadero cambio. 
Tabla $N^{\circ}$ 6. Definición de Educación en Derechos Humanos por parte de las Defensorías de Familia:

\begin{tabular}{|l|l|l|}
\hline DEFINICIÓN EDUCACIÓN EN DDHH & \multicolumn{1}{|c|}{$\begin{array}{c}\mathbf{N}^{\circ} \text { DE } \\
\text { FUNCIONARIOS }\end{array}$} & $\begin{array}{c}\text { PORCENTAJE EN } \\
\text { RELACIÓN A LA } \\
\text { MUESTRA }\end{array}$ \\
\hline $\begin{array}{l}\text { Forma pedagógica de transmitir valores, } \\
\text { deberes y derechos }\end{array}$ & 4 & $36.3 \%$ \\
\hline Reconocimiento de derechos & 3 & $27.2 \%$ \\
\hline $\begin{array}{l}\text { Sensibilización sobre derechos estipulados } \\
\text { en las leyes }\end{array}$ & 2 & $18.1 \%$ \\
\hline Informar sobre derechos & 2 & $18.1 \%$ \\
\hline
\end{tabular}

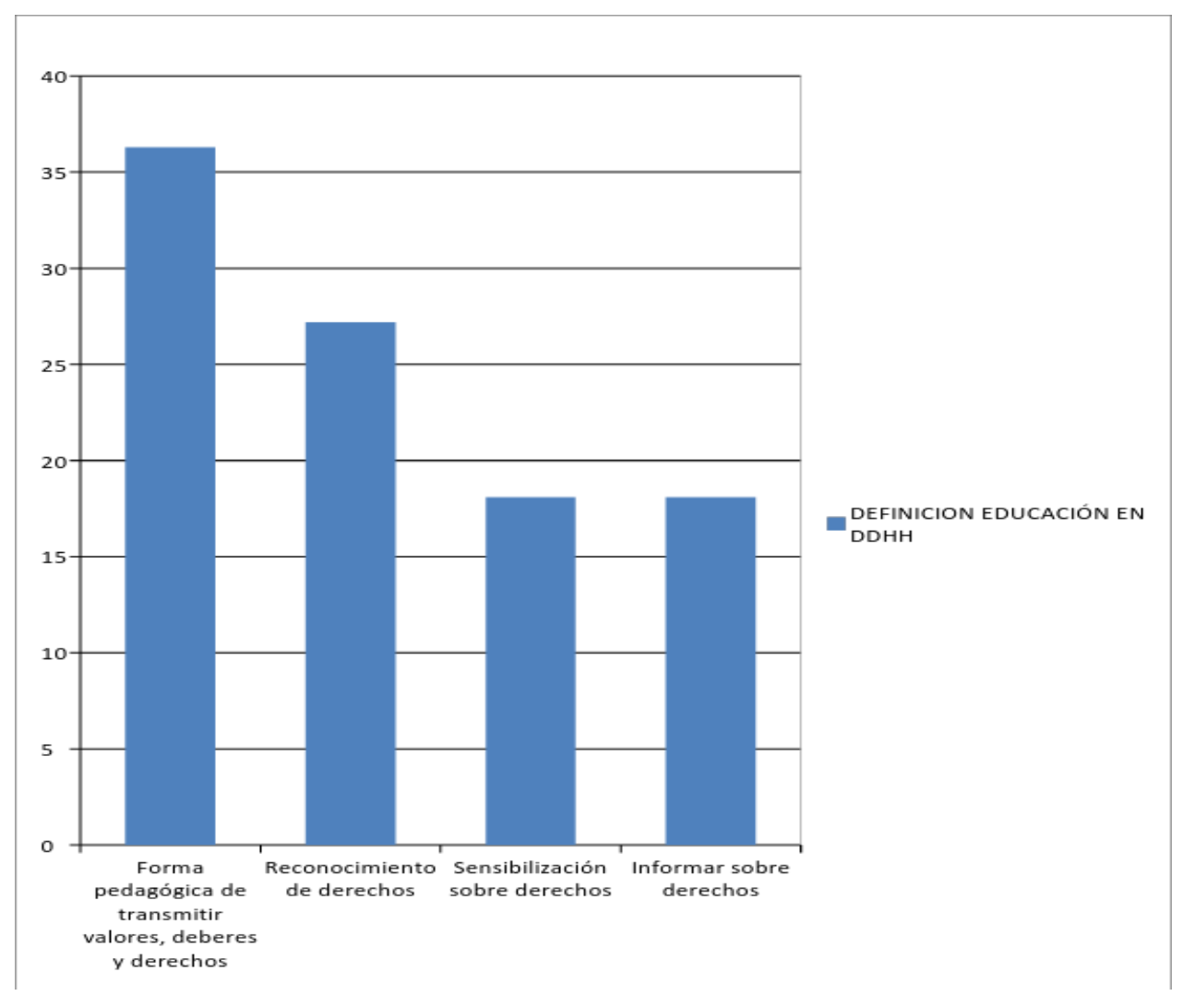

Gráfico $\mathrm{N}^{\circ}$ 6. Definición EDH 
Tabla $N^{\circ}$ 7. Importancia que le asignan las Defensorías de Familia a la Educación en Derechos Humanos en la atención que brindan a las familias

\begin{tabular}{|l|l|l|}
\hline \multicolumn{1}{|c|}{$\begin{array}{c}\text { IMPORTANCIA DE LA EDUCACIÓN } \\
\text { EN DDHH }\end{array}$} & \multicolumn{1}{|c|}{$\begin{array}{c}\text { N }{ }^{\circ} \text { DE } \\
\text { FUNCIONARIOS }\end{array}$} & $\begin{array}{c}\text { PORCENTAJE EN } \\
\text { RELACIÓN A LA } \\
\text { MUESTRA }\end{array}$ \\
\hline $\begin{array}{l}\text { Fomenta el conocimiento y respeto de } \\
\text { deberes y derechos }\end{array}$ & 7 & $63.6 \%$ \\
\hline Respeto por el usuario & 1 & $9.0 \%$ \\
\hline $\begin{array}{l}\text { Construcción de estrategias de comunicación } \\
\text { en las familias }\end{array}$ & 1 & $9.0 \%$ \\
\hline $\begin{array}{l}\text { Tomar decisiones adecuadas } \\
\text { Mejorar las relaciones interpersonales }\end{array}$ & 1 & $9.0 \%$ \\
\hline Contribuye a la garantía de derechos & 1 & $9.0 \%$ \\
\hline Aclara el tema a los usuarios & 1 & $9.0 \%$ \\
\hline
\end{tabular}

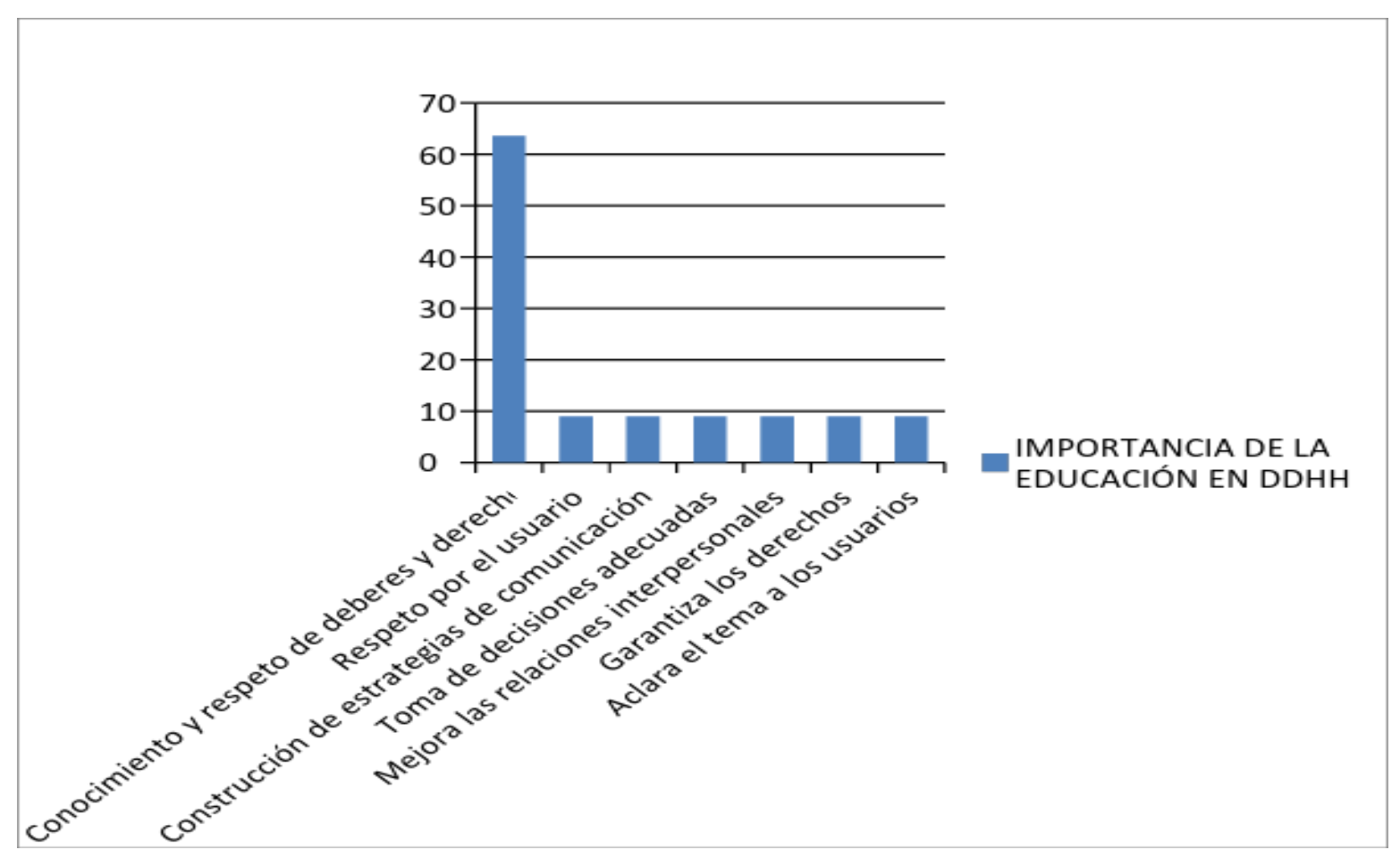




\section{Anexo 2: Estado de la cuestión}

De acuerdo a los objetivos de la investigación, se indago sobre el contexto socio político en el cual surgió el ICBF, así como investigaciones previas adelantadas por ésta entidad; y en el marco nacional e internacional en cuanto al tema de educación en derechos humanos, que permitió evaluar la pertinencia de la misma.

El trabajo etnográfico realizado por el ICBF (Rojas y Arteaga, 2012), coordinado por la Subdirección de Familia, permite identificar el contexto histórico en el cual surgió el ICBF. Dentro del mismo se indica que las situaciones generadas por los grandes cambios que ocurrieron a partir de la mitad del siglo XX a nivel social, económico y cultural exigieron su creación; entre ellos, el desplazamiento forzado por la violencia política ocurrida durante los años 50’ y 60’, obligando a la mujer a vincularse laboralmente, desempeñando un papel importante en el sector productivo debido a situaciones económicas de la familia y del país, además su mano de obra representaba menos gasto para las empresas ${ }^{1}$.

De modo que la vinculación de la mujer al campo laborar generó que NNA y ancianos permanecieran solos durante el día y tuvieran que cuidar de sí mismos; además se empezaron a presentar rompimientos en las relaciones conyugales, que a su vez causaron que los hijos permanecieran separados de sus padres, surgiendo con ello cambios en la estructura familiar y por ende, nuevas tipologías. Ello no quiere decir que sea la mujer la responsable exclusiva de los cuidados en los niños o ancianos, esta responsabilidad ha de ser compartida con el hombre.

Estos cambios ocurridos al interior de las familias en Colombia, generaron retos para el Estado en cuanto al replanteamiento de políticas públicas. Es así que mediante la Ley 75 de 1968

\footnotetext{
${ }^{1}$ Pese a la independencia económica y social que ha adquirido la mujer a partir de su vinculación al medio laboral, de acuerdo con Herrera (2000) patrones sociales y culturales mantienen la tendencia a delegarle labores exclusivas del hogar, como la limpieza, cocinar y cuidar de los hijos y ancianos; mientras que el hombre se percibe como el proveedor y autoridad en el hogar; por tanto, alterar dichos roles genera conflictos.
} 
surge el ICBF como entidad encargada de la protección y garantía de derechos de los NNA del país, además se consideró necesario crear hogares de bienestar en diferentes modalidades en donde los niños recibieran atención y cuidado mientras sus progenitores o representantes legales se encontraban laborando, así mismo se promovieron programas encaminados a la prevención de la violencia intrafamiliar y promoción de la convivencia familiar.

Es así que el ICBF progresivamente fue enfocándose en las necesidades de la familia, para promover programas de protección y prevención que permitiera el fortalecimiento de dicha población en su rol coadyuvador como cuidadores y formadores de sus NNA. Expidiéndose en 1989 el Código del Menor, que tenía por objetivo la protección de los niños y niñas con derechos vulnerados; modificado posteriormente por la ley 1098 de 2006 o código de Infancia y Adolescencia. En cuanto a la atención de familias en el año 2007 se expidió la Resolución № 002366 mediante la cual el ICBF aprobó los lineamientos técnicos para la inclusión y atención de familia, bajo la primacía del modelo solidario que destaca la participación y corresponsabilidad de la familia, el cual rige en la actualidad.

Sin embargo, se presentan dificultades en la atención que se brinda a las familias por parte de los funcionarios de dicha entidad, considerándose importante para efectos de la presente investigación complementar dicho modelo solidario con la Educación en Derechos Humanos, ya que de acuerdo a la revisión de antecedentes del ICBF dicho tema no se ha abordado por parte de ésta entidad, por tanto no se reconoce la relevancia que el mismo tiene en la atención a familias, que en conjunto con el "modelo solidario", se podrían lograr transformaciones significativas a nivel de la dinámica laboral y las relaciones familiares en la medida en que cada uno es tratado como sujeto de derechos. 
Por tanto, se llevó a cabo una exploración de las investigaciones relacionadas con la EDH llevadas a cabo desde el ICBF, encontrando que la mayoría se han concentrado en las problemáticas familiares y pocos trabajos se han enfocado en las dificultades relacionadas con la atención que se les brinda a las familias por parte de los funcionarios de ésta entidad y mucho menos existen investigaciones en donde se aborde de manera específica el tema de EDH. Entre las investigaciones que el ICBF ha desarrollado, se encuentran las siguientes:

En el 2002 se llevó a cabo en el Centro Zonal Suba del ICBF una investigación como parte del proyecto de Observatorios de Infancia y Familia titulado "Creencias, prácticas y conversaciones en el Centro Zonal Suba - ICBF”, analizado y dirigido por Esperanza Pérez y Myriam Fernández. Para la presente investigación se consideró importante, en la medida en que éste resalta aspectos a tener en cuenta para una mejor intervención por parte de los funcionarios del ICBF, entre ellos colocarse en el lugar del otro y de esta manera encontrar soluciones al problema a través del aporte que realice cada parte, sin que la familia atendida se sienta atacada o vulnerada en sus derechos, lo cual sólo se logra si las defensorías de familia desarrollan las intervenciones desde un enfoque de educación en derechos humanos.

En la regional Caldas del ICBF se llevó a cabo una investigación en el año 2010 por parte de los investigadores Martha Gutiérrez, Myriam Salazar, Santiago Castellanos, Gloria Giraldo, Liliana Gallego y Yaneth Cardona, titulada “Análisis de los procesos de atención de los niños y niñas en situación de adoptabilidad o vulneración en seis instituciones de restablecimiento de derechos - Modalidad Internado - ICBF - Regional Caldas", cuyo objetivo era evaluar los factores potenciales y los que no lo eran, en las intervenciones realizadas por los profesionales de dichas instituciones. De este trabajo,ha sido importante retomar las estrategias planteadas para un mejor proceso de intervención. 
En el 2011 la Universidad de la Amazonía y el Centro Zonal Florencia I de la Regional Caquetá del ICBF, en cabeza de la investigadora Elizabeth Hurtado, desarrolló la investigación denominada: "El conocimiento de la dinámica intrafamiliar: Una posibilidad para transformar".A través de la propuesta psicosocial que se diseñó en éste trabajo de investigación, es posible generar transformaciones en las dinámicas familiares de los ciudadanos atendidos en el Centro Zonal Fontibón del ICBF, en la medida en que una atención basada en la educación en derechos humanos facilita la compresión de aspectos socio - culturales.

En el 2012 la investigadora Blanca Arteaga, bajo la coordinación de la subdirección de familia de la Dirección de Prevención del ICBF, llevó a cabo una caracterización de las familias en Colombia con el objetivo de "Identificar un marco apropiado, capaz de armonizar los énfasis institucionales con los desarrollos internacionales sobre derechos de los niños, niñas y adolescentes, y la Constitución Política, el Plan de Desarrollo y el Plan País” (Arteaga, 2012).Partiendo del objetivo en el que se basa la caracterización mencionada, el presente trabajo de grado puede facilitar aún más la comprensión de la influencia de dichos vínculos e interacciones en el comportamiento humano, en la medida en que se sustenta en una visión holística desde la perspectiva de la educación en derechos humanos, que le permite al funcionario comprender la realidad del otro (NNA o familia), siendo consciente de su deber de respetar los derechos individuales y colectivos sin transgredir su dignidad.

En el año 2013 bajo el Convenio No 529 / NAJ 661 suscrito entre el ICBF y la Organización Internacional para las Migraciones (OIM), a través de la Agencia para el Desarrollo Internacional (USAID), se llevó a cabo el observatorio del bienestar de la niñez $\mathrm{N}^{\circ}$ 15, denominado: “La familia: el entorno protector de nuestros niños, niñas y adolescentes colombianos". Por tanto, es necesario que las defensorías de familia, bajo la primacía de la 
educación en derechos humanos, brinden una atención orientada hacia la restructuración de las dinámicas familiares, de manera que las mismas representen un contexto adecuado para la sana convivencia de los NNA.

En el 2014 el Centro Zonal Sur Oriente del ICBF en Barranquilla, llevó a cabo el proyecto titulado "Reconstrucción de los modelos de manejo de conflictos en familias adscritas al Centro Zonal Sur Oriente del ICBF en Barranquilla”; así, es posible que a través de una re significación de los procesos de atención por parte de las defensorías de familia (al colocar en práctica la educación en derechos humanos), pueden lograr cambios significativos en las familias.

Respecto de otras investigaciones realizadas sobre educación en derechos humanos, existen algunos trabajos relacionados con dicho tema, aunque no se trata de manera específica, algunas de ellas resaltan la intervención con familias realizada por profesionales del área psicosocial. Para efectos del presente trabajo de investigación se consideró importante mencionar las siguientes tesis, artículos e informes:

Carrillo (2009), en su tesis doctoral denominada "La familia, la autoestima y el fracaso escolar del adolescente", resalta la influencia del contexto familiar en los seres humanos, por lo cual es importante que las defensorías de familia, ejerzan sus funciones desde una educación en derechos humanos que les permita contar con las herramientas necesarias para una adecuada atención orientada al fortalecimiento de las familias.

Carias (2010), desarrolló su tesis de maestría denominada "Las prácticas de la violencia escolar entre iguales en el contexto del aula de clase: una perspectiva desde la educación en Derechos Humanos”, dicha investigación muestra una vez más la necesidad de fortalecer a las defensorías de familia en la educación en derechos humanos al momento de atender familias, ya 
que esto facilita que se tengan en cuenta sus verdaderas necesidades y se incentive la formación de NNA en valores y principios, como forma de prevenir conductas violentas.

Aunque Céspedes (2010) con su tesis doctoral titulada "El significado psicosocial de las capacitaciones en derechos humanos de la niñez", se enfoca en capacitaciones dirigidas a NNA, se consideró pertinente tener en cuenta algunos aspectos, como lo es la importancia de que las defensorías de familia del ICBF cuenten con habilidades durante la intervención a familias, que generen procesos de introspección respecto a los derechos de los cuales gozan y el rol protector que deben asumir frente a los menores de edad; así mismo colocarse en el lugar del otro respetando y promoviendo los derechos del sistema familiar, de tal manera que en la atención que brinden, se refleje realmente lo estipulado en las normas y leyes internacionales enfocadas en el tema de educación en derechos humanos.

Dueñas (2012), llevó a cabo una estrategia educativa denominada "Educación, derechos humanos y familia. Análisis de una experiencia de gestión comunitaria Colegio Ciudadela Educativa La Presentación, Cali”. Pese a que se desarrolló en un contexto escolar, la autora consideró que una propuesta sobre derechos humanos debe empezar por la familia, luego la escuela y posteriormente la sociedad.

Otra de las tesis elaborada sobre educación en derechos humanos es la realizada por San Romualdo (2013), la cual se titula: "Educación en derechos humanos como propuesta transversal en un aula de educación". Teniendo en cuenta el enfoque sistémico en el que se basa ésta investigación y los objetivos del presente trabajo de grado, es importante incluir dentro de los actores responsables de la formación en valores a los funcionarios del ICBF, ya que es la entidad del Estado encargada de trabajar en pro del bienestar de la niñez, la adolescencia y sus familias. 
En el año 2005, la profesora de educación de la UNED en Madrid España Martha López Jurado, llevó a cabo el proyecto de investigación denominado "Derechos humanos, familia y educación", como aporte se encuentra la necesidad en las defensorías de familia de llevar a cabo procesos de intervención con base en lo estipulado en el tema de educación en derechos humanos en la jurisdicción interna como internacional.

En el 2010 (Pradolini), llevó a cabo un trabajo de investigación basado en el Programa Social Aleros. Dicho programa atendía familias vulnerables, con el desafío de empoderarlas para que lograran ser las protagonistas de su propia lucha por defender sus derechos humanos. Fue importante retomar algunos aspectos de esta investigación al momento de atender familias, como por ejemplo: la importancia de conocer e involucrarse en el contexto en el cual residen las mismas que para efectos de la presente investigación se requirió añadir el componente de educación en derechos humanos, a fin de facilitar el reconocimiento de los demás y el respeto por los derechos propios y los del otro.

En el año 2015 la Secretaría de Educación Distrital en asociación con el CINEP / Programas por la paz y Fe y Alegría, publicó el manual "Derechos humanos y paz. Manual de ciudadanía y convivencia desde la construcción colectiva de sentidos y redes", que tuvo en cuenta tres ejes temáticos relacionados con la persistencia de los derechos humanos, reconocimiento de la diversidad y generaciones de paz, desarrollados a través de diversas actividades didácticas con el fin de que los temas fueran comprensibles para la comunidad participante.

Así mismo en Octubre de 2015 la Secretaría de Educación del Distrito, la Caja de Compensación Familiar COMPENSAR y el CINEP / Programas por la paz, publicaron el artículo denominado "Experiencias de comunidades escolares que transforman realidades", el 
cual hace parte de la estrategia INCITAR, que tiene como objetivo promover cambios educativos e iniciativas, enfocadas en generar una convivencia pacífica, por medio de la participación de estudiantes, profesores y padres de familia de las entidades educativas de la ciudad de Bogotá. De manera que a través de relatos elaborados por los participantes del proyecto, se fomente la construcción de instituciones educativas en donde primen los derechos humanos y por ende actúen en pro de mejorar la convivencia.

Para concluir este recorrido de investigaciones sobre educación en derechos humanos, se observa que la mayoría de ellas se han desarrollado en un contexto escolar, reflejan la falta de coherencia en cuanto a lo establecido en las leyes y la realidad de la sociedad en cuanto al tema de educación en derechos humanos y las investigaciones llevadas a cabo por el ICBF en su mayoría se tratan de estudios realizados a las familias más no directamente sobre las dinámicas de las defensorías de familia y menos aún sobre el tema de educación en derechos humanos.

Por tanto éste trabajo de grado se enfocó en lograr que las defensorías de familia brinden una atención desde una mirada holística y bajo los preceptos de una educación en derechos humanos, de modo que a la vez se promueva una atención coherente con lo estipulado en los lineamientos del ICBF, así como en las leyes y normas establecidas a nivel nacional e internacional. 


\section{Anexo 3: Contexto de la descripción del problema}

El propósito de ésta investigación obedece a las dificultades observadas ${ }^{2}$ en la atención que brindan las defensorías de familias del Centro Zonal Fontibón a la población que acude a dicha entidad, por tanto se abordan y analizan dichas problemáticas desde la perspectiva de la educación en derechos humanos de manera integrada con los fundamentos del enfoque sistémico, a partir de ello se planteó una propuesta de intervención. Para tal efecto se inicia éste acápite con antecedentes de la localidad novena de Fontibón ubicada al noroccidente de la ciudad de Bogotá, lo cual permite comprender las características de la población objeto de investigación.

De acuerdo con el reporte de la Alcaldía Mayor de Bogotá (2012) ${ }^{3}$, a partir de la transformación que afrontó Fontibón como consecuencia de la llegada de población desplazada por la violencia que se desencadenó en el país en los años 50’, los habitantes de dicha zona empezaron a caracterizarse por su alto nivel de vulnerabilidad y con ello el incremento de dificultades a nivel familiar que involucraba a niños, niñas y adolescentes (NNA) ${ }^{4}$,

\footnotetext{
${ }^{2}$ Previo al desarrollo de la presente tesis, se llevó a cabo un trabajo de campo con las defensorías de familia del Centro Zonal Fontibón del ICBF, el cual consistió en revisión documental, observaciones y aplicación de una entrevista no estructurada, que permitiera identificar las necesidades de éstas en cuanto al fortalecimiento de la Educación en Derechos Humanos.

Según la Alcaldía Mayor de Bogotá (2012), Fontibón era un municipio pequeño de Cundinamarca, que en la época de la colonia servía de puente a los españoles para el trasporte de mercancía y viajar entre Santa Fe y el Rio Magdalena, catalogándose en 1538 como el "Pueblo de la Real Corona". En el siglo XIX se convirtió en un poblamiento rural alrededor de la hacienda y posteriormente su cercanía a la capital fue transformando su vida rural con la aparición de la industria en 1940, además del avance tecnológico que causo la llegada de la radio y el ferrocarril. Sin embargo, el desplazamiento causado por la oleada de violencia en el campo, conllevó a que Fontibón se convirtiera en una localidad de Bogotá, perdiendo su calidad de municipio y transformando sus haciendas en barrios durante el periodo de 1960 a 1980.

Hoy en día la localidad de Fontibón se divide en Planeamientos Zonales que a su vez se subdividen en barrios, de acuerdo a estadísticas del DANE citadas por la Secretaría Distrital de Planeación (2009), al año 2005 la localidad contaba con 297.933 habitantes, estimándose para ese entonces que en el año 2015 aumentaría a 380.453, así mismo se estableció que el 80.7\% de la población se dedicaban a actividades industriales, el $37.0 \%$ al comercio, el $40.4 \%$ a servicios, el $10.5 \%$ a otras actividades y el $0.4 \%$ se encontraban desempleados.

${ }^{4}$ De acuerdo con el ICBF (2012) la vinculación de la mujer al campo laboral, implicó que NNA, se quedaran solos en casa, ya que un porcentaje significativo eran de viudas como consecuencia de los hechos de violencia o la misma condición socio económica obligaba a que buscaran empleo para apoyar a su pareja con los gastos del hogar; por lo cual las mujeres llegaron a cambiar de manera significativa su estilo de vida que conllevo a una modificación de las dinámicas familiares, al dejar de dedicar tiempo completo a su hogar, labor que era exclusiva de las mujeres.
} 
considerándose en su momento la necesidad de instalar en la localidad un Centro Zonal del

$\mathrm{ICBF}^{5}$ que atendiera dichas problemáticas a fin de garantizar el bienestar de la niñez, la

adolescencia y sus familias.

De acuerdo al trabajo de campo desarrollado con 11 funcionarios del Centro Zonal Fontibón, hoy en día éste cuenta con cinco Defensorías de Familia ${ }^{6}$, que se encargan de la atención a familias que acuden allí por diversos motivos, cada una de ellas conformada por un defensor de familia quien se encarga de asumir la parte legal del proceso, por tanto las medidas que éste toma deben garantizar los derechos ${ }^{7}$ a los NNA y sus familias, cumpliendo con las funciones que se le establecen en la Ley 1098 de 2006, Art. 82; un psicólogo y trabajador social, desde su área llevan a cabo valoraciones iniciales, intervenciones y seguimientos a los NNA y sus familias a fin de conceptuar sobre la realidad de las mismas; se encuentran además dos nutricionistas que apoyan las cinco defensorías de familia, quienes valoran a nivel nutricional a los NNA.

Tres de las Defensorías de Familia atienden casos en los que se presume una amenaza, vulneración o inobservancia de derechos de NNA, a partir del principio de la corresponsabilidad ${ }^{8}$ son remitidos por la Policía de Infancia y Adolescencia, Centros Educativos, entidades de salud, Comisarías de Familia, la sociedad o la misma familia del afectado. Al revisar estadísticas del

\footnotetext{
${ }^{5}$ El Instituto Colombiano de Bienestar Familiar de acuerdo al Decreto 1084 de 2015, en su artículo 2.4.1.3 presta un servicio público de bienestar familiar que se define como: "el conjunto de acciones del Estado que se desarrollan para cumplir en forma integral y permanente con el reconocimiento, la garantía, protección y restablecimiento de los derechos de los niños, niñas y adolescentes, así como la prevención de su amenaza o vulneración y el fortalecimiento familiar".

${ }^{6}$ De conformidad con el estatuto integral del defensor de familia, las defensorías de familia son dependencias multidisciplinarias del ICBF, que tienen como función prevenir, garantizar y restablecer los derechos de los niños, niñas y adolescentes; integrados por un equipo interdisciplinario conformado por defensor de familia, psicólogo, trabajador social y nutricionista. Entendiéndose el restablecimiento de derechos de NNA como: "la restauración de su dignidad e integridad como sujetos y de la capacidad para hacer un ejercicio efectivo de los derechos que le han sido vulnerados" ( Ley 1098 de 2006, Art. 50), que implica tomar cualquiera de las medidas contempladas en el Art.53 de la Ley 1098 de 2006.

${ }^{7}$ El artículo 52 de la ley 1098 de 2006, determina que cualquier caso que sea atendido por las defensorías de familia: “... la autoridad competente deberá, de manera inmediata, verificar el estado de cumplimiento de cada uno de los derechos de los niños, las niñas y los adolescentes”, los cuales se encuentran estipulados en el Título I del Libro I de dicho código.

${ }^{8}$ La ley 1098 de 2006 en su Art. 10 define la corresponsabilidad como "la concurrencia de actores y acciones conducentes a garantizar el ejercicio de los derechos de los niños, las niñas y los adolescentes. La familia, la sociedad y el Estado son corresponsables en su atención, cuidado y protección".
} 
Sistema de Información Misional (en adelante SIM), se encuentra que durante el mes de agosto de 2016 atendieron las siguientes problemáticas:

\begin{tabular}{|l|l|}
\hline MOTIVO DE ATENCIÓN & $\begin{array}{l}\mathbf{N}^{\circ} \text { DE CASOS } \\
\text { EN AGOSTO }\end{array}$ \\
\hline Maltrato por negligencia & 21 \\
\hline Abuso sexual & 18 \\
\hline Maltrato físico & 11 \\
\hline Problemas de comportamiento & 10 \\
\hline Consumo de sustancias psicoactivas & 8 \\
\hline $\begin{array}{l}\text { Conductas sexualizadas entre menores de 14 } \\
\text { años }\end{array}$ & 3 \\
\hline Abandono & 2 \\
\hline Carencia de representante legal & 2 \\
\hline Maltrato de niño en gestación & 2 \\
\hline Maltrato psicológico & 1 \\
\hline
\end{tabular}

Fuente: SIM ( Septiembre de 2016 )

Estas estadísticas se corroboran con la percepción que tienen las Defensorías de Familia de este Centro Zonal, quienes refieren como motivos de atención más comunes: maltrato físico y/o psicológico, abuso sexual y consumo de sustancias psicoactivas, seguido por problemas de comportamiento (ver anexo $\mathrm{N}^{\circ} 1$, tabla $\mathrm{N}^{\circ} 4$, Gráfica $\mathrm{N}^{\circ} 4$ ).

Se ha encontrado en investigaciones anteriores adelantadas por el ICBF que algunas de las causas de estas situaciones están asociadas a la falta de comunicación apropiada entre los miembros de las familias, intolerancia, manejo inadecuado de la autoridad por parte de los padres quienes tienden a asumir medidas extremas entre el autoritarismo o la permisividad, además de que en muchos casos las ocupaciones laborales de los padres representan un impedimento para dedicar tiempo a los hijos y estar prestos a atender sus necesidades ${ }^{9}$.

\footnotetext{
9 En el caso de una adolescente que ingresó a través del Centro Zonal Fontibón bajo medida de protección en julio de 2017 por consumo de SPA, se identifica en la valoración psicológica algunos de los posibles factores familiares asociados a dicha problemática: “...sus padres se separaron cuando ella aún se encontraba muy pequeña, de dicha unión existen tres hijos...de 23, 19 y 17 años de edad respectivamente, refiere desconocer los motivos de dicha separación. Inicialmente vivía con su progenitora, pero al encontrarse sin trabajo ésta decidió entregarla al padre cuando tenía aproximadamente cuatro años de edad, junto con sus otros dos hermanos. Afirma que con éste permaneció hasta los 10 años, el cual vivía con su madrastra de la cual se separó posteriormente; refiere que su progenitor solía pegarle "con lo que encontraba" y en cualquier parte del cuerpo debido a que su madrastra refería situaciones de ella que no eran ciertas, afirma que siempre sostuvo una relación conflictiva con ella de la cual afirma: "ella no me quería", mientras que por sus hermanos mostraba preferencia al igual que su padre...
} 
Las otras dos defensorías de familia se denominan extra procesales, encargadas de atender asuntos conciliables. En el Centro Zonal Fontibón según cifras del SIM en el mes de agosto de 2016 se atendieron los siguientes:

\begin{tabular}{|l|l|}
\hline \multicolumn{1}{|c|}{ MOTIVO DE ATENCIÓN } & $\begin{array}{l}\text { N }^{\circ} \text { DE CASOS } \\
\text { EN AGOSTO }\end{array}$ \\
\hline Revisión de cuota de alimentos & 41 \\
\hline Fijación de custodia y cuidado personal & 27 \\
\hline Fijación cuota de alimentos & 21 \\
\hline Revisión de custodia y cuidado personal & 16 \\
\hline $\begin{array}{l}\text { Reconocimiento voluntario de paternidad / } \\
\text { maternidad }\end{array}$ & 7 \\
\hline Revisión de visitas & 6 \\
\hline
\end{tabular}

Pese al volumen de casos que atiende el área extraprocesal, las defensorías de familia le restan importancia en relación a los que ingresan por protección, puesto que refieren como principal motivo de ingreso problemáticas que son competencia de éstos equipos (ver anexo $\mathrm{N}^{\circ}$ 1, tabla $\mathrm{N}^{\circ}$ 4, Gráfica $\mathrm{N}^{\circ}$ 4). Además, se percibe que en caso de identificarse alguna vulneración de derechos, cobra mayor importancia, no obstante, todos los casos deben ser atendidos con calidad y transparencia de acuerdo a la misión del ICBF.

\footnotetext{
En suma a lo anterior, señala que a los 10 años regresó con su progenitora debido al maltrato que le proporcionaba su padre. Indica que ésta vive con su padrastro..., refiere que con éstos ha convivido desde ese entonces, aunque por su consumo de SPA ha permanecido gran parte del tiempo en institución de rehabilitación. Señala que desde los 14 años inicio el consumo de SPA (bóxer), con una frecuencia de cada dos días...pese a los diversos procesos de rehabilitación a los que ha asistido, recae en dicha conducta, atribuyendo dicho hecho a que se "aburre" en la casa. Afirma que con su progenitora siempre ha sostenido una relación distante, nunca le ha tenido la confianza para contarle aspectos personales..."
} 


\section{Anexo 4: Marco normativo de los DDHH y la EDH}

Dentro de los antecedentes jurídicos de la Educación en Derechos Humanos se encuentra: la Declaración de los Derechos del Niño (1959), estableció el derecho y la obligatoriedad de la educación, la cual debe fomentar capacidades para emitir juicios bajo una responsabilidad moral y social. En 1960 la UNESCO adoptó la convención relativa a la lucha contra las discriminaciones en la esfera de la enseñanza, que de acuerdo con el informe del Instituto Interamericano de Derechos Humanos (2009), consideró a la educación como un medio para fortalecer el respeto por los derechos humanos e incentivar la comprensión, tolerancia y la amistad entre las naciones, grupos raciales y religiosos.

Bajo esta perspectiva, la Convención Internacional sobre la eliminación de todas las formas de discriminación racial (1965), planteó que a través de la educación se pueden establecer medidas que eliminen la discriminación racial y que el Estado es uno de los principales responsables para lograr dicho objetivo; el Pacto Internacional de Derechos Económicos, Sociales y Culturales (1966), enfatiza en el derecho a la educación, que debe estar orientado hacia los Derechos Humanos y demás temas relacionados; la Declaración de los principios de la cooperación cultural internacional (1966), hace referencia al respeto por los derechos de las culturas; la Declaración sobre la Raza y los Prejuicios Sociales, aprobada por la UNESCO en 1978, establece que mediante acciones pedagógicas el Estado, autoridades competentes y docentes, deben combatir el racismo.

Igualmente, la Convención sobre la eliminación de todas las formas de discriminación contra la mujer (1979), propuso eliminar a través de la educación los estereotipos que se mantienen en cuanto a temas de género, de manera que se promueva una equidad entre hombre y mujer, 
además en el artículo 5 señala la obligación de los Estados en implementar dichas medidas educativas; la Convención Interamericana para prevenir y sancionar la tortura (1985), prohíbe el uso de la tortura a personas privadas de la libertad por parte de la policía u otros funcionarios públicos, por tanto en el artículo 7 se establece que el Estado debe generar estrategias educativas para esta población a fin de evitar el empleo de la tortura; el Protocolo adicional a la Convención Americana sobre Derechos Humanos en materia de derechos económicos, sociales y culturales: Protocolo de San Salvador (1988), resalta "el derecho a la educación en derechos humanos como parte del derecho a la educación" (Instituto Interamericano de Derechos Humanos, 2009). En el artículo 13 enfatiza en la importancia de que la educación facilite la formación de sujetos que participen eficazmente dentro de una sociedad democrática y plural, enfocada en la consecución de la justicia, la paz y el respeto por la dignidad humana, elementos que son tenidos en cuenta por la Carta Democrática Interamericana (2001), al enfatizar en el rol que desempeña la educación en la promoción de los derechos humanos y la democracia, por tanto debe ser de calidad y estar al alcance de todos.

Así mismo, el Convenio de los pueblos indígenas tribales en países independientes $\left(\mathrm{N}^{\circ} 169\right)$ de la Organización Internacional del Trabajo (1989), indica en el artículo 31 el derecho que tienen las minorías a recibir una educación en donde se eliminen los prejuicios contra las mismas, desde un enfoque diferencial que tenga en cuenta sus derechos y deberes; la Convención sobre los Derechos del Niño (1989), puntualiza en la importancia de formar niños y niñas en el respeto por los derechos humanos y libertades fundamentales; en 1990 en la Habana Cuba, se llevó a cabo el VIII Congreso de las Naciones Unidas sobre la Prevención del Delito y el Tratamiento del Delincuente, dentro del cual surgieron las directrices para la prevención de la 
delincuencia juvenil (Directrices del RIAD), el cual establece que los sistemas educativos deben promover valores, la identidad propia, los derechos humanos y libertades fundamentales.

La Convención Interamericana para prevenir, sancionar y erradicar la violencia contra la mujer - Convención Belem do pará -(1995), en el Art. 8, enfatiza en los derechos que tiene la mujer al buen trato y estipula que el Estado debe capacitar a sus funcionarios judiciales, policía y demás encargados de administrar justicia en temas relacionados con el maltrato hacia el género femenino; la Convención interamericana para la eliminación de todas las formas de discriminación contra las personas con discapacidad (1999), en su artículo 3 compromete al Estado a generar medidas educativas que eliminen la discriminación contra éste tipo de población y se promueva el respeto hacia la misma.

Otro de los mecanismos a nivel internacional relacionados con la educación en derechos humanos, se encuentra en el Derecho Internacional Humanitario, en el cual se establece que los países que han ratificado los convenios de Ginebra de 1949 deben garantizar que la población conozca sobre el Derecho Internacional Humanitario, en especial los militares encargados de la protección de víctimas de guerras y conflictos armados, quienes deben conocer y aplicar sus normas. Por otro lado, se encuentra la declaración sobre el derecho y el deber de los individuos, los grupos y las instituciones de promover y proteger los derechos humanos y las libertades fundamentales universalmente reconocidos (1999), la cual hace referencia a la protección que deben tener los defensores de derechos humanos, así como la responsabilidad de éstos de promover la educación en derechos humanos.

Adicional a los instrumentos internacionales mencionados anteriormente, en 1993 en Montreal (Canadá), se llevó a cabo el Congreso Internacional sobre Educación para los Derechos Humanos y la Democracia, convocados por la UNESCO y el Centro de Derechos Humanos de 
las Naciones Unidas. De acuerdo al informe emitido por el Director General, al finalizar dicho Congreso se aprobó el Plan de Acción Mundial sobre Educación para los Derechos Humanos y la Democracia, en el cual se planteó: implementar y promover la educación en derechos humanos tanto en el sistema escolar como en contextos externos y aplicarla en ámbitos determinados y problemáticos. Así mismo en 1995 se llevó a cabo en París, la Conferencia General de la UNESCO, en la cual se planteó el Plan de Acción Integrado sobre la Educación para la Paz, los Derechos Humanos y la Democracia.

Existen además normas internacionales que obligan a los Estados a la formación y capacitación de servidores públicos en Derechos Humanos, de manera que en el desempeño de sus funciones prevalezca la dignidad humana e imparcialidad hacia el otro, reconociéndolo como sujeto de derechos.

Por otro lado, en Colombia se han implementado Políticas Públicas que se acercan a los objetivos de una EDH, como por ejemplo el Plan Nacional para el Desarrollo (1994 - 1998); el Plan Nacional de Educación (1996 - 2005); Plan Estratégico de Educación, el cual planteó que cada establecimiento educativo creará su propio Proyecto Educativo Institucional (PEI), los Municipios debían elaborar su Proyecto Educativo Municipal (PEM) y cada Departamento su Proyecto Educativo Departamental (PED).

Uno de los logros más representativos en materia de EDH es el Plan Nacional de Educación en Derechos Humanos (PLANEDH), el cual fue planteado por la Vicepresidencia de la República, el Ministerio de Educación Nacional y la Defensoría del Pueblo, durante el periodo comprendido entre el año 2006 al 2014; va dirigido a contextos de educación formal, informal y educación para el trabajo y el desarrollo humano (antes educación no formal); y tiene como 
propósito transformar la sociedad mediante el empoderamiento de los individuos para la defensa de sus derechos y de los demás, de manera que se caractericen por ser sujetos de derechos.

Es de anotar que para elaborar el PLANEDH también se tuvo en consideración los antecedentes que existen en Colombia respecto a programas de EDH desde el ámbito de la educación formal, educación para el trabajo y el desarrollo humano, y educación informal, entre los cuales se encuentran: el programa nacional de capacitación en derechos humanos para Personeros Municipales, el cual va dirigido a funcionarios de la Procuraduría General de la Nación, la Defensoría del Pueblo y del Alto Comisionado de las Naciones Unidas para los derechos humanos con sede en Colombia; Proyecto de Red Nacional de Promotores de Derechos Humanos, que se desarrolló desde el año 2000 y bajo un componente pedagógico tenía por objetivo fortalecer a la ciudadanía en cuanto a la defensa de los DDHH para contribuir a una cultura democrática de paz.

En cuanto a la defensa de derechos humanos de la niñez y la adolescencia a nivel internacional, según Cillero (2007), durante el siglo XX se realizaron esfuerzos por reconocer y proteger los derechos de los niños y niñas, por lo cual se expidió la Declaración de Ginebra (1924) y posteriormente la Declaración Universal de Derechos del Niño (1959). Según la UNICEF (2006), esta Declaración fue reconocida por organizaciones a nivel internacional que velan por la garantía de derechos de la niñez, enfatizando en la responsabilidad de los ciudadanos, autoridades locales y gobierno nacional de velar por la observancia de los mismos. Además fue adoptada por la Asamblea General el 20 de Noviembre de 1959 y reconocida por el Pacto Internacional de Derechos Civiles y Políticos, específicamente el artículo 24. De igual manera fue tenida en cuenta por el Pacto Internacional de Derechos Económicos, Sociales y 
Culturales, particularmente en el artículo 10, que señala el deber del Estado de resguardar los derechos de las familias principalmente de las madres, los niños y adolescentes.

A nivel interno la Ley 1098 de 2006 o Código de Infancia y Adolescencia, la cual modificó el código del menor de 1989, es la norma jurídica por la cual se rige el estado colombiano para el cumplimiento de la garantía de derechos de los NNA y sus familias. Para su cumplimiento el ICBF cuenta con equipos interdisciplinarios que son liderados por el defensor de familia.

De conformidad con Jiménez (2012), el defensor de familia tiene su génesis antes de la creación del ICBF mediante la ley 83 de 1946 o Ley Orgánica del Niño, en la cual se le denominaba "curador de menores", tenía como función defender los intereses de los menores de edad que se encontraban involucrados en procesos penales por algún delito y determinar medidas de protección frente a situaciones de vulneración de derechos. Con la expedición de la ley 75 de 1968, a través de la cual se creó el ICBF, se le denominó Defensor de menores, mediante la Resolución 773 de 1981 se reglamentaron sus funciones en relación a la protección de NNA y con la Resolución 1586 las actuaciones extrajudiciales y su intervención ante los juzgados de menores. Con el paso del tiempo las funciones del defensor de familia se han incrementado, las cuales dependen del campo en el cual desarrolle las mismas ya sea a nivel extra procesal o de protección.

Los asuntos conciliables o de tipo extra procesal, hacen referencia a las acciones que emprende el defensor de familia en procesos como: regulación de alimentos, definición de custodia, trámite para salida del país, investigación e impugnación de paternidad, entre otros. Respecto a casos no conciliables o de protección, el defensor de familia actúa mediante un proceso administrativo de restablecimiento de derechos (en adelante PARD), cuando un derecho de un NNA se encuentra ya sea: vulnerado, amenazado o inobservado. 
En cuanto a los principios que rigen la labor del defensor de familia, de acuerdo al estatuto integral del defensor de familia, éste debe actuar conforme al interés superior del NNA; a los hechos fácticos, es decir, deben ser consideradas las situaciones en su contexto de manera global y no aisladamente; a hechos jurídicos, respecto a parámetros y criterios que se encuentran establecidos desde el ámbito legal en pro del bienestar de los NNA. Así mismo debe tenerse en cuenta el principio de corresponsabilidad establecido en la Constitución de 1991, respecto a la responsabilidad conjunta del Estado, la sociedad y la familia en la garantía de derechos de los NNA; debe regirse desde la perspectiva de género, es decir que dentro de sus intervenciones en el caso tenga como criterio de análisis las diferencias que pueden existir a nivel social, biológico y psicológico en las relaciones entre los seres humanos de acuerdo al sexo, edad, etnia y el rol que desempeñan en diferentes contextos; por último, debe tener en cuenta en su actuar las normas internas e internacionales que han sido ratificadas por Colombia, así como los conceptos emitidos por cada profesional que conforma la defensoría de familia, ya que éste no actúa de manera aislada, sino de conformidad con el trabajo en equipo que debe realizar cada defensoría de familia para la resolución de los casos atendidos.

Respecto al tema específico de la atención que deben brindar los funcionarios del ICBF a los NNA y sus familias, en septiembre de 2007 mediante la Resolución Nº02366 se aprobaron los Lineamientos Técnicos para la Inclusión y Atención de Familias, soportados en la corresponsabilidad existente entre la familia, la sociedad y el Estado, para el bienestar, la garantía de derechos y de la dignidad del ser humano, siendo el Estado el responsable de que se respeten dichos derechos; la familia por su parte debe ser un actor participante en la creación de políticas públicas, de manera que en realidad se tengan en cuenta sus necesidades al ser escuchadas las voces de sus integrantes, de manera que la intervención que realicen las 
defensorías de familia debe estar enfocada hacia la transformación, de manera que se traten de equipos transdisciplinarios y no multidisciplinarios que se basan en el modelo solidario planteado desde el enfoque sistémico.

En cuanto a las competencias que deben caracterizar a los agentes de intervención para la implementación de un modelo solidario, el lineamiento se mencionan las siguientes: observar las realidades familiares y sociales desde una postura eco sistémica; lograr establecer cómo el problema influye en el sistema durante el proceso de atención; plantear soluciones a las dificultades identificadas, de acuerdo a las fortalezas de la familia; actuar bajo principios éticos; y trabajar de manera transdisciplinaria. Así mismo se resalta la importancia de que los profesionales que conforman las defensorías de familia, tengan la capacidad de tomar decisiones en conjunto con la familia, que permitan definir medidas que beneficien a los NNA.

El 22 de junio de 2016 bajo la Dirección General de Cristina Plazas Michelsen el ICBF expidió las Resoluciones $\mathrm{N}^{\circ} 5863$ y 5864 a través de las cuales se aprobaron los Lineamientos Técnicos de Modalidades para la Atención de NNA, con Derechos Inobservados, Amenazados o Vulnerados y Los Lineamientos Técnicos del Modelo para la Atención de los NNA, con Derechos Inobservados, Amenazados o Vulnerados, respectivamente. 